\title{
Preliminary Feasibility of Value-Added Products from Cogeneration and Hybrid Energy Systems in Wyoming
}

November 2012

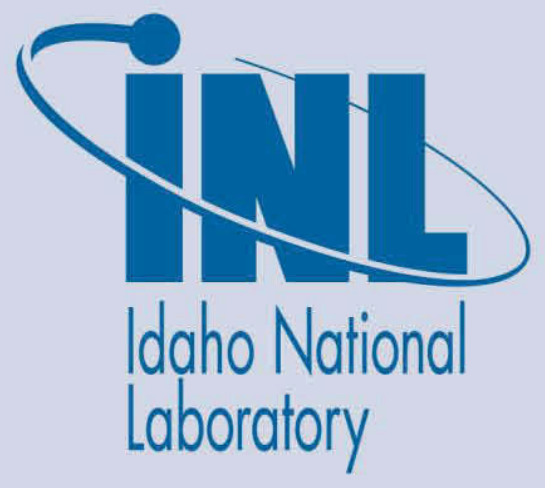

The INL is a U.S. Department of Energy National Laboratory operated by Battelle Energy Alliance 


\section{DISCLAIMER}

This information was prepared as an account of work sponsored by an agency of the U.S. Government. Neither the U.S. Government nor any agency thereof, nor any of their employees, makes any warranty, expressed or implied, or assumes any legal liability or responsibility for the accuracy, completeness, or usefulness, of any information, apparatus, product, or process disclosed, or represents that its use would not infringe privately owned rights. References herein to any specific commercial product, process, or service by trade name, trade mark, manufacturer, or otherwise, does not necessarily constitute or imply its endorsement, recommendation, or favoring by the U.S. Government or any agency thereof. The views and opinions of authors expressed herein do not necessarily state or reflect those of the U.S. Government or any agency thereof. 
INL/EXT-12-27249

\title{
Preliminary Feasibility of Value-Added Products from Cogeneration and Hybrid Energy Systems in Wyoming
}

November 2012

\author{
Idaho National Laboratory \\ Idaho Falls, Idaho 83415
}

http://www.inl.gov

Prepared for the

Wyoming Business Council and for the

U.S. Department of Energy

Under DOE Idaho Operations Office

Contract DE-AC07-05ID14517 



\section{SUMMARY}

Wyoming has a wealth of primary energy resources in the forms of coal, natural gas, wind, uranium, and oil shale. Most of Wyoming's coal and gas resources are exported from the state in unprocessed form rather than as refined higher value products. Wyoming's leadership recognizes the opportunity to broaden the state's economic base energy resources to make value-added products such as synthetic vehicle fuels and commodity chemicals. Producing these higher value products in an environmentally responsible manner can benefit from the use of clean energy technologies including Wyoming's abundant wind energy and nuclear energy such as new generation small modular reactors including the high temperature gas-cooled reactors.

The Wyoming Business Council (WBC), under direction from the State's Legislature, commissioned the Idaho National Laboratory (INL) to complete evaluations of selected energy futures for Wyoming, focusing specifically on the benefits of hybrid energy systems that would take advantage of all of the state's energy resources. This work was accomplished by two complementary activities. First, a collaborative effort of the Wyoming Business Council, the University of Wyoming and the Idaho National Laboratory focused on screening-level analysis of a range of hybrid energy systems using new small modular nuclear reactors for the conversion of coal and natural gas into synthetic fuels and commodity chemicals in configurations designed to also stabilize wind power generation. This report summarizes the outcome of this first activity. Second, a more rigorous analysis led by the NGNP Industry Alliance in collaboration with the Idaho National Laboratory to evaluate the application of the high temperature, gas-cooled nuclear reactor (HTGR) to enhance coal and natural gas conversion to higher value products and electrical power. The results, conclusions, and recommendations of the HTGR applications work are presented in INL/EXT-12-26732, Energy Development Opportunities for Wyoming. The conclusions of these evaluations provide a conceptual foundation upon which Wyoming can form a partnership with industry to lay out a strategy and plan of action that can develop leading to a state-wide energy economy.

The hybrid energy systems of this report integrate complementary energy conversion processes with multiple inputs and outputs into coordinated systems that operate dynamically, allowing them to mitigate the variability of diurnal demand or wind generation on the regional grid. As one example out of many possible hybrid energy system configurations, a nuclear power plant can supply heat to a synthetic fuels manufacturing plant and electricity to the regional power grid as illustrated in Figure ES-1. The nuclear plant produces heat in the form of steam or hot gases that can be used to generate electrical power or to help convert coal and natural gas into transportation fuels. During periods of high power demand such as daylight hours the nuclear plant produces greater amounts of electricity for the grid. During this period, the manufacturing process simply generates its own heat and steam by burning fossil fuels in a conventional boiler. When power demand is lower, the nuclear plant delivers less electricity to the grid and more steam to the process plant which in turn reduces the amount of fossil fuels that are combusted to produce steam. In this manner, the nuclear plant is operated at constant capacity to take advantage of its capital investment and thermodynamic efficiency. Because nuclear energy produces very low green house gas (GHG) emissions, both the electricity and fuel products have a lower life-cycle impact on the climate. Additional benefits may include decreased water use for cooling (by using more wind generation rather than conventional power plants) and increased energy supply stability. 


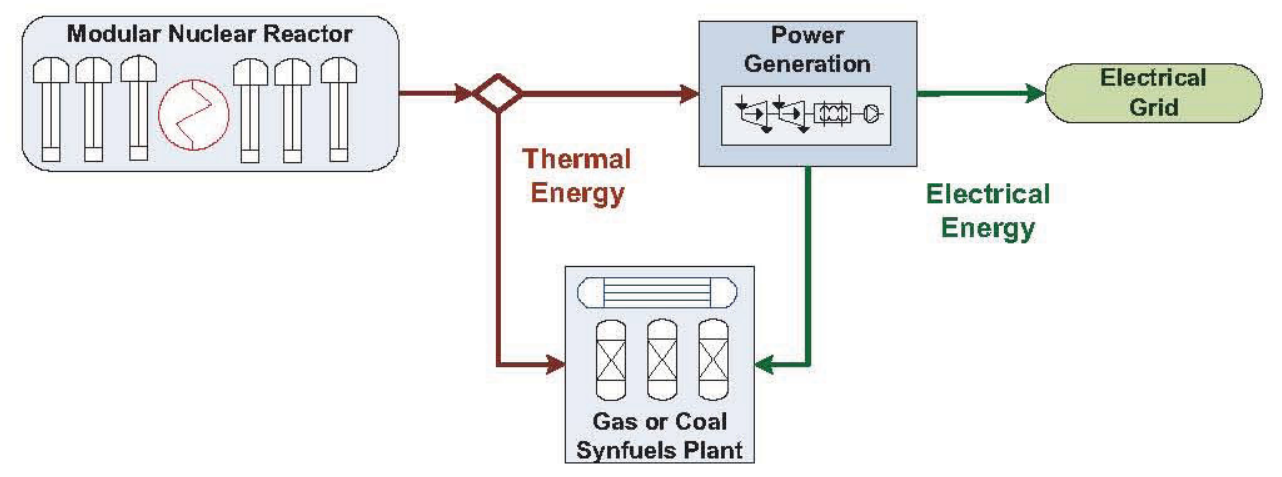

Figure ES- 1. Simplified Nuclear-Fossil Hybrid Energy Plant Illustration

Dynamic adjustment of the heat delivery between power generation and the process industry can greatly increase the amount of intermittent renewable energy that can be brought into service.

Additionally, energy system hybridization can be done using other power generation units, including existing coal-fired power plants and natural gas/combined cycle units that are being built more frequently with the low cost of natural gas. In addition to conversion of coal and natural gas into synfuel or chemicals, transiently excess thermal and electrical energy can be used by a broad set of process-oriented heat applications, for example slow heating of oil shale, distillation and cracking processes in an oil refinery, fertilizer production, waste water treatment or a desalination plant, and hydrogen production by either steam-methane reforming or steam electrolysis. Technical, economical, and environmental assessments of several steady-state heat applications have determined practical uses for the hightemperature gas-cooled reactor. ${ }^{\mathrm{b} \mathrm{c} \mathrm{d}}$ The potential for dynamic hybrid energy system operations that integrate the use of light-water nuclear reactors and conventional fossil fuel plants has also been analyzed by the INL. ${ }^{\text {f } g \text { h }}$ Collectively, these studies provided incentive for the focus on hybrid system opportunities for Wyoming.

This study presents a preliminary analysis of options that may enhance the development of a vibrant energy economy for future generations in Wyoming. The broad objectives of this effort were to identify ways in which Wyoming's coal and gas resources might be upgraded to higher value products through the use of hybrid energy system concepts, and how the state's wind energy potential might be similarly used to create additional value beyond its value purely as export electricity.

${ }^{a}$ Lee Nelson, Anastasia Gandrik, Michael McKellar, Mike Patterson, and Rick Wood, Integration of High Temperature GasColled Reactors into Industrial Process Applications, INL/EXT-09-16942, Rev 2., 2012

${ }^{b}$ Lee Nelson, Anastasia Gandrik, Michael McKellar, Mike Patterson, Eric Robertson, and Rick Wood, Integration of High Temperature Gas-Cooled Reactors Into Selected Industrial Process Applications, INL/EXT-11-23008, 2011

'Forsberg, C. (2008). "Sustainability by combining nuclear, fossil, and renewable sources." Progress in Nuclear Energy $\mathbf{5 1}(1)$ : $192-200$

'Forsberg, C. (2009). "Meeting U.S. liquid transport fuel needs with a nuclear hydrogen biomass system." International Journal of Hydrogen Energy 34(9): 4227-4236

${ }^{8}$ R. S. Cherry, S. E. Aumeier, and R. Boardman (2012), Large Hybrid Energy Systems for Making Low CO 2 Load-Following Power and Synthetic Fuel, Energy Env. Sci., 5, 5489-5497.

${ }^{\mathrm{f}} \mathrm{S}$. Aumeier, R. Cherry, R. Boardman and J. Smith (2011), Nuclear Hybrid Energy Systems: Imperatives, Prospects and Challenges. Energy Procedia, 7, 51-54.

${ }^{g}$ Humberto Garcia, Amit Mohanty, Wen-Chiao Lin, Robert S. Cherry, "Dynamic Analysis of Hybrid Energy Systems under Flexible Operation and Variable Renewable Generation Part I: Dynamic Performance Analysis, Preprint submitted to Energy, May 2012.

${ }^{\text {h }}$ Humberto Garcia, Amit Mohanty, Wen-Chiao Lin, Robert S. Cherry, "Dynamic Analysis of Hybrid Energy Systems under Flexible Operation and Variable Renewable Generation Part II: Dynamic Cost Analysis, Preprint submitted to Energy, May 2012 
The possibility of using variable non-dispatchable wind power to operate an air separation unit to provide oxygen to an oxy-fired pulverized coal power plant was evaluated (Figure ES-2). Oxy-firing replaces the air that is normally used to burn coal with a mixture of oxygen and flue gas to produce a flue gas that is mostly $\mathrm{CO}_{2}$. Part of the flue gas is recirculated, while the bulk is cleaned and compressed for utilization or sequestration. In this example, the power plant would continue to produce power as needed, while high purity $\mathrm{CO}_{2}$ could be captured and sold for enhanced oil recovery. This approach could be deployed in Wyoming and elsewhere to convert existing coal plants into clean coal plants without derating the power output from existing facilities.

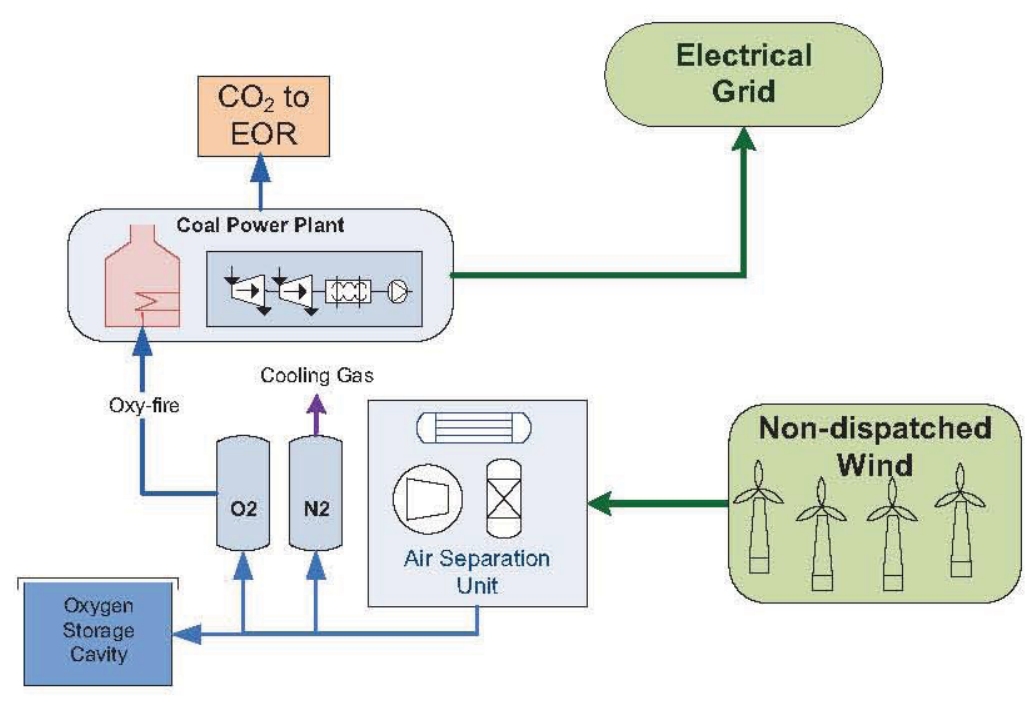

Figure ES-2. Reference case using nondispatchable wind for oxy-combustion power generation.

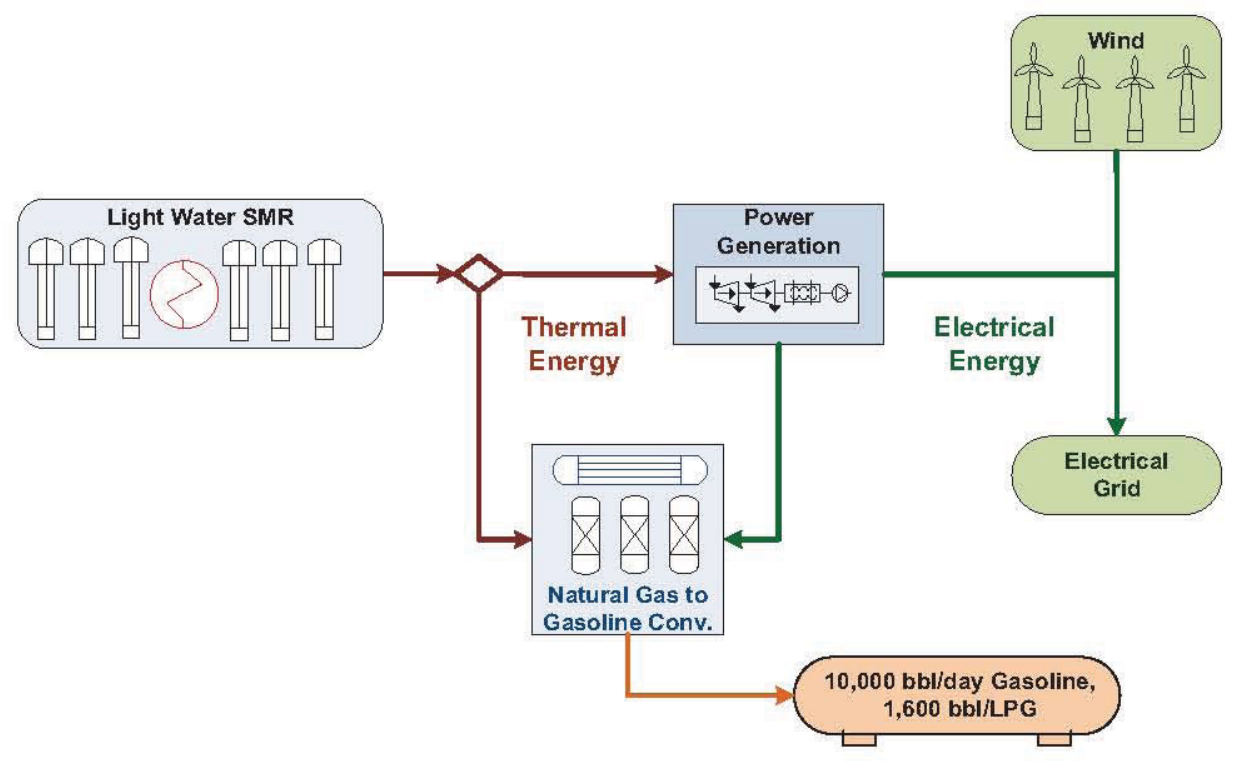

Figure ES-3. Electrical power/gasoline production nuclear dynamic hybrid energy system case.

Another hybrid energy system case analyzed was a nuclear-fossil-wind example that could smooth the intermittency of wind power generation by dynamically diverting steam delivered from the nuclear power plant to a synfuels plant (Figure ES-3). In this example, natural gas is converted to gasoline and 
and a smaller amount of liquefied petroleum gas. A reference $10,000 \mathrm{bbl} /$ day of gasoline product would be readily consumed in the Colorado-Montana-Utah-Wyoming transportation fuels market. Additional plants could be built as demand by the market area or penetration increases. This study case illustrated the potential to mitigate short-term transient spikes associated with either variable power demand or wind power production on the grid.

The nuclear-fossil-wind hybrid energy system reference case was compared to the substantially similar natural gas/combined-cycle hybrid energy system synfuels case shown in Figure ES-4.

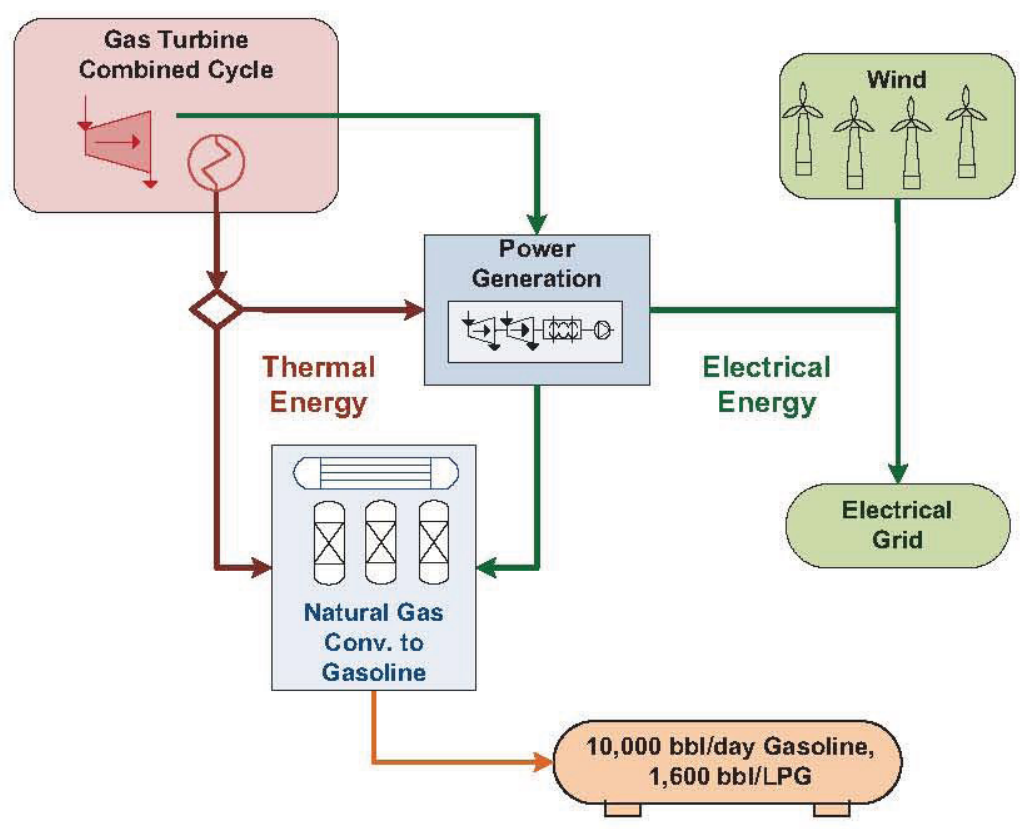

Figure ES-4. Electrical power/gasoline production fossil dynamic hybrid energy system case.

Pairing wind generation with a hybrid energy system creates a high availability, low variability source of electricity from low $\mathrm{CO}_{2}$ sources that may be attractive to grid operators. A natural gas boiler can maintain steam to the synfuels plant to meet its total demand as the quantities from the power generation operations vary. The advantages of this type of hybrid system are being able to operate a power grid reliably with a large fraction of renewable but variable wind energy, having an assured supply of low cost, low $\mathrm{CO}_{2}$ nuclear electricity during peak demand periods, and being able to use that nuclear energy to convert Wyoming minerals into fuels for U.S. light vehicles. Facilitating the use of wind (or solar) energy in place of fossil-fired systems can also save significant amounts of water that might otherwise be lost to the atmosphere in evaporative cooling systems.

The ability to maneuver thermal energy in a hybrid energy system provides an alternative to massive grid-scale electric battery storage, pumped hydro, and Compressed-Air Energy Storage as ways to address mismatches of generation and demand in grids with large amounts of wind or solar energy. The otherwise excess energy, whether electrical or thermal, can be converted into chemical energy, avoiding the need for costly storage options while generating revenue for the cooperating energy partners.

The case examples and outcomes of this study are consistent with a recent screening analysis of advanced coal/wind hybrid options funded by the U.S. Office of Electricity Delivery and Energy 
Reliability, Permitting, Siting, and Analysis. ${ }^{i}$ Hybrid energy systems can cost effectively firm up wind generation. Fuel production can further improve the utilization of capital intensive power generation assets resulting in increased revenues or lower total adjusted levelized cost of electricity.

A number of next steps are identified in this report. They cover a variety of areas, including market assessments, technical evaluations, and business case development. Some of the major activities which might be done include the following.

- A comprehensive overview of Wyoming's current and planned energy industry and infrastructure (such as rail corridors, pipelines, transmission lines, water availability) could be prepared as background for further analysis of integrated hybrid energy systems

- Evaluation of where and how pipeline networks for distributing synthesis gas and $\mathrm{CO}_{2}$.might be developed across Wyoming and neighboring states would be valuable. This would have to include a long term assessment of the value and use of large amounts of $\mathrm{CO}_{2}$ and possibly $\mathrm{N}_{2}$ for enhanced oil recovery.

- Wind energy - being a clean, renewable energy resource - is perceived as being desirable and therefore of value. How some of that value might be captured by the participants in a hybrid energy system should be analyzed. The value of addressing the variability of wind energy to make it more easily used in quantity would also be a valuable topic to address.

- How wind energy, including its variability, might be used to run a modified air separation unit is a technical effort that might extend the lifetime of coal-fired power plants if they can be economically converted to oxycombustion to control their $\mathrm{CO}_{2}$ emissions.

- The use of new types of nuclear reactors in Wyoming creates a possible new industry supplying special products or services needed by those new technologies. In particular, the potential to locate a new facility dedicated to building small modular nuclear reactors should be assessed because of the large economic impact it would have.

- The potential for siting a new facility in Wyoming to convert yellowcake uranium into uranium hexafluoride is attractive and is worthy of more detailed attention.

\footnotetext{
${ }^{i}$ Amol Phadke, Charles Goldman, Doug Larson, Tom Carr, Larry Rath, Peter Balash, and Wan Yih-Huei, LBNL-128E, 2008
} 


\section{CONTENTS}

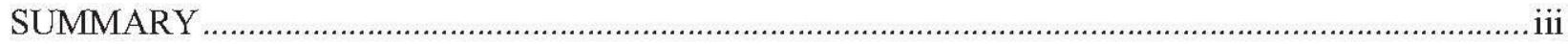

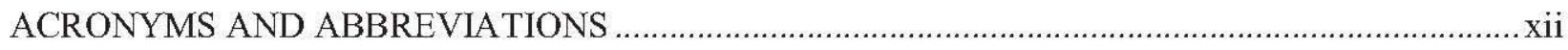

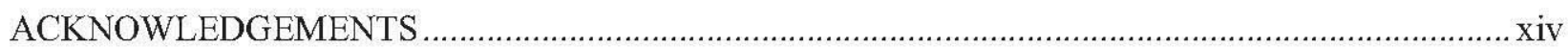

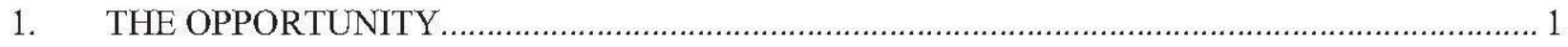

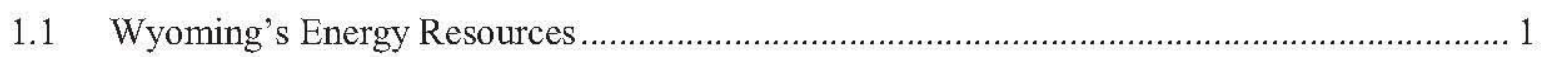

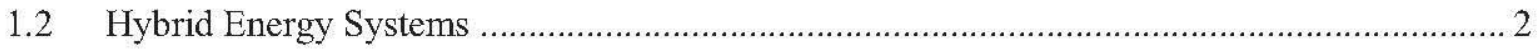

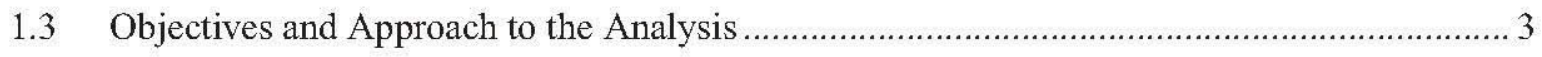

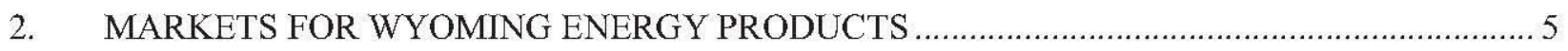

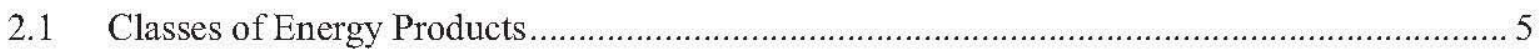

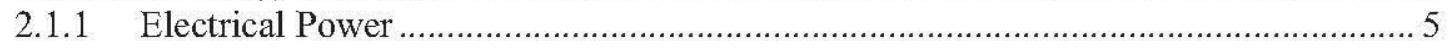

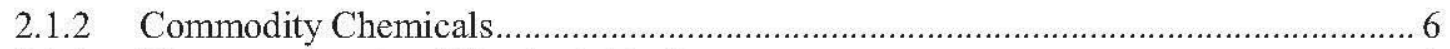

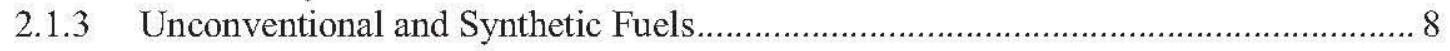

2.2 Size and Location of Vehicle Fuel Markets .............................................................

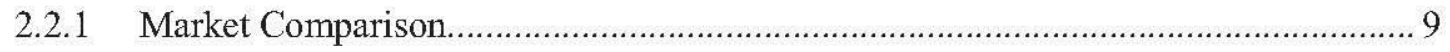

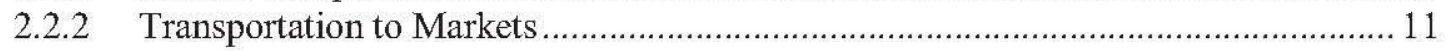

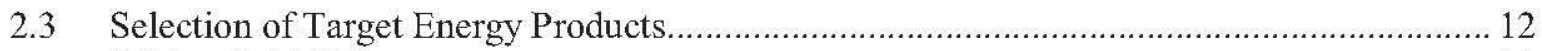

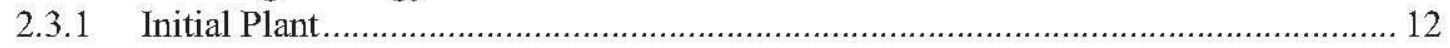

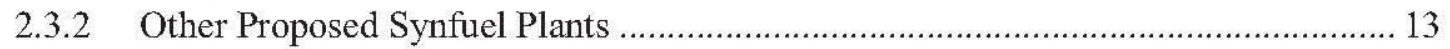

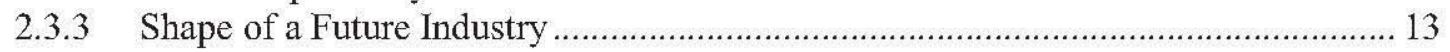

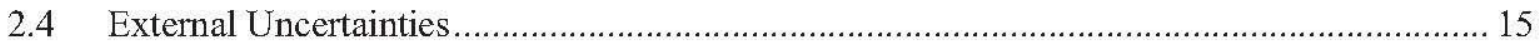

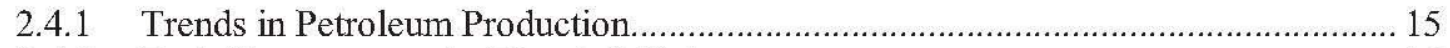

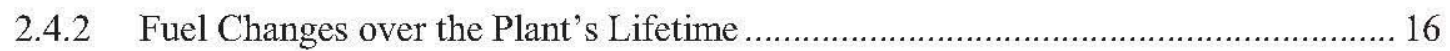

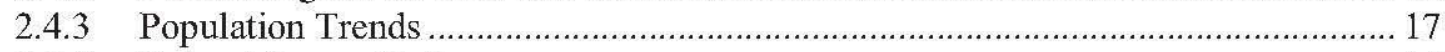

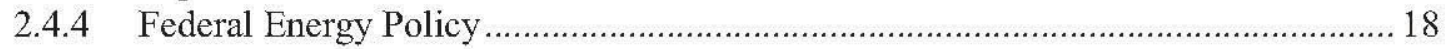

3. FEASIBILITY AND INCENTIVES FOR DYNAMIC OPERATION OF PROCESS

PLANTS

3.1 Conventional Operation of Large Plants ............................................................ 19

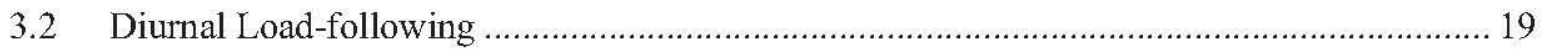

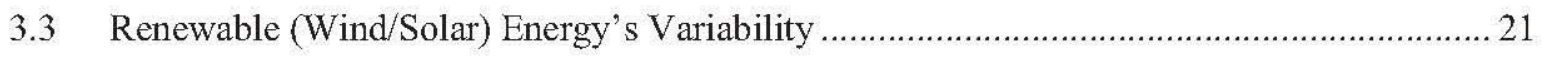

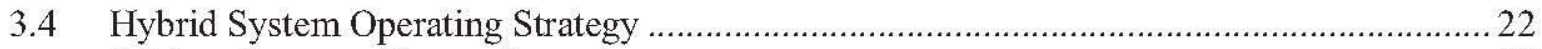

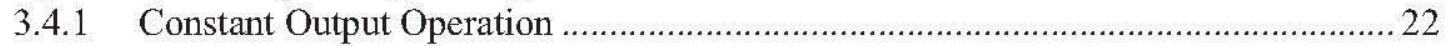

3.4.2 Operation to Reduce Only High Frequency Variability ..................................... 22

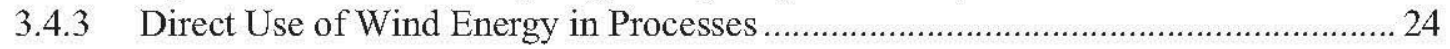

3.5 Feasibility of Dynamic Operation of a Chemical Process .......................................... 25

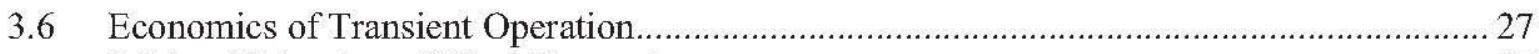

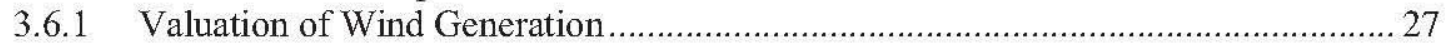

3.6.2 Cost of Hybrid Heat as a Co-product of Wind Generation ...................................2 28

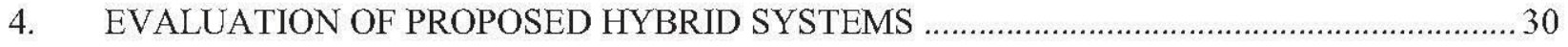

4.1 Process Description of Hybrid Synfuel Cases ............................................................. 30 
4.1.1 Comparison of Conventional Fossil Energy Options for Synfuels .........................30

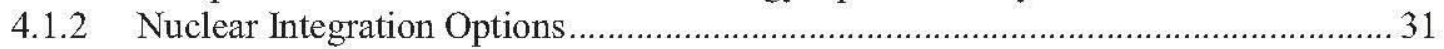

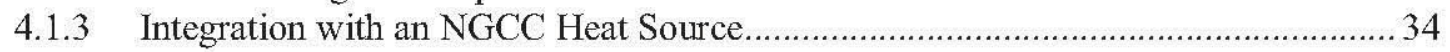

4.1.4 Recommended Load-following Strategies .................................................. 35

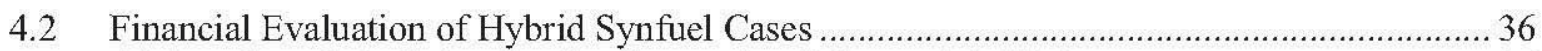

4.2.1 Cost Calculation for the Conventional Gas-to-MTG Plant.................................. 36

4.2.2 Cost Calculation for the Steady State Nuclear-integrated Gas-to-MTG Plant.......... 37

4.2.3 Economic Comparison of Conventional and Nuclear-integrated Natural Gas-

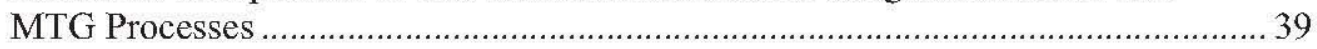

4.2.4 Hybrid System Supplying Both Heat and Variability-Reducing Power ................... 39

4.2.5 Cost Calculation for the NGCC-integrated Gas-to-MTG Plant .............................40

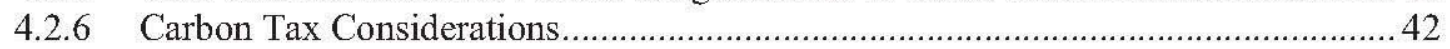

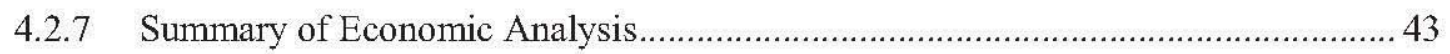

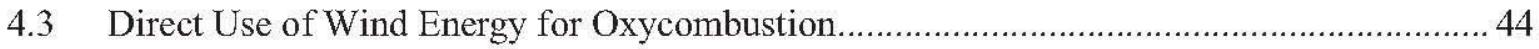

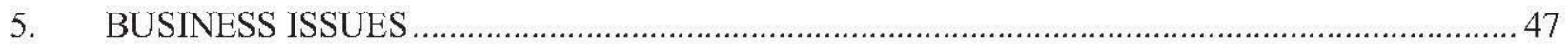

5.1 Permitting: Air, Water, Wildlife, and Reactor Licensing ....................................... 47

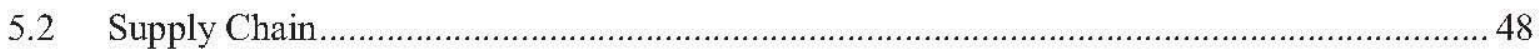

5.3 Education and Training - Challenges, Needs and Opportunities................................ 50

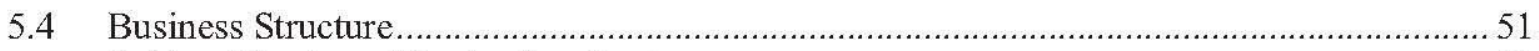

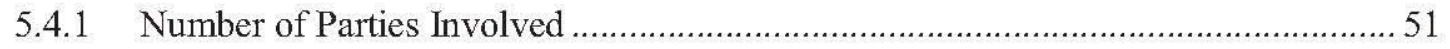

5.4.2 Individual Plant Construction Schedule and Lifetimes ...................................... 52

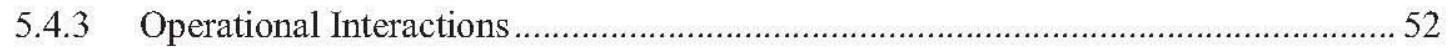

6. ADDED-VALUE STEPS IN THE URANIUM SUPPLY CHAIN …......................................54

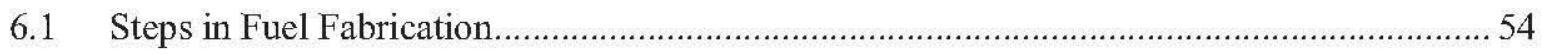

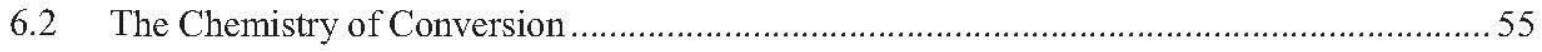

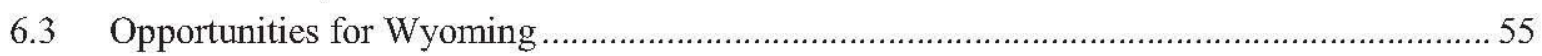

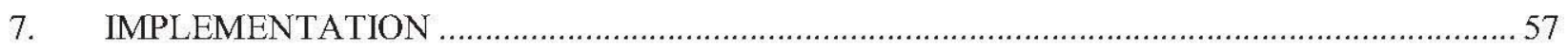

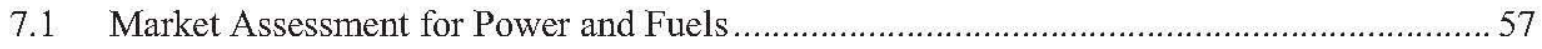

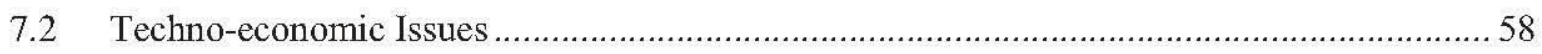

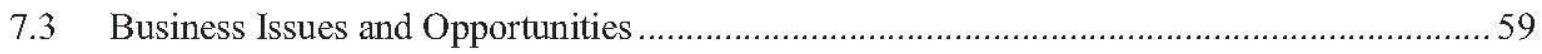

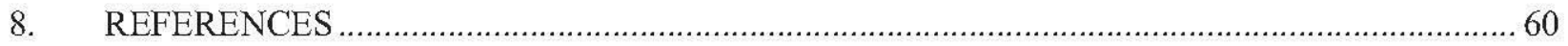

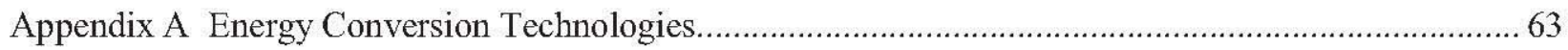

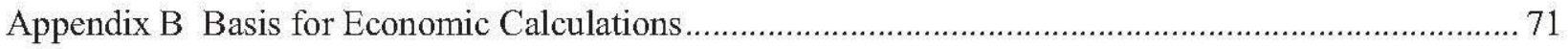

\section{FIGURES}

Figure 1. Wind generation potential, with purple and red showing the best locations 1

Figure 2. Most current Wyoming power plants are 30-50 years old and burn coal. Additions since 2005 are mainly wind. Data is from Wyoming Geologic Survey .......................................... 2

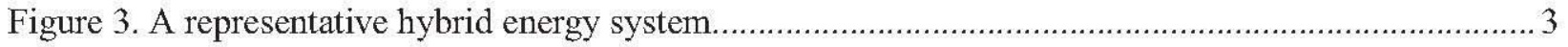


Figure 4. Current transmission line projects under development in Wyoming. [WyIA, 2012].

Figure 5. Recent U.S. chemicals production history. Basic inorganic chemicals includes

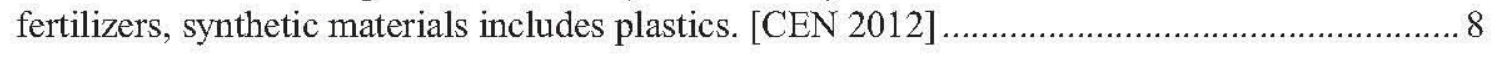

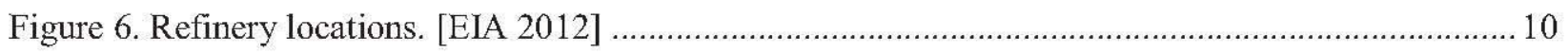

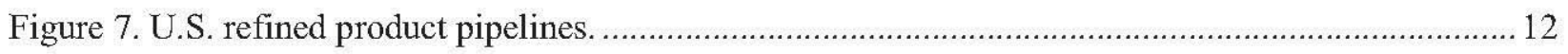

Figure 8 . Structure of a future integrated synfuel and chemical industry. ..................................... 14

Figure 9. Top Five Sources of U.S. Petroleum Imports, 2010 [EIA 2012] .................................... 16

Figure 10. Three weeks of electrical demand data [Midwest Independent System Operator 2012] .........20

Figure 11. Annual trends of daily peak power demand. Rockies/Southwest region includes Wyoming, Colorado, New Mexico, and Arizona. [FERC 2012] .......................................20

Figure 12. Map of wind generation potential in the southeast quadrant of Wyoming ..........................21

Figure 13. Example output of $300 \mathrm{MW}$ of wind turbines over seven days at the end of January. ............22

Figure 14. Hybrid system operation to smooth but not eliminate wind's variability.............................23

Figure 15. Allowing modest variability in wind farm output greatly reduces the demand for energy from the hybrid system's nuclear reactor. Wind farm capacity is $300 \mathrm{MWe}$...............24

Figure 16. Natural gas to methanol to gasoline plant in Montunui, New Zealand. ............................. 30

Figure 17. Reconfigured reformer section of a nuclear-integrated natural gas to gasoline plant. $\mathrm{HX}$ represents a train of heat exchangers.

Figure 18. A natural gas combined cycle plant serves in place of the nuclear reactor prior to construction of the nuclear reactor.

Figure 19. IRR vs. gasoline selling price for the conventional natural gas-to-MTG plant.

Figure 20. Ranges of levelized costs of electricity for coal, gas, nuclear and onshore wind power plants.

Figure 21. IRR vs gasoline selling price for different nuclear heat $(\mathrm{NH})$ costs, at a natural gas price of $\$ 4 / \mathrm{MSCF}$ (a) and $\$ 8 / \mathrm{MSCF}$ (b).

Figure 22. IRR versus gasoline price for different plant availabilities of a nuclear hybrid energy system ( $\$ 6 / \mathrm{MSCF}$ natural gas, 2.32 cents/kWh nuclear heat, $92 \%$ plant availability for the conventional case).

Figure 23. IRR versus gasoline price for different natural gas prices for the conventional case and the NGCC-integrated process.

Figure 24. IRR versus gasoline price for the conventional case, the NGCC-integrated process assuming 92 and $82 \%$ plant availability (Natural gas price $\$ 6 / \mathrm{MSCF}$, cost of steam $2.59 \mathrm{cent} / \mathrm{kWh}$ ).

Figure 25. Gasoline price versus carbon tax for different hybrid energy systems. The plot assumes

$12 \%$ IRR and \$6/MSCF natural gas. Operating conditions were (a) $82 \%$ plant availability, steam cost 2.32 cents/ $\mathrm{kWh}$, and (b) $82 \%$ plant availability, steam cost 2.59 cents $/ \mathrm{kWh}$.

Figure 26. Typical nuclear fuel cycle. Source: Converdyn.

Figure A-1. Dual reformer system that converts natural gas to syngas for liquid fuel synthesis. 


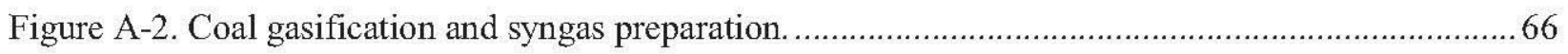

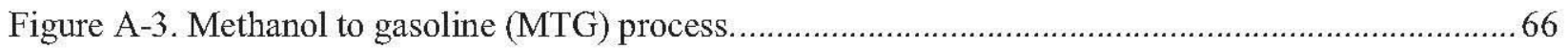

Figure A-4. Fischer-Tropsch (FT) synthesis, with refinery producing diesel as the principal product.

\section{TABLES}

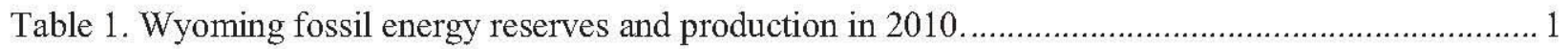

Table 2. Commodity chemical production compared to Wyoming fossil fuel production...................... 7

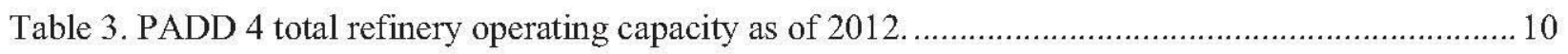

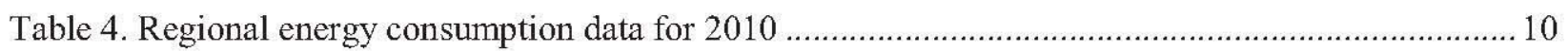

Table 5. Percentage impact on state markets of a 10,000 bpd plant.............................................. 11

Table 6. Population projections for Wyoming and surrounding states, 2000-2030 ............................ 17

Table 7. Selected previous results for fossil energy only cases. .................................................. 31

Table 8. Comparison of cases for natural gas to methanol to gasoline............................................. 33

Table 9. Estimates for the levelized costs of electricity based on literature data.................................. 38

Table 10. Amount of $\mathrm{CO}_{2}$ released by the various systems..........................................................42

Table 11. Natural gas-to-MTG economic results summary for an IRR of $12 \%$ and an average

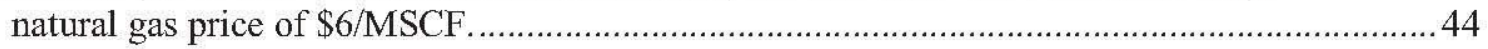

Table 12. Projected costs of air separation for oxycombustion ....................................................46

Table 13. Comparison of the amount of steel and concrete needed for the fabrication of wind turbines and nuclear reactors per TWh of power [Peterson et al., 2005].....

Table A-1. Categories of heat sources used in the process analysis. "Reactor" refers to nuclear systems. 68

Table A-2. Thermal characteristics of US small modular reactors under development .69

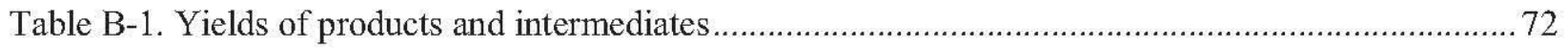

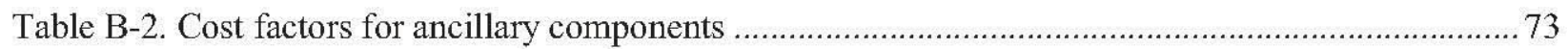

Table B-3. Total capital investment for the natural gas-to-fuels plant.............................................. 73

Table B-4. Estimation of manufacturing cost for the natural gas-to-fuels plant.................................. 73

Table B-5. Manufacturing costs for the natural gas-to-fuels plant and the nuclear-integrated natural gas-to-fuels plant assuming various natural gas prices......................................... 74

Table B-6. Manufacturing cost estimate for a low natural gas price $(\$ 4.00 / \mathrm{MSCF}) \ldots \ldots \ldots \ldots \ldots \ldots \ldots \ldots \ldots . \ldots \ldots$

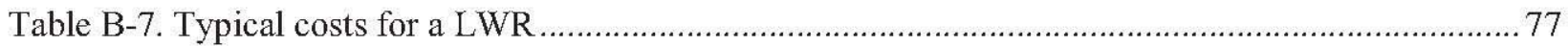




\section{ACRONYMS AND ABBREVIATIONS}

$\begin{array}{ll}\text { bbl } & \text { barrel of petroleum } \\ \text { bcf } & \text { billion cubic feet } \\ \text { BLM } & \text { Bureau of Land Management } \\ \text { bpd } & \text { barrel per day } \\ \text { CCS } & \text { carbon capture and sequestration } \\ \text { CCGT } & \text { combined cycle gas turbine } \\ \text { COL } & \text { construction and operations license } \\ \text { DEQ } & \text { Department of Environmental Quality } \\ \text { EIA } & \text { Energy Information Administration } \\ \text { EPA } & \text { Environmental Protection Agency } \\ \text { EPR } & \text { European Pressurized Reactor } \\ \text { EPRI } & \text { Electric Power Research Institute } \\ \text { FERC } & \text { Federal Energy Regulatory Commission } \\ \text { FT } & \text { Fischer-Tropsch } \\ \text { HRSG } & \text { heat recovery steam generator } \\ \text { IGCC } & \text { integrated gasification combined cycle } \\ \text { INL } & \text { Idaho National Laboratory } \\ \text { IRR } & \text { internal rate of return } \\ \text { kWh } & \text { kilowatt-hour } \\ \text { LCOE } & \text { levelized cost of electricity } \\ \text { LPG } & \text { liquefied petroleum gas } \\ \text { LUEC } & \text { levelized unit of electricity cost } \\ \text { LWR } & \text { light water reactor } \\ \text { MIT } & \text { Massachusetts Institute of Technology } \\ \text { MM } & \text { million } \\ \text { MMSCFD } & \text { million standard cubic feet per day } \\ \text { MSCF } & \text { thousand standard cubic feet } \\ \text { MTBE } & \text { methyl tertiary-butyl ether } \\ \text { MTG } & \text { methanol tog } \\ \text { megawatt } \\ \text { megawatt electric } \\ \text { megawatt-hour } \\ \text { MWe }\end{array}$




$\begin{array}{ll}\text { NEA } & \text { Nuclear Energy Agency } \\ \text { NEI } & \text { Nuclear Energy Institute } \\ \text { NG } & \text { natural gas } \\ \text { NGCC } & \text { natural gas combined cycle } \\ \text { NRC } & \text { Nuclear Regulatory Commission } \\ \text { O\&M } & \text { operations and maintenance } \\ \text { OPEC } & \text { Organization of Petroleum Exporting Countries } \\ \text { PADD } & \text { Petroluem Administration for Defense District } \\ \text { PC } & \text { pulverized coal } \\ \text { SER } & \text { School of Energy Resources } \\ \text { SMR } & \text { small modular reactor or steam methane reforming } \\ \text { T+E } & \text { threatened and endangered } \\ \text { TWh } & \text { terawatt-hour } \\ \text { U.S. } & \text { United States }\end{array}$




\section{ACKNOWLEDGEMENTS}

Funding for this Cooperative Research and Development Agreement (CRADA) project was provided by the Wyoming Legislature through the Wyoming Business Council. A companion study on high temperature gas reactors and the carbon economy in Wyoming was funded as a matching effort through the US Department of Energy's Next Generation Nuclear Plant program with assistance from the NGNP Alliance, an industry group.

A number of people contributed in various ways to this report. Richard Boardman's (INL) long relationship with Wyoming authorities on energy issues led to the commissioning of this report. Robert Jensen (CEO of the Wyoming Business Council) provided on-going guidance about the direction and emphasis of the work. Contributors to different sections of this report include Robert Cherry (lead author, Idaho National Laboratory), David Bell (University of Wyoming), Robert Breckenridge (INL), Thomas Foulke (University of Wyoming), Janine Lichtenberger (Portage, Inc.), and Scott Lieske (University of Wyoming). Reviewers of both the manuscript and the ideas in it included Robert Ballard (University of Wyoming), Richard Boardman (INL), Laurence Demick (INL), and Rick Wood (INL). Bob Ballard was also quite helpful as the project manager coordinating the Wyoming aspects of this effort. Penny Simon (INL) provided text processing assistance. 


\section{Preliminary Feasibility of Value-Added Products from Cogeneration and Hybrid Energy Systems in Wyoming}

\section{THE OPPORTUNITY}

\subsection{Wyoming's Energy Resources}

Wyoming has a wealth of primary energy resources in the forms of coal, natural gas, wind, uranium, and oil shale. The state produces about $41 \%$ of the United States' coal and about $10 \%$ of its natural gas. It produces the second highest amount of energy (in BTUs) after Texas and is the source of $14.2 \%$ of the country's total energy production [EIA 2012]. The state also has great potential for generating electricity from wind (Figure 1). However, this renewable resource has not been fully utilized: wind was the source of only $6.7 \%$ of the state's total generation in 2010 . Wyoming holds about $41 \%$ of the

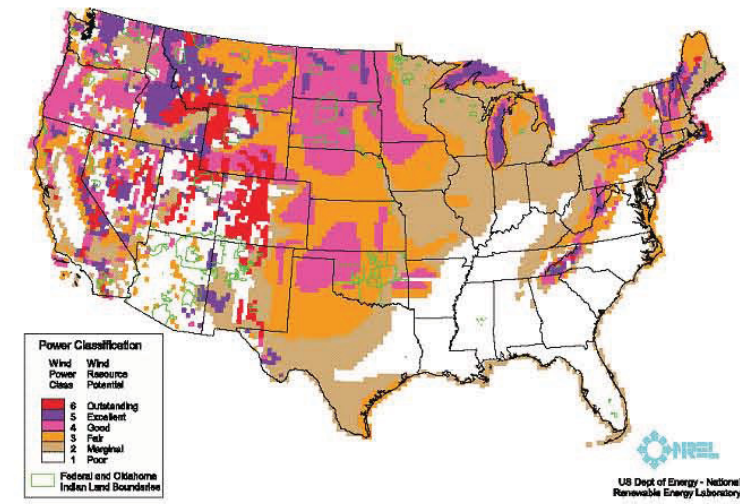

Figure 1. Wind generation potential, with purple and red showing the best locations nation's uranium reserves that are economically recoverable at a $\mathrm{U}_{3} \mathrm{O}_{8}$ price of $\$ 50$ /pound. The state's oil shale resources, equivalent to 300 billion barrels of crude oil and found primarily in the Green River and Washakie Basins, could equal one quarter of the world's proven oil reserves [EIA 2012] but for technical, economic, and environmental reasons oil shale has not been developed commercially.

Wyoming's reserves and annual production of primary energy resources are summarized in Table 1. Petroleum exists in the state and is produced but only in relatively small amounts, about 146,000 barrels per calendar day in 2010. While Wyoming has large reserves of fossil fuels, it appears from the data in Table 1 that only about 15 years of natural gas and coal remain. This number is low because it is calculated using reserve estimates based on proven existence of coal that can be produced economically at current prices and with current technology. The actual amount ultimately available is expected to be much greater.

Most of Wyoming's coal and gas resources are exported from the state in their native form rather than as more refined, higher value products. For instance, in contrast to its production of $41 \%$ of U.S. coal, Wyoming produces only $3.0 \%$ of all coal-fired electricity in the country [EIA 2012]. The upgrading that is done primarily produces electricity from coal or refined products from petroleum. Of the small amount of its coal production that Wyoming converts to power, it exports a large fraction of that amount with further increase limited by the ability to move the

Table 1. Wyoming fossil energy reserves and production in 2010 .

\begin{tabular}{|l|r|r|}
\hline & Reserves & $\begin{array}{r}\text { Annual } \\
\text { production }\end{array}$ \\
\cline { 1 - 2 } $\begin{array}{l}\text { Crude oil } \\
\text { (million bbls) }\end{array}$ & 583 & 53.3 \\
\cline { 1 - 2 } $\begin{array}{l}\text { Dry natural gas } \\
\text { (BCF) }\end{array}$ & 35,283 & $\begin{array}{r}2,306 \\
\text { (BCF wet) }\end{array}$ \\
\cline { 1 - 2 } $\begin{array}{l}\text { Natural gas liquids } \\
\text { (million bbls) }\end{array}$ & 1010 & 642.5 \\
\cline { 1 - 2 } $\begin{array}{l}\text { Coal (million of } \\
\text { short tons) }\end{array}$ & 6610 & 440.5 \\
\hline
\end{tabular}
electricity to markets. In 2010 the state generated 48.1 million megawatt-hours compared to 17.1 million MWh of consumption [EIA 2012]. A number of projects are underway to increase the ability to export 
electricity to consumers around the West [WyIA 2012] with these aimed at the state's renewable wind energy potential. Wyoming also has six refineries with a total refining capacity of 166,100 barrels per calendar day, slightly more than its oil production and slightly more than twice the state's 2010 consumption of refined hydrocarbons.

Possible future restrictions on emissions of the greenhouse gas $\mathrm{CO}_{2}$ present a significant challenge to the ongoing use of Wyoming's coal, gas, and petroleum resources both in-state and elsewhere. Similar to the way that restrictions in the 1960s and 1970s on sulfur oxide (SOx) emissions from power plants led to a boom in use of Wyoming's low sulfur coal in place of high sulfur Eastern coals, possible future restrictions on $\mathrm{CO}_{2}$ emissions as well as the low current price are spurring greater interest in natural gas for power generation. Its combustion produces $40-50 \%$ less $\mathrm{CO}_{2}$ per unit of heat but in the longer term, several decades, greater reductions than this might be required. The addition of $\mathrm{CO}_{2}$ capture systems to power plants, aside from being a large capital cost, can reduce their power output by $15-30 \%$. The economics of such additions, coupled with the age of the plants on which they would be used (Figure 2), are likely to lead to retirement of some existing coal-fired plants. Any transmission capacity carrying that generation to out-of-state markets would then be available to new power plants.

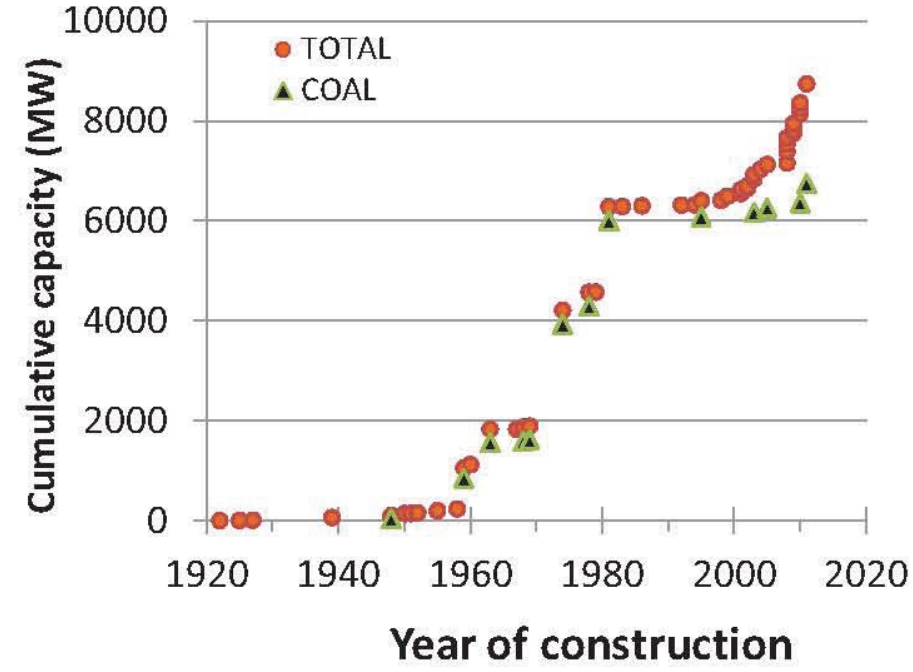

Figure 2. Most current Wyoming power plants are 30-50 years old and burn coal. Additions since 2005 are mainly wind. Data is from Wyoming Geologic Survey.

Wyoming's leadership recognizes the opportunity to broaden the state's economic base by using its coal, natural gas, and other energy resources to make value-added products such as synthetic vehicle fuels and commodity chemicals. These could be exported from the state to regional and national markets. This report was commissioned by the Wyoming legislature through the Wyoming Business Council to explore the use of hybrid energy systems to make those higher value products and to facilitate the increased use of renewable wind energy.

It should be noted that this analysis specifically considers hybrid energy systems in Wyoming. However, similar objectives of developing a value-generating downstream industry from raw energy resources located far from markets have been considered in Alberta, Saudi Arabia, and China, among other places. A review of their experience, though outside the scope of this report, would likely be informative to those planning Wyoming's energy future.

\subsection{Hybrid Energy Systems}

Hybrid energy systems integrate complementary energy conversion processes with multiple inputs and outputs into coordinated systems with advantages that can include better usage of capital equipment, lower costs of electricity production, reduced $\mathrm{CO}_{2}$ emissions, and enhanced energy security through domestic production of vehicle fuels [Cherry et al. 2012].

As one example out of many possible configurations, a nuclear power plant supplies electricity to a regional power grid that also receives a large amount of variable wind-generated power (Figure 3). During periods of high demand such as daylight hours or when the wind turbines are not generating much power, the nuclear plant supplies electricity to the grid. As power demand drops at night or if the wind farm is actively generating, some amount of the steam generated by the nuclear reactor is diverted to and 
used by a chemical plant that converts natural gas into methanol. Methanol is a large volume industrial chemical that can be further converted by commercial processes into gasoline, dimethyl ether (a substitute for diesel fuel), biodiesel (as the methyl component added to fatty acids from vegetable oils), or the plastics precursors ethylene or propylene. When the methanol plant is not receiving nuclear heat, it can either idle or run at reduced rates, or use natural gas in a conventional boiler to generate steam to continue to run the methanol process at full capacity. The advantages of this type of hybrid system are being able to operate a power grid reliably with a large fraction of renewable but variable wind energy, having an assured supply of low cost, low $\mathrm{CO}_{2}$ nuclear electricity during peak demand periods, and being able to use that nuclear energy to convert Wyoming minerals into fuels for U.S. light vehicles.

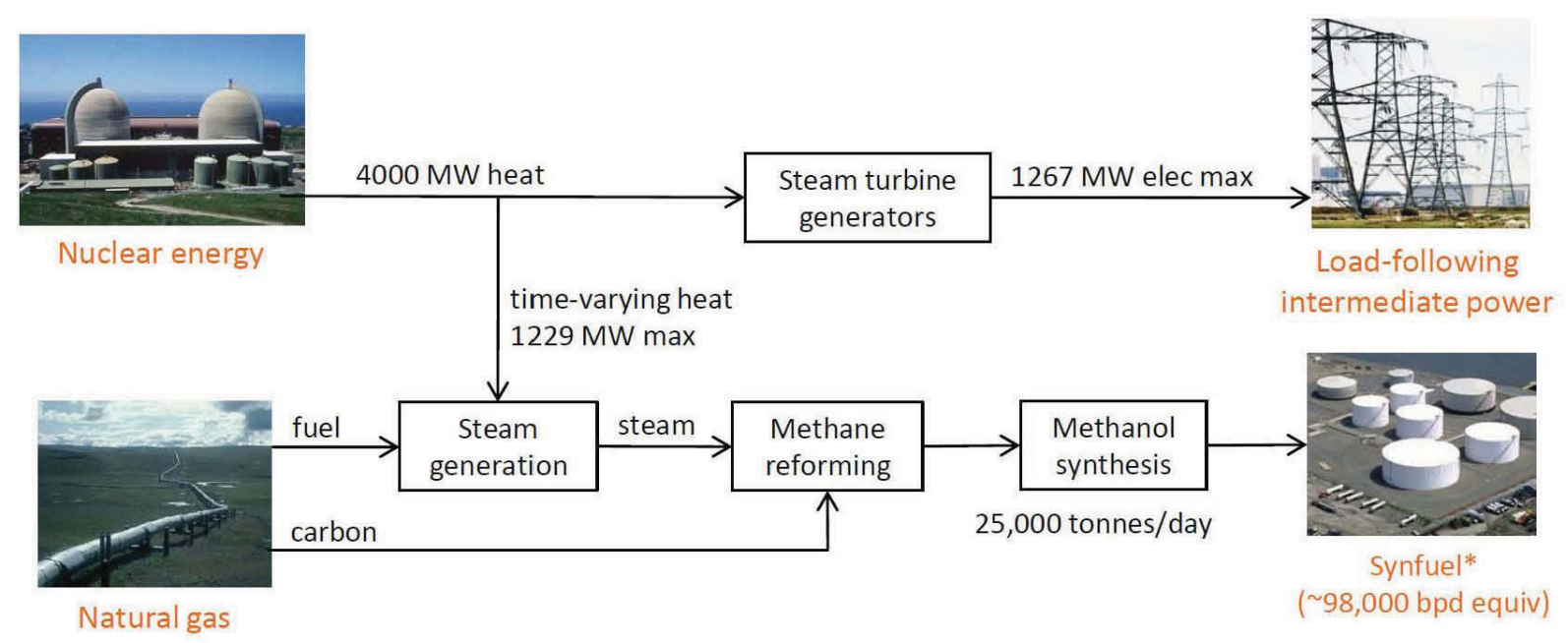

Figure 3. A representative hybrid energy system.

There are examples of such combined plants in industry. General Electric has announced a hybrid solar-natural gas power plant to be built in Turkey [http:/green.blogs.nytimes.com/2011/06/07/a-hybridpower-plant-takes-shape-in-turkey/]. FPL has announced a similar solar-natural gas system for Florida [http://www.fpl.com/environment/solar/pdf/Martin.pdf]. Both of these, however, produce only electricity as a product, using solar energy to reduce the overall amount of fuel needed.

Various configurations and applications of hybrid systems have been explored in recent years by the Idaho National Laboratory (INL), a U.S. Department of Energy multi-program laboratory. One conclusion of that work is that, if $\mathrm{CO}_{2}$ generation is to be minimized for economic, regulatory, or disposal reasons, energy resources such as coal, natural gas, or biomass best use their carbon content to build the desired synthetic vehicle fuel molecules. The energy for that conversion and upgrading should be supplied by low $\mathrm{CO}_{2}$ sources such as wind or nuclear power rather than by combustion or chemical oxidation of carbon-containing feed stocks.

\subsection{Objectives and Approach to the Analysis}

The primary objective of this report is to examine nuclear and nonnuclear hybrid systems for making value-added energy products from the primary resources available in Wyoming. In particular, the work looks at producing synthetic fuels and commodity chemicals and offsetting the variability of wind energy. The operating concepts of hybrid energy systems are well suited to addressing both of these goals. Rather than using the hybrid system's generation capacity to make bulk power (from either fossil or nuclear heat sources) which would have to be exported, this report examines how to use the flexibility of hybrid generation to reduce the high frequency components of wind variability to make Wyoming's wind power-with some supplementary hybrid power-most attractive to users inside and outside the state. 
The many possible combinations of multiple primary energy resources and multiple energy products include, for example, three classes of electricity: base load generation, intermediate generation to follow diurnal cycles, and rapid load-following to offset the variability of wind generation. Comprehensive analysis of all possible combinations of energy products is not practical. Instead, the problem of selecting combinations that achieve Wyoming's goal is decomposed into several parts. First, a successful industry must be based on a healthy market. Wyoming, the least populous state, is not a sufficient market by itself to support an industry of the scale of fuel or chemical manufacturing. To identify markets large enough to absorb the output of a newly built plant, the magnitude of regional and national energy product usage is compared in Chapter 2 to the scale of a representative synthetic fuels or chemical plant. The region contains Wyoming, Montana, Colorado, Utah, and Idaho, the states in Petroleum Administration for Defense District (PADD) 4, a Department of Energy statistical reporting holdover from gasoline rationing in World War II. South Dakota and Nebraska, the last of the states surrounding Wyoming, are also included in the analyses but have little effect on the results. The market assessment also examines the transportation of energy products from prospective plant sites in Wyoming to the regional population and refining centers of Denver, Salt Lake City, and Billings. This overall market assessment is necessary to determine what products should be considered.

Chapter 3 discusses whether and how chemical or synfuel processes can be operated transiently to allow them to follow either diurnal electrical demand changes or the variability of wind generation. Handling wind's variability would allow Wyoming to much better capitalize on its wind generation potential. With these market and technical selection criteria specified, the most promising processes are identified for further analysis in Chapter 4. This analysis includes a review of the changes needed to adapt the conventional power plant and fuel or chemical process to hybrid operation. Process performance data as predicted by ASPEN-PLUS simulation software was used to estimate operating cost as input to INL financial analysis software. Chapter 5 discusses nontechnical issues affecting hybrid energy systems and the support industries that might be based on hybrid systems, while Chapter 6 addresses value-added processing of Wyoming's uranium resources. Chapter 7 on findings and recommendations closes the report. A chapter of references and several appendices providing additional details of the technical and financial analysis follow. 


\section{MARKETS FOR WYOMING ENERGY PRODUCTS \\ 2.1 Classes of Energy Products}

There are three broad groups of potential non-nuclear products from Wyoming's energy resources: electricity, commodity chemicals, and synthetic vehicle fuels. Through the operation of appropriately designed hybrid energy systems, products from one, two, or all three of these could be made. This section will explore the potential for products within each of these groups and investigate the size and location of their markets. Heat, a common energy product in Europe for district heating, is not considered because its large scale use in industry would be to make other energy products while its small scale use for residential and commercial (district) heating is limited by Wyoming's low population density. Nuclear products derived from Wyoming's uranium resource are treated separately in Chapter 6.

\subsubsection{Electrical Power}

Electricity already is one of Wyoming's energy exports with large amounts carried by transmission lines to cities in California, Nevada, and Arizona. A large coal-fired power plant adjacent to a coal mine has been one of the most cost efficient ways of generating electricity, although future penalties for $\mathrm{CO}_{2}$ emissions could greatly reduce coal's economic advantage. In the last decade, wind generation capacity in Wyoming has grown rapidly spurred by federal incentives and demand for renewable energy in nearby states with Renewable Portfolio Standards.

Electrical generation capacity can be broken down into several categories based on their operating characteristics. Typically about half of power production is base load generation, power that is supplied to the regional grid at a constant rate. This mode allows the power plant to operate efficiently at a steady rate close to the design value for the plant, creating the most revenue for the plant. Large plants powered by coal, natural gas, and nuclear energy are used for this type of service because the cost of their highly efficient equipment can be distributed across large amounts of output.

The next category is intermediate demand, generation which cycles on and off over a day to follow diurnal variations in demand. Because this generation operates only part time, plant revenues are lower and the ability to pay back capital costs is reduced. This leads to the use of smaller plants, older fully depreciated plants including dams, and lower cost natural gas-fired plants.

The third category is peak power, generation generally needed on short notice for short periods. It runs for only a small fraction of a year, perhaps only a few hundred hours, and consequently is designed with minimal capital costs at the expense of much higher operating costs. Capital and fixed operating costs are incurred whether the plant runs or not, while variable operating costs - primarily for fuelappear only during the short periods when the system is generating both power and revenue. Simple cycle gas turbines are typically used in this service.

The previous three categories can describe both power demand (also called load) as well as the generation systems that meet that type of demand. There is also the category of variable renewable generation which covers wind farms, solar photovoltaic, and solar thermal systems. This renewable power is generated at essentially uncontrolled rates at unscheduled times and, because of its part time availability, averages only $15-35 \%$ of the amount of generation that would be expected from full time operation at design rates. Although these systems have no fuel costs, their costs per megawatt-hour are relatively high because there is not a large amount of output over which to spread the capital and operating costs.

The comments regarding capital cost of these systems also apply directly to the cost of transmission lines that might carry this power over long distances to market. Transmission capacity that is used at full capacity all the time is less expensive because it can spread its costs over a greater number of megawatthours carried. Power that follows diurnal cycles or has uncontrolled variability must be charged more to cover the transmission system's costs while ultimately delivering less total power to the end users. With the siting and permitting of transmission lines becoming increasingly expensive and difficult, there is a 
large incentive to utilize existing capacity to the extent possible. Furthermore, line losses to distant markets such as the West coast make long distance sales less attractive financially. Closer markets such as the Wasatch Front (Salt Lake City area) and the Front Range (Denver) are more attractive.

Wyoming already sends $60 \%$ of its power generation out of state over transmission lines that are generally fully subscribed. Any new generation, except if specifically intended to replace a retiring older facility, would increase the amount to be exported. Construction of new transmission capacity in the state is facilitated by the Wyoming Infrastructure Authority (WyIA). The transmission projects under development in Wyoming (Figure 4) have over 15,000 MW of capacity (WyIA 2012) but the regulatory process is lengthy and not all of the projects may be built. Because of transmission constraints, planning to generate large new amounts of electricity from hybrid energy systems is not a preferred strategy for Wyoming. Nonetheless, power generated by wind farms will be in demand by neighboring states with Renewable Portfolio Standards for their power supplies. Wind generation therefore could be the preferred replacement for retiring coal-fired plants. As more wind generation comes on-line, however, hybrid energy systems will be required to mitigate the effects of that variable, nondispatchable power on the grid's supply-to-demand balance.

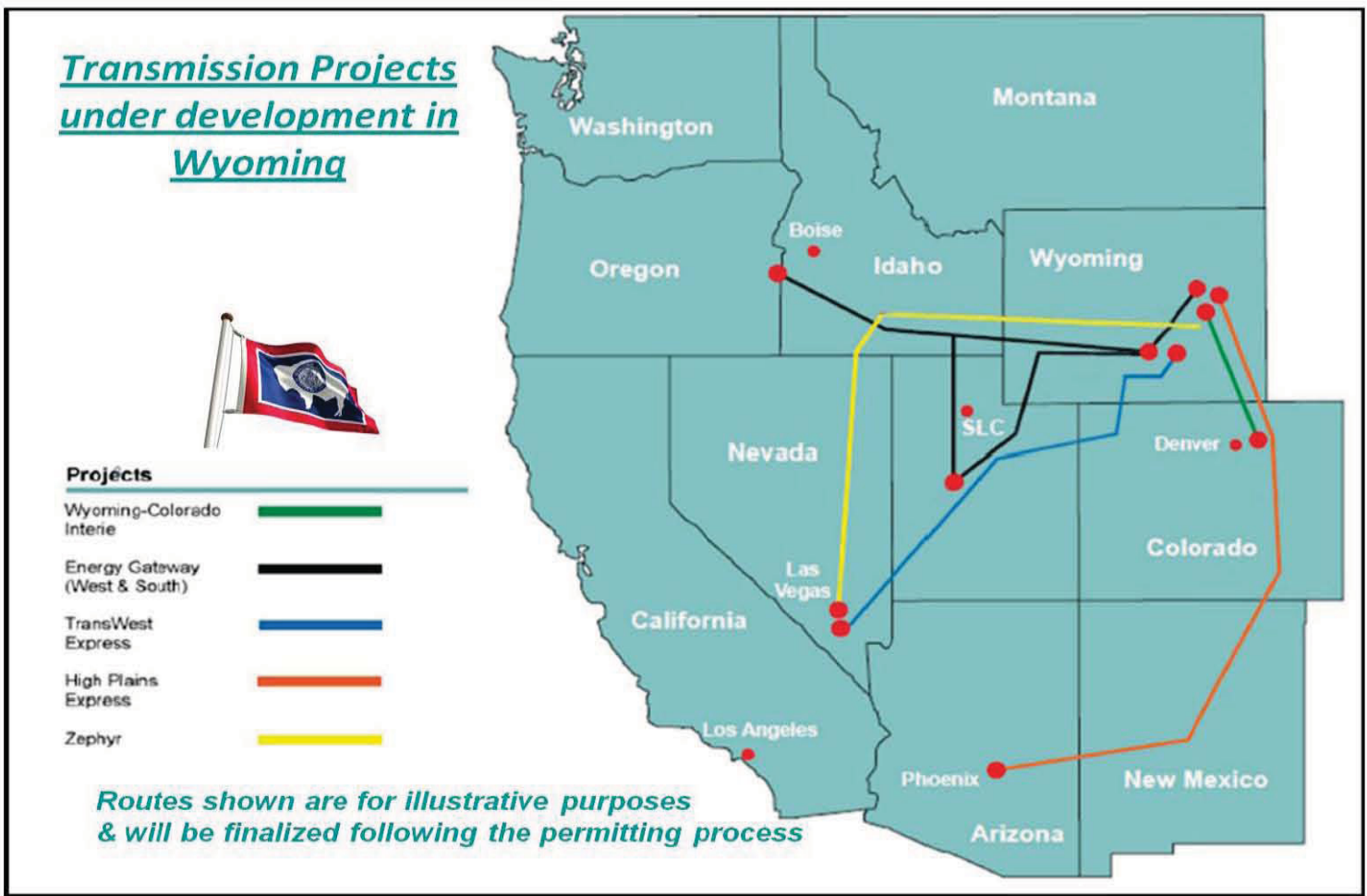

Figure 4. Current transmission line projects under development in Wyoming. [WyIA, 2012].

\subsubsection{Commodity Chemicals}

Commodity chemicals present a number of possibilities as alternative uses of carbon from Wyoming's coal and natural gas. Ethylene, the precursor to the plastic polyethylene, is the largest volume organic chemical in the U.S. Propylene and ethylene dichloride, precursors to other plastics, also are made in great quantities. Methanol is used for a variety of purposes, the main one being to make formaldehyde, a component of urethane foams. Ammonia, an inorganic chemical, is produced using natural gas to make hydrogen as the first step. The ammonia ultimately appears in a variety of fertilizer compounds: anhydrous ammonia, ammonium nitrate, ammonium sulfate, urea, urea-ammonium nitrate (UAN), and others. Explosives too are made from ammonia, but the amounts are much smaller. 
Methanol and ammonia are conventionally made by first making synthesis gas (syngas), a mixture of two parts hydrogen to one part carbon monoxide. The chemistry exists to commercially make ethylene, propylene, and ethylene dichloride from syngas too, although the conventional routes to these products rely on thermal cracking of larger feed molecules rather than synthesis from smaller molecules. Syngas can be made from natural gas, coal, biomass, or almost any carbonaceous feed stock and it is this linkage that makes these commodity chemicals of interest to Wyoming. None of them are currently produced in the State except ammonia for fertilizer and explosives at a small Dyno Nobel plant in Cheyenne.

Commodity chemicals are not an especially attractive option for Wyoming. One reason for not pursuing production of one of them is the small size of those markets compared to those for natural gas or coal. Table 2 shows recent production data for these chemicals as well as for coal and natural gas in Wyoming. Dyno Nobel's Cheyenne ammonia plant has an annual capacity of 0.174 million metric tonnes (about 530 metric tonnes per day). A new world scale plant for any of these commodity chemicals would have a capacity of 1500-5000 metric tons per day, or about $0.5-1.6$ million metric tons per year. Assuming that new Wyoming production could capture $10 \%$ of the domestic market soon after entering it, no more than $0.5 \%$ to $1 \%$ of Wyoming's current coal production would need to be diverted to this new use. The impact on the coal industry would be negligible. Because the production of natural gas on a weight basis is about one fifth that of coal, the impacts on that industry would be about five times larger, $2.5 \%$ to $5 \%$, visible but still not a major effect.

Table 2. Commodity chemical production compared to Wyoming fossil fuel production.

\begin{tabular}{|c|c|c|}
\hline Material & Year & U.S. Production (million metric tons) \\
\hline Ethylene $^{\mathrm{a}}$ & 2010 & 23.975 \\
\hline Propylene $^{\mathrm{a}}$ & 2010 & 14.085 \\
\hline Ethylene dichloride $^{a}$ & 2010 & 8.810 \\
\hline Methanol $^{\mathrm{b}}$ & 2010 & 0.79 (estimate) \\
\hline Ammonia $^{c}$ & 2011 & $8.10(13.8$ consumed $)$ \\
\hline $\mathrm{Coal}^{\mathrm{d}}$ & $\begin{array}{l}52 \text { weeks to } \\
8 / 25 / 2012\end{array}$ & 230.9 (Wyoming only) \\
\hline Natural gas ${ }^{\mathrm{d}}$ & 2011 & $44.0^{\mathrm{e}}$ (Wyoming only) \\
\hline \multicolumn{3}{|c|}{$\begin{array}{l}\text { a. Chemical and Engineering News, July 4, } 2011 \\
\text { b. Bromberg and Cheng, } 2010 \\
\text { c. U.S. Geologic Survey Mineral Commodity Summaries (Nitrogen), January } 2012 \\
\text { d. U.S. Energy Information Agency, August } 2012 \\
\text { e. calculated from 2,175,824 million scf reported }\end{array}$} \\
\hline
\end{tabular}

The economic impacts are potentially much greater because the value of these chemical products is much higher than that of coal. Their selling prices vary greatly with feed stock costs and market conditions, but are on the order of $\$ 0.20$ to $\$ 1.00$ per pound. In comparison to coal at perhaps $\$ 20$ per ton of carbon (not per total weight of coal as received) for Wyoming delivery, the chemicals are worth roughly 20 to 100 times more per pound than coal. The envisioned chemical industry at $10 \%$ market share would have $10-100 \%$ the current revenues of coal depending on what chemical product is made. The comparable ratios for natural gas at $\$ 3$ per thousand standard cubic feet $(\$ 0.067$ per lb) are that chemicals are 3 to 16 times more valuable per pound that natural gas and, if they were produced at rates equal to $2.5 \%$ to $5 \%$ of gas production, would have $7-80 \%$ of the revenues of natural gas production.

While these comparisons make commodity chemicals appear attractive, they are based on selling out the production of a new world scale plant (and perhaps a second one) to reach 10\% market share. However, lower prices for feed stocks overseas have over the last three decades moved chemicals production out of North America. As an example, the 2010 production of methanol in Table 2, only 0.79 million metric tons, can be compared to the U.S. production capacity available at the start of the decade, 7.73 million metric tons. In addition, the markets for basic commodity chemicals are still soft because of 
the weak economy. Figure 5 shows that for the last four years the U.S. production of chemicals has been at a level well below peak capacity.

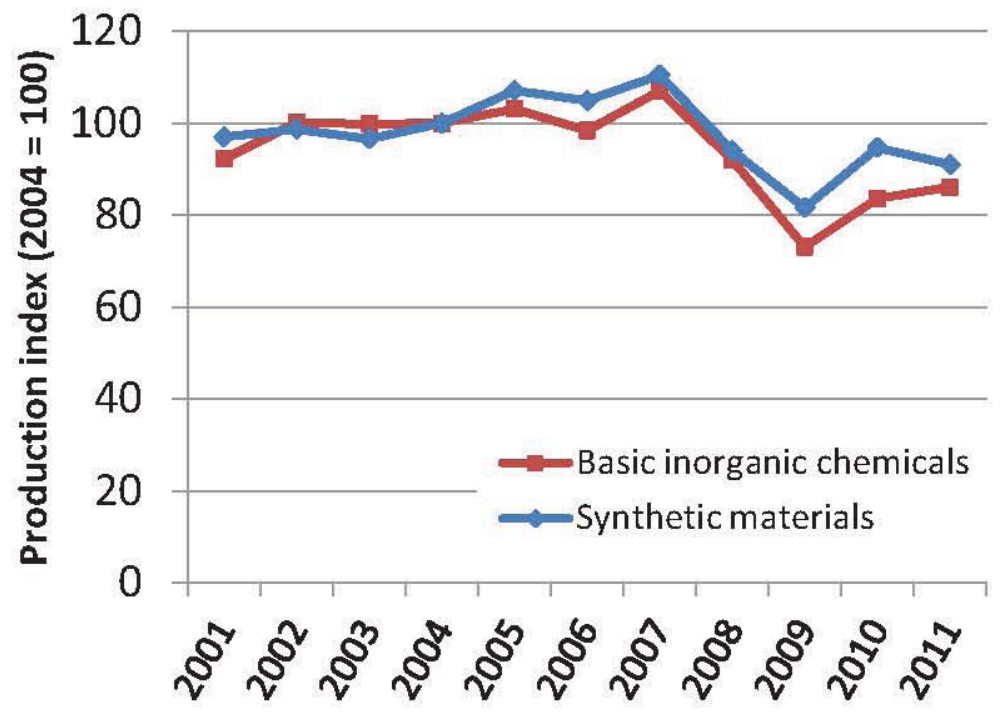

Figure 5. Recent U.S. chemicals production history. Basic inorganic chemicals includes fertilizers, synthetic materials includes plastics. [CEN 2012]

The large drop in North American natural gas prices over the last several years has now made U.S. production cheaper than foreign production, restoring the incentive for domestic production and creating an opportunity for export sales. With the lower prices appearing to have some longevity, restarts and new capacity have been announced by the major producers of these chemicals [Nitrogen+Syngas 2012] despite demand for chemicals still being weak. Entry into these highly competitive markets in the next several years by possible new production in Wyoming could be difficult, especially if U.S. natural gas prices return to higher levels during that time.

\subsubsection{Unconventional and Synthetic Fuels}

The term fuel covers products intended for a wide variety of applications. In this report the use is in vehicles including automobiles, light trucks, heavy trucks, locomotives, and airplanes, all of which are users of gasoline, diesel fuel, or turbine fuel. Heavy fuel oils and bunker fuel as used by ships are not considered because of the comparatively small market size and Wyoming's distance from ship-related markets. Also excluded are plug-in and fuel cell electric vehicles because they are not in widespread usage and plug-in vehicles' energy needs can be met from the existing power grid. Although natural gas products (compressed natural gas CNG and liquefied natural gas LNG) are not in widespread use as vehicles fuels either, they would utilize a Wyoming resource. While low natural gas prices encourage use of natural gas vehicles, they would also encourage other use of natural gas such as power generation or gas-to-liquids conversion. As with electric vehicles, until there is a national policy that successfully encourages the use of natural gas-fueled vehicles, the uncertainty around their adoption makes them poor choices for a central role in Wyoming's objective of developing a value-added industry around fossil resources.

The fuel candidates that are left are gasoline and distillate fuels. These are currently made by refining petroleum. The common expectation, but not yet official policy, is that the United States should reduce its reliance on petroleum from problematic foreign sources by producing more petroleum domestically using better exploration and production methods and by supporting continued access to crude oil from allied countries such as Canada. Related ideas include reducing the use of petroleum products through 
efficiency improvements and extending the life-time of petroleum supplies and fuel-associated infrastructure by developing "drop-in" synthetic fuels fully compatible with current vehicle fuels.

Unconventional sources of petroleum include oil shale which requires substantial thermal treatment either above ground or in situ to make a light oil that can be added to and refined with conventional petroleum. Wyoming has large deposits of oil shale and using intermittently available heat for in situ thermal treatment would be a good fit. However, until the economic and environmental issues are addressed the use of hybrid system heat for oil shale production is unlikely to be needed for many years.

Drop-in synthetic fuels include additives such as ethanol or methyl tertiary-butyl ether (MTBE) used at modest levels in petroleum-based fuels. They are considered synthetic fuels because they are not based on fractionation of fossil resources; they have to be created through chemical or biochemical reactions. New synfuels that might fully drop into the current infrastructure to displace petroleum as an engine's energy supply will be based on carbon, hydrogen, and perhaps oxygen. That carbon, the major component of a synfuel, is a value added opportunity for Wyoming's coal and natural gas. Synfuel's attractive characteristics as a product include the large consumption of vehicle fuel, the large scale at which synfuel can be produced, and its ready transport to markets outside Wyoming.

\subsection{Size and Location of Vehicle Fuel Markets}

Understanding the market for a product is a key step in deciding to invest in the facilities to produce that product. Hydrocarbon markets in the United States are particularly well developed. Hydrocarbon products and drop-in fuels in particular are fungible, meaning that a unit of the product from one source is completely substitutable for a unit from another source. For example, a barrel of diesel from Wyoming will have similar properties and value as one produced on the Gulf coast. The difference between them comes down to cost of production and transportation. This section addresses the options for Wyoming when choosing a specific synfuel and manufacturing process from among the several possibilities.

\subsubsection{Market Comparison}

A complete market study of liquid transportation fuels is outside the scope of this report. The analysis will be confined to Wyoming and the surrounding states so Wyoming's distance from the highly populated coasts will not lead to higher transportation costs for either the feed materials or the finished product(s). (Transportation cost is not an equivalent issue for Powder River Basin coal because its low sulfur content means it is not a fungible product.) This marketing region includes the PADD 4 states of Wyoming, Montana, Colorado, Utah and Idaho along with South Dakota and Nebraska from PADD 2. Fuel markets operate nationally and internationally, so Wyoming synfuel production costs must be competitive with conventionally refined crude oil shipped into Wyoming.

As shown in Figure 6, there are medium sized refining centers near Billings, Montana; Salt Lake City, Utah; and Denver, Colorado. All of these are potential blending or distribution sites for Wyoming synfuel. The amount of refining capacity in each of the four states is roughly equal (Table 3 ) and provides some guidance on the scale of additional capacity that a new synfuel plant might add without excessively disrupting the existing market. Using a $10 \%$ change as acceptable suggests a plant size of 10,000 to $20,000 \mathrm{bpd}$ of total production if the markets are tightly tied to each state's refining centers or up to perhaps $65,000 \mathrm{bpd}$ if the market is well distributed across the region. All of these figures are in the range of what is discussed for full-scale synfuel plants, with DKRW proposing a coal-to-liquids plant in Wyoming of 15,000 bpd and with Shell's new Pearl gas-to-liquids facility in Qatar, the world's largest, producing $140,000 \mathrm{bpd}$ of fuel and $120,000 \mathrm{bpd}$ of light hydrocarbons.

Table 4 shows selected regional energy consumption data by fuel type. In that table, distillate refers to a range of products from diesel fuel through fuel oils (jet fuel is a distillate but is also reported separately) and LPG refers to liquefied petroleum gas, a mixture of propane and butane used for building heating and

as chemical process feed stock. The differences in consumption between states are largely a result of their populations. Wyoming's high consumption of distillate fuel relative to gasoline is a consequence of a 
small population driving cars and, relative to the population, a large number of industrial facilities and equipment using diesel engines. Jet fuel consumption in Colorado and Utah reflects the major airports in Denver and Salt Lake City.

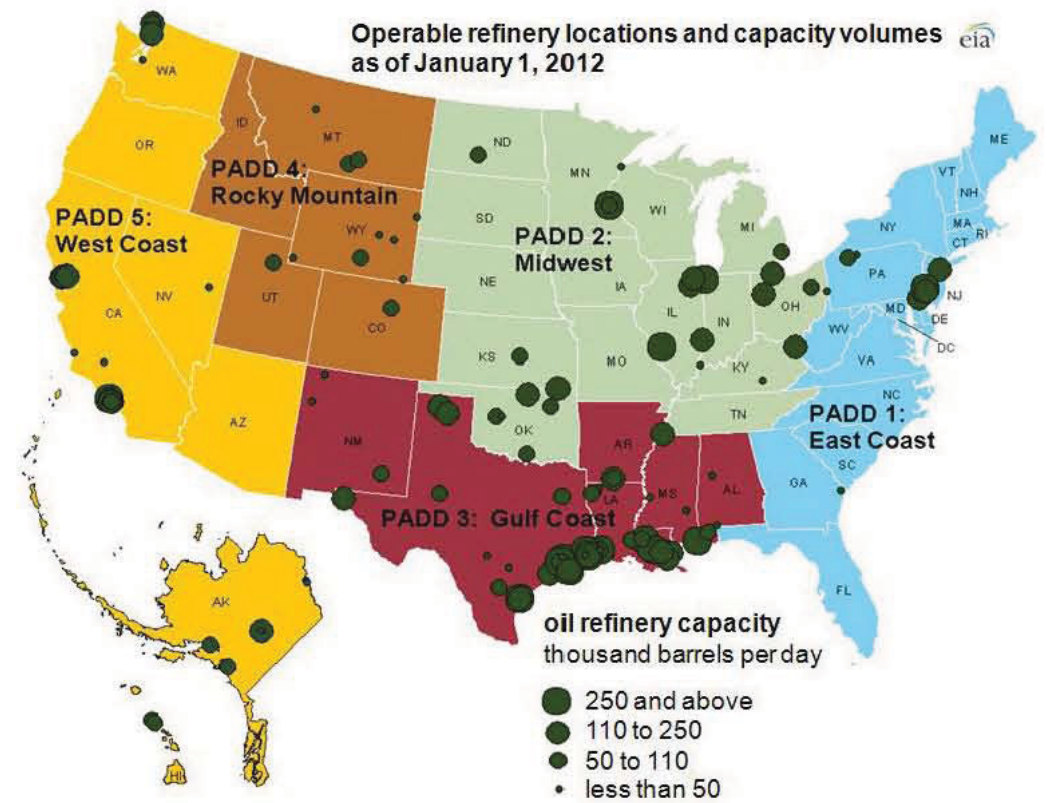

Figure 6. Refinery locations. [EIA 2012]

Table 3. PADD 4 total refinery operating capacity as of 2012 .

\begin{tabular}{|l|c|}
\hline & $\begin{array}{c}\text { Refining capacity } \\
\text { (barrels per stream day) }\end{array}$ \\
\hline Colorado & 110,000 \\
\hline Montana & 196,400 \\
\hline Utah & 176,400 \\
\hline Wyoming & 184,800 \\
\hline Total & 667,600 \\
\hline Data Source: [EIA 2012] & \\
\hline
\end{tabular}

Table 4. Regional energy consumption data for 2010

\begin{tabular}{|l|r|r|r|r|r|r|r|}
\hline & \multicolumn{1}{|c|}{ WY } & \multicolumn{1}{c|}{ MT } & \multicolumn{1}{c|}{ CO } & \multicolumn{1}{c|}{ UT } & D & NE & SD \\
\hline Gasoline (million barrels) & 8.30 & 12.00 & 50.80 & 24.60 & 16.40 & 20.50 & 10.40 \\
\hline Distillate (million barrels) & 15.50 & 8.90 & 19.80 & 12.90 & 10.50 & 15.70 & 7.70 \\
\hline LPG (million barrels) & 1.40 & 2.50 & 6.10 & 1.10 & 1.40 & 3.20 & 2.00 \\
\hline Jet fuel (million barrels) & 0.50 & 0.90 & 11.30 & 5.90 & 0.60 & 0.80 & 0.70 \\
\hline Natural gas (billion cubic feet) & 144.00 & 72.01 & 501.40 & 219.18 & 83.33 & 169.00 & 71.51 \\
\hline Data source: [EIA 2012] &
\end{tabular}

The refining capacity data of Table 3 are total feed rates which roughly equal the sum of the range of products made by the refineries. A synfuel plant, however, generally has a narrower range of products. Table 5 helps select between the several candidate fuel products by comparing the prospective new synfuel plant output to each state's consumption of each product. Liquefied petroleum gas has been eliminated as a candidate product because its usage is so small. A first hybrid energy synfuel plant of 
modest size, producing 10,000 barrels per day for 330 days on-stream per year, would produce 3.3 million barrels per year. A 10,000 bpd plant is small compared to refineries (their average size in the U.S. is about $140,000 \mathrm{bpd}$ ) but is in the range of what is often proposed for new synfuel processes. With this production rate and the assumption that a $10 \%$ addition to the market would not be disruptive and could be accommodated by consumption growth, shutdown of an older local refinery, or reduced imports from outside the region, only one combination of product and region has less than $10 \%$ impact: making gasoline for sale in Colorado. Gasoline delivery to Utah at $13 \%$ impact is close to meeting the criterion. Less obvious, a 7\% impact can be obtained if distillate (diesel fuel) is sold across the combined markets of Utah, Wyoming, and Colorado. These all confirm the intuitive answer of making the most popular product for the largest market(s).

Table 5. Percentage impact on state markets of a 10,000 bpd plant.

\begin{tabular}{|l|c|c|c|c|c|c|c|}
\hline & WY & MT & CO & UT & ID & NE & SD \\
\hline Gasoline & $40 \%$ & $28 \%$ & $7 \%$ & $13 \%$ & $20 \%$ & $16 \%$ & $32 \%$ \\
\hline Distillate & $21 \%$ & $37 \%$ & $17 \%$ & $26 \%$ & $31 \%$ & $21 \%$ & $43 \%$ \\
\hline Jet fuel & $660 \%$ & $367 \%$ & $29 \%$ & $56 \%$ & $550 \%$ & $413 \%$ & $471 \%$ \\
\hline
\end{tabular}

This simple comparison is useful not so much for choosing the best fit but for showing potential difficulties of the other possibilities. By its method it assumes all product is delivered to one or a few selected locations. If shipments go by truck or rail, this is overly restrictive. If the Wyoming synfuel industry in combination with its conventional refining grow to the point of using pipeline delivery, the single-market assumption becomes more appropriate. However, the capacity typical of pipelines is much more than the 10,000 bpd used for the market size analysis. To not flood the destination market, a fully utilized new pipeline from Wyoming would have to feed other pipelines or rail terminals to other parts of the country. If a vigorous synfuel industry is to grow in Wyoming, it will have to deliver its products outside the low-population region immediately around Wyoming.

\subsubsection{Transportation to Markets}

This report assumes that addressing the regional market for vehicle fuel is a valid strategy because it reduces transportation costs to give the nascent industry a small advantage. Those costs will depend on the delivery distance and difficulty. This report does not attempt to identify where a first hybrid energy system might be located in Wyoming. However, with Denver and Salt Lake City as primary targets and Billings as a secondary one simply because all are population centers with existing refineries, it is evident that transportation for only a few hundred miles will be needed for the first plant and several more afterward.

For a capacity of $10,000 \mathrm{bpd}$ of refined products, truck and rail shipments are adequate. This amount of production corresponds to 30 truck shipments (full tank trailer with a second "pup" trailer behind) per day, or 17 railroad tank cars per day, both modest amounts of traffic. These transport modes also offer great flexibility in where the shipments go and how big they might be for smaller customers, allowing users almost anywhere in the country to be potential buyers of the synfuel. If it develops that one customer takes all the plant output, a unit train of 111 cars once a week would have the necessary capacity.

As other plants are added in a developing synfuel industry, it might become feasible to build a pipeline dedicated to both those plants and possibly some existing conventional refineries. Pipelines are economical ways of moving large amounts of product, but only between fixed locations. Before a dedicated line is planned, available capacity in any existing pipelines to the desired destination would have to be determined. There is only a modest network of existing product pipelines to utilize (Figure 7), but it reaches two of three regional refining centers. Passing north-south near Rawlings and Casper, it extends to near Billings and Denver, with branches to Gillette and Rapid City, South Dakota. Although 
the flow direction and capacity utilization were not available, this pipeline would be useful whether it is carrying Wyoming products to large markets or is bringing into the state refined products that could be displaced by local production. Even if it has only limited unused capacity, if an older existing refinery using that pipeline were nearing retirement, the capacity it was using could become available.

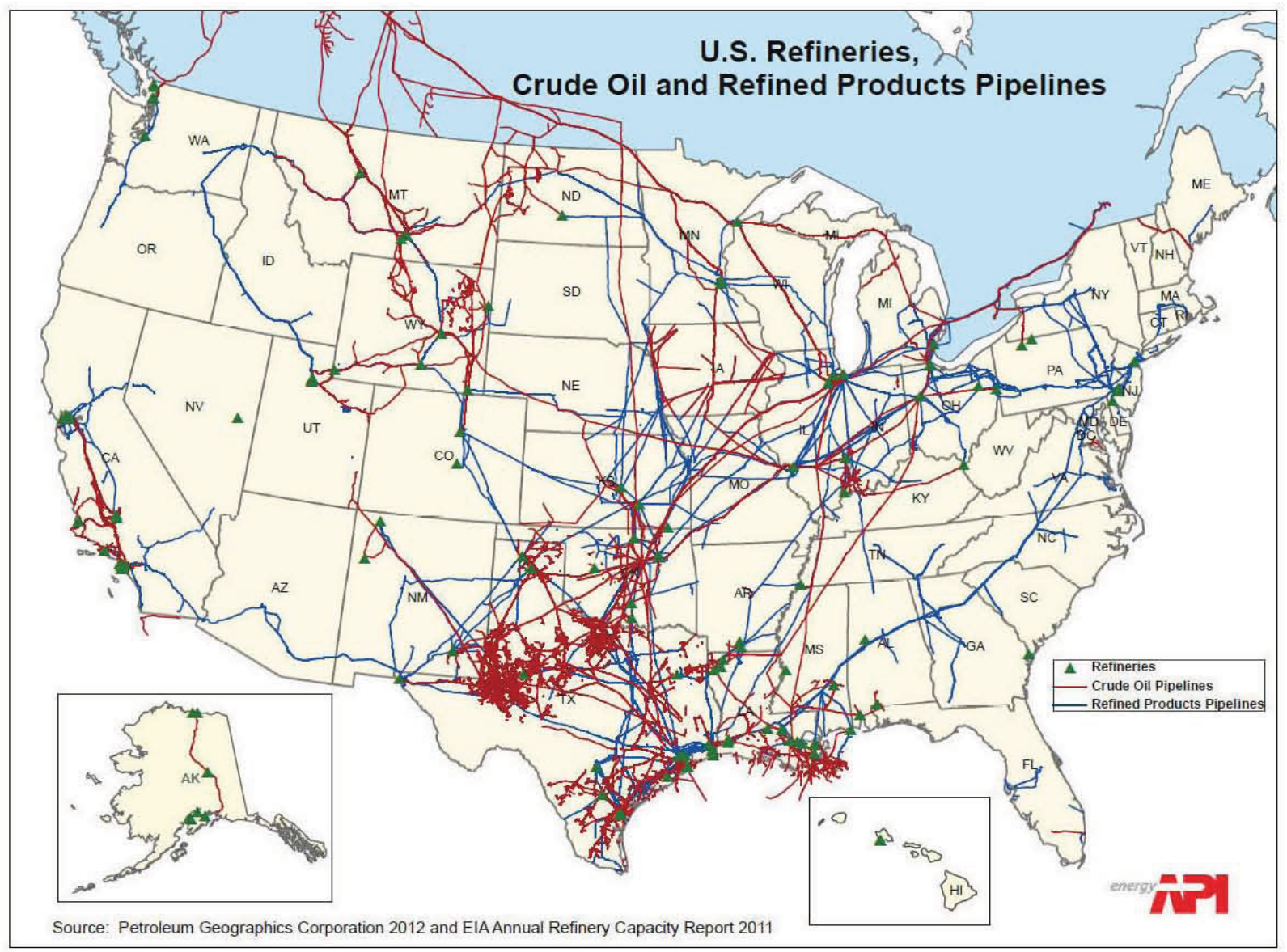

Source: American Petroleum Institute

Figure 7. U.S. refined product pipelines.

\subsection{Selection of Target Energy Products}

\subsubsection{Initial Plant}

This chapter has examined a number of issues about the energy products that might be made by a hybrid energy system. The focus has been on the inputs and output of the system, not on the processes by which they are transformed. On the basis of product volume, market size, transportation options, and qualitative technical issues including both technology maturity and the complexity of integrating several processes, one small set of product options appears most attractive. They are

- Use natural gas as the carbon source because the relative simplicity of processing it leads to a much lower plant capital cost

- Make gasoline as the preferred product, with diesel fuel as an alternative, because of the commercially demonstrated technology and the large markets for the product

- Produce a modest amount of electricity as a co-product of synfuel, and use it to firm the variable output of wind farms. Renewable electricity should have a premium value because of neighboring 
states' Renewable Portfolio Standards mandating its use in preference to fossil-fired generation. This and the next conclusion have been pulled forward from Chapter 3 which examines the value of renewable wind energy.

- Evaluate how the schedule for new power transmission capacity to other states matches a nominal schedule for building hybrid systems. Evaluate whether retirement of older coal plants can generate enough capacity to accommodate the power output of the initial combined wind-hybrid systems

- Size an initial plant relatively small at about 10,000 barrels per day of production to reduce the overall project risk of operating a new process concept (a hybrid system) and to avoid flooding the regional market with product

- Plan initially to sell the gasoline into the Colorado and/or Utah markets, or diesel fuel into all three of Utah, Wyoming, and Colorado, but allow for customers anywhere

- Transport this gasoline or diesel fuel from the initial plant by trucks and/or rail cars

- Investigate the availability of capacity on the refined products pipeline to Billings, Rapid City, and Denver. Identify whether any older refineries using that pipeline will retire in the near future, freeing the capacity they have been using.

This has been a simplified market analysis to identify the broad design objectives that will allow selection of a specific conversion process. The candidate process configurations and economic analyses of their performance are presented in Chapter 4.

\subsubsection{Other Proposed Synfuel Plants}

Two other independent and substantive proposals for synthetic fuel plants in Wyoming are in the development stage. Their eventual operation would be steps toward a large industry of value-added products made from fossil resources.

DKRW Advanced Fuels has proposed a coal-to-liquids plant to be built in Medicine Bow, in the southeast part of the state [DKRW 2012]. It would make about 11,000 barrels per day of gasoline using the methanol-to-gasoline process, with the possibility of future expansion to $44,000 \mathrm{bpd}$. The product gasoline will be sent through a new 100 mile pipeline to Cheyenne, where the entire plant output has been committed to Vitol, Inc., a fuel trading company. All of the byproduct $\mathrm{CO}_{2}$ made in the gasification step will be sold to Denbury Resources for use in enhanced oil recovery. This project is now seeking financing. It is estimated to cost $\$ 1.8$ billion.

Nerd Gas Co. of Casper is pursuing a modular, Wyoming-based gas to liquids project that would convert 10 to 20 million standard cubic feet per day of natural gas to 1,000 to 2,000 barrels per day of diesel and naphtha. No other information was available for this report, although a company representative said that a more detailed announcement is planned for the near future.

\subsubsection{Shape of a Future Industry}

Significant development of value-added products from Wyoming's coal and natural gas will require more than just one plant. As the industry builds out to a number of plants in different parts of the state, it is unlikely that the plants will be identical in scale, what feed stocks they use, or what products they make. Each plant will be optimized to fit the available resources, markets, and economic conditions at the time. However, if the plants are complementary there will be advantages in skilled employee availability, transportation options, and industrial synergies. Because the first hybrid system facility will also be part of this future fleet its design should consider how it might fit into an industry long-term, not just how its immediate performance can be optimized.

One possible synfuel industry structure would have a number of independent plants each converting coal or natural gas to gasoline or diesel fuel and delivering their output to regional customers and pipeline hubs. This model resembles the petroleum refining industry. 
In such a structure there are commonalities that can be further built upon. First, many (but not all) coal and natural gas conversion processes have an initial step of converting those materials into synthesis gas, a mixture of hydrogen and carbon monoxide which is then further converted to the desired products. When several plants in this industry are established, it would be feasible for them to develop an integrated syngas exchange network for operational backup, to allow the synthesis of small amounts of specialty products using another plant's possible excess syngas production capacity, and to allow companies to begin specializing in either the conversion of the primary carbon resource or the production and sales of commodity and specialty fuels and chemicals. This network structure is more similar to the petrochemicals industry than it is to petroleum refining.

One of the chemical products could be methanol, an important commodity chemical that also can be further converted to many other chemicals and plastics. This variety of uses could lead to a second regional product distribution network specifically for it. The overall concept is shown schematically in Figure 8. In this diagram, the initial plant proposed in this report is shown broken into its three constituent processing blocks: steam reforming of natural gas, methanol synthesis, and synthesis of gasoline from the methanol. The future industry would have alternative uses for the two intermediate streams between those blocks in what would initially operate as an integrated plant. This approach allows a variety of products to be made in less than world-scale amounts because they need not build their own front end to make syngas. It also provides greater flexibility if product markets change. If, for example, in thirty years gasoline were no longer needed in large amounts for the light vehicle fleet, other fuel or chemical products could be made from the syngas formerly used to make it. Depending on the old and new processes, it is plausible that the old synthesis plant need not be scrapped but only converted to make the new product.

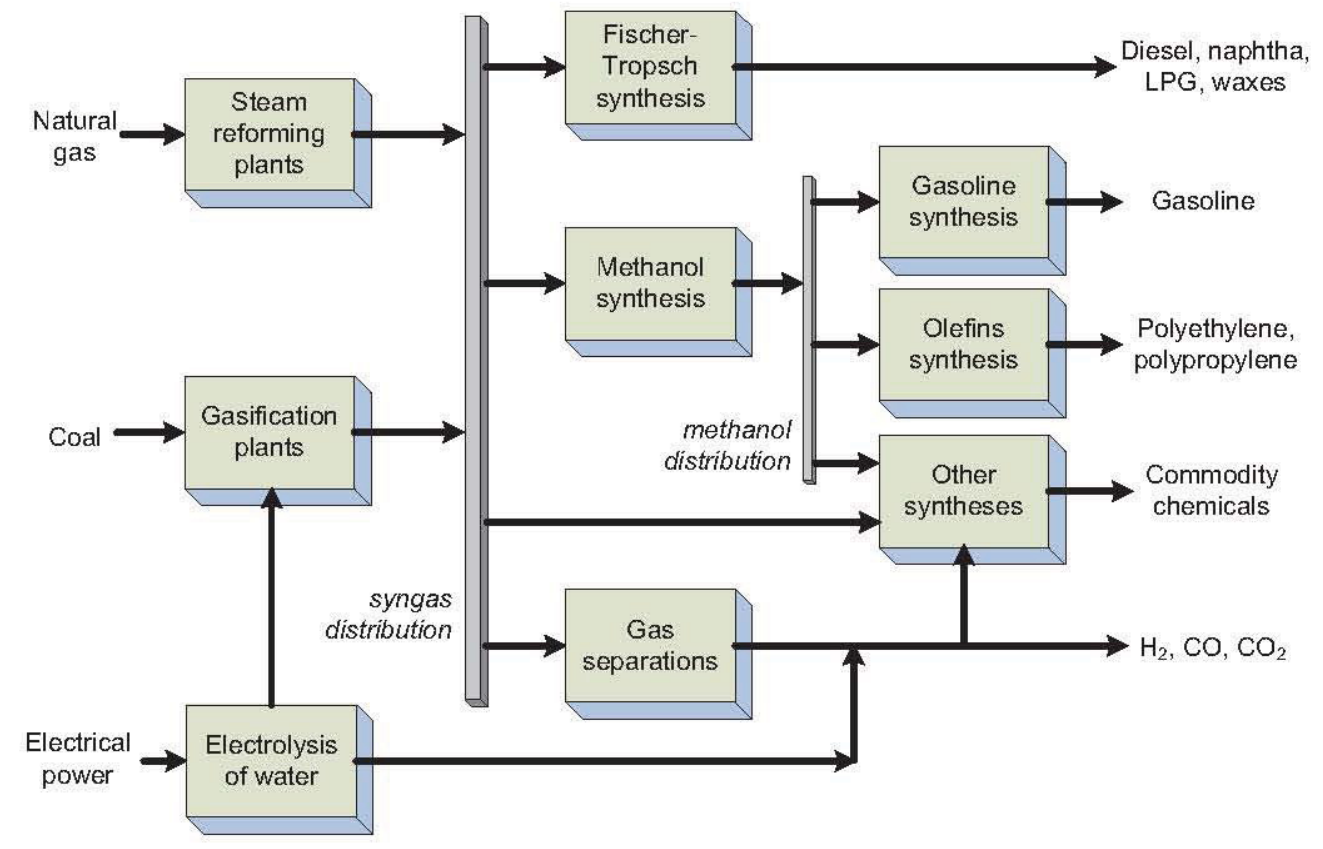

Figure 8 . Structure of a future integrated synfuel and chemical industry.

This industry could also utilize Wyoming's power generation capacity to electrolyze water to hydrogen and oxygen. The oxygen can be used for coal gasification, while hydrogen would be valuable for blending with coal-derived crude syngas to get the proper ratio of hydrogen to carbon monoxide for general use. Hydrogen would also be valuable to regional petroleum refineries to upgrade heavy oils and remove their sulfur and nitrogen impurities. Hydrogen could also be made from synthesis gas using a simple chemical reaction (the water-gas shift reaction) to convert the carbon monoxide fraction and supplemental steam into carbon dioxide and additional hydrogen. While the resulting $\mathrm{CO}_{2}$ could be used 
in some high volume chemical syntheses such as urea fertilizer from ammonia or acetic acid from methanol, its greatest initial value would likely be for enhanced oil recovery.

This envisioned industry would utilize raw materials available around Wyoming, delivering synfuel products to the regional refining and pipeline centers and shipping higher-value commodity chemicals and plastic resin beads in bulk to customers around the country. Geographically, the new facilities could be spread across the triangle formed by Billings, Salt Lake City, and Denver. The major new infrastructure it would require would be a syngas pipeline across the part of Wyoming where the syngas conversion plants might be located, possibly extending to the major refining centers if there is interest in buying syngas for plants to be sited there. $\mathrm{A} \mathrm{CO}_{2}$ pipeline might generally follow that corridor but would have to branch off to the locations of oil reservoirs suitable for $\mathrm{CO}_{2}$ flooding. While that same pipeline corridor could be used for a hydrogen pipeline to the refining centers, another option would send syngas to the refineries for them to convert hydrogen, sending the byproduct $\mathrm{CO}_{2}$ back via a parallel pipeline. This would require only two different pipeline networks and would allow collection of additional $\mathrm{CO}_{2}$ from the refining centers for use in enhanced oil recovery or for sequestration in suitable formations.

In addition to these gas pipelines, a fully developed synfuel industry could justify refined product pipelines to the refining centers or pipeline hubs for product delivery. Although these pipelines could be built in stages only as actually needed, it would help establish this industry if all the pipeline and railroad easements expected to be needed were secured during the initial planning and development. Planning the pipelines to have adequate capacity for future expansion would be valuable.

\subsection{External Uncertainties}

Uncertainty and the risk arising from it are a part of any business decision. Hybrid energy systems are complex systems with many opportunities, some controllable, some not, for their future performance and operating environment to be different from what an analysis assumes. This section identifies and briefly discusses several topics where the uncertainties lie in the course of future events, not just in the numerical inputs to a cost model.

\subsubsection{Trends in Petroleum Production}

Domestic crude oil production is projected by the Energy Information Agency stay in the range of 5.5 to $6.5 \mathrm{MMbpd}$ from now until 2035, the end of their forecast period. This stability is based on the expected development of unconventional oil such as in the Bakken shale in North Dakota. Depending how actual global production changes while demand is also changing, the future price of crude oil and the products refined from it might swing dramatically. This has been demonstrated numerous times during the last four decades. Changing prices for refined products will affect the profitability of a synfuel plant by immediately changing its revenues and eventually changing the number and nature of competitors in the vehicle fuel industry.

The future price of petroleum products will depend on the amount of oil available for import compared to expectations or market needs. Because OPEC oil production may be hard to forecast or to be assured of, other North American sources bear consideration (Figure 9). As imports from them might increase or decrease, the need for domestic synfuels will move in the opposite direction. 


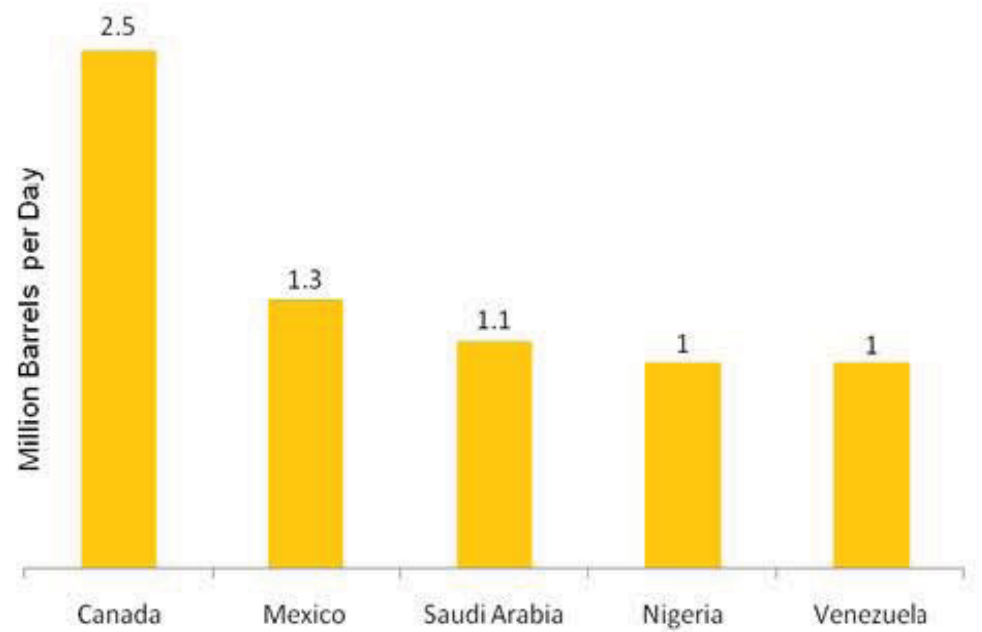

Figure 9. Top Five Sources of U.S. Petroleum Imports, 2010 [ELA 2012]

Canada is by far the largest source of imported oil (Figure 8). Being both adjacent and from a longtime ally, Canadian oil is of strategic importance to the United States. The primary source of Canadian oil is the oil sands in Alberta that hold approximately 97 percent of Canada's proven oil reserves of 175 billion barrels (ELA 2012). Oil sands production has been rapidly increasing in the past decade and is planned to expand further. Oil sands now account for over half of Canadian oil production (1.35 MM bpd in 2009) and are forecast to continue to grow in the next two decades, with some estimates reaching to 4 MM bpd. Canada's main export market is the U.S. Midwest and Gulf Coast where refineries have been configured to accept Canadian oil that has been modestly processed so it might be more easily pumped through pipelines. However, there has been strong Chinese interest in piping oil from Alberta to the coast of British Columbia for shipment to China. The long term consequences of this, coupled with environmentalist opposition to oil sand production because of the associated $\mathrm{CO}_{2}$ emissions and the disturbances caused by pipelines, are difficult to foresee.

Mexico has been another important source of oil for the U.S. over the past several decades. Mexican oil resources are concentrated off-shore of the state of Tabasco in the Gulf of Mexico, particularly in the massive Canterell oil field. This field was once one of the largest oil fields in the world. Production has been declining in the last decade, leading to forecasts by the ELA that Mexico will become a net importer of oil by 2020 (EIA 2012). With Mexico currently the number two source of imported oil for the U.S. (Figure 8), decline of Mexico as a regional source of oil will create additional pressures favoring a domestic synfuel industry.

Venezuela has very large reserves of heavy oil which some U.S. Gulf Coast refineries have been modified to process well. It, along with Saudi Arabia and Nigeria in Table 8, is an OPEC member. Even though its relationship with the U.S. has been politically turbulent, it sells the U.S. about one million barrels per day. The outlook is difficult to forecast.

\subsubsection{Fuel Changes over the Plant's Lifetime}

The operating life of a potential future hybrid energy facility is expected to surpass 50 years based on experience with refineries in Wyoming that are approaching 70 years old (e.g., Frontier in Cheyenne). Once a plant is built and operational, there is a strong tendency to refurbish and replace equipment as it ages as opposed to relocating to a new facility. Similarly, nuclear reactors, likely in the long-term to be a component of these systems, have had licensed lifetimes in the power industry of 40 years that are now being extended to 60 years with consideration of 80 years. However, the productive lifetime used for financial calculations is considerably shorter, on the order of $15-20$ years for chemical process facilities and $30-40$ years for reactors in utility service where the market is more stable. 
The issue with these lifetimes is how much the market for synthetic vehicle fuels will evolve during the plants' lifetimes. High federally mandated mileage standards would, over the average lifetime of an automobile (about 13 years), reduce the total national demand for gasoline and diesel fuel. More significantly to a fuel producer, a wide variety of other vehicle fuels is being used or is under active development: E85 ( $85 \%$ ethanol, 15\% gasoline), compressed natural gas, liquefied natural gas, hydrogen, methanol (for fuel cells), and electricity for battery vehicles. Which of these will gain large market shares depends on government policies and vehicle performance. Changes in fuels can be rapid: consider the history of methyl tertiary-butyl ether in gasoline since its introduction in 1979 as an octane enhancer, its use in the 1990 s as a federally mandated oxygenated fuel additive, and its being banned from gasoline in 16 states by 2003 [EIA 2003]. The dynamics of ethanol usage in gasoline, in part a response to the MTBE bans, have been similarly rapid.

A different class of fuel uncertainty comes from rising sea level, an expected consequence of global climate change during the next half century, if it were to threaten refineries and distribution infrastructure along the Gulf Coast. While this situation might create demand for hydrocarbon fuels produced well inland and well above sea level, it might also spur federal policy action toward the use of other fuel types.

The risk tied to this uncertainty is whether the product of a synfuel plant will be in demand two or three decades after a decision to build is made. At a minimum, evaluating the economics with a short operating life would be necessary. Early decommissioning would be a potential and foreseeable cost within this time horizon. More strategically, planning the facility to be able to easily convert to making other energy products would be valuable. If the nuclear and synfuel plants were to have different owners, handling of this potential problem of significantly different plant lifetimes would be an important part of how their relationship is structured.

\subsubsection{Population Trends}

Population growth will contribute to the demand for transportation fuels. The western United States is projected to be one of the fastest growing areas of the country through 2030 , growing by 46 percent or almost 29 million people (Census Bureau 2004). However, that does not extend to all Western states as seen in Table 6. Idaho and Utah have the highest projected growth, both above $50 \%$, while Wyoming has the lowest at $5.9 \%$. The total for the region in 2010 (updated projections for 2030 not yet available) was 13.6 million people. Within the nominal region of retail sale of Wyoming synfuel, an additional 1.8 million people in the next two decades will lead to additional demand for vehicle fuels. If per capita usage stays constant, about $13 \%$ more fuel than today will be needed in 18 years. This provides support for production in Wyoming of synfuel for the region.

Table 6. Population projections for Wyoming and surrounding states, 2000-2030.

\begin{tabular}{|c|c|c|c|c|}
\hline & 2000 & 2030 & Increase & $\%$ change \\
\hline Montana & 902,195 & $1,044,898$ & 142,703 & 15.8 \\
\hline Idaho & $1,293,953$ & $1,969,624$ & 675,671 & 52.2 \\
\hline Wyoming & 493,782 & 522,979 & 29,197 & 5.9 \\
\hline Colorado & $4,301,261$ & $5,792,357$ & $1,491,096$ & 34.7 \\
\hline Utah & $2,233,169$ & $3,485,367$ & $1,252,198$ & 56.1 \\
\hline S. Dakota & 754,844 & 800,462 & 45,618 & 6.0 \\
\hline Nebraska & $1,711,263$ & $1,820,247$ & 108,984 & 6.4 \\
\hline Total & $11,690,467$ & $15,435,934$ & $3,745,467$ & 32.0 \\
\hline
\end{tabular}




\subsubsection{Federal Energy Policy}

One of the greatest uncertainties affecting the decision to invest in a plant is federal energy and environmental policy. This has been noted in the earlier discussion of mileage standards and fuel selection. These policies can be implemented through regulations, laws, and various forms of financial incentives or penalties.

Two aspects of energy policy will have direct consequences for a synfuel plant. The first relates to the rather amorphous concept of energy security, specifically the value of domestic production of fuels rather than relying on significant amounts of petroleum imported from possibly unreliable sources. While the economic and strategic arguments around this issue are complex, their consequence for hybrid energy systems in Wyoming is whether there will be incentives (or the removal of disincentives) for producing vehicle fuels from domestic or non-petroleum sources. At this time there are no such incentives, so this factor has only a positive possible effect.

The second factor is policies to limit greenhouse gas emissions, specifically carbon dioxide $\left(\mathrm{CO}_{2}\right)$. These can take form of incentives for renewable energy such as wind or penalties for the release of carbon dioxide. The production of synfuels from coal entails a considerable energy input, primarily to generate hydrogen directly or indirectly, and if the feed coal is used to generate this energy a large $\mathrm{CO}_{2}$ production results. This can be avoided by using other sources of energy such as natural gas (about half the $\mathrm{CO}_{2}$ generation) or nuclear energy (essentially no $\mathrm{CO}_{2}$ generation). If $\mathrm{CO}_{2}$ emissions carry a high cost, the use of nuclear heat for synfuel production offers a significant cost advantage compared to the fossil-fired systems used in conventional refineries. The nature and magnitude of greenhouse gas penalties are still unsettled. 


\section{FEASIBILITY AND INCENTIVES FOR DYNAMIC OPERATION OF PROCESS PLANTS}

Large chemical plants and power plants are commonly assumed to be able to run only at constant high rates. This concern is frequently raised with regard to the time-varying operation of hybrid energy systems. While steady operation is preferable, it is not mandatory. This chapter examines the reasons for believing that dynamic operation of large process and power plants is feasible.

\subsection{Conventional Operation of Large Plants}

Large process plants such as refineries, commodity chemical plants, and large coal-fired or nuclear power plants typically operate at steady high rate and are designed accordingly. Continuous steady operation allows for easier optimization of plant performance and avoids off-optimal operation and possible upsets during changes of operating rate or mode. This is not to say that these large plants cannot operate with time-varying conditions. Startups and shutdowns require this capability, as does changing rate to match market demand for the plant's product. These situations occur infrequently - perhaps no more than weekly for production rate changes - so these plants spend the great majority of their time at steady conditions. Hourly or daily differences between the rate at which product is produced and the rate at which it is shipped are buffered by the ability to easily store most chemical and fuel products.

Managers of these process plants also prefer operation at high rates to generate the most revenue to recover the typically high capital cost of these plants. Running at reduced rates saves the variable operating costs, but does not alter the fixed costs for things such as labor, insurance, and loans used to finance plant construction. For refineries and commodity chemical plants, both capital and operating costs are significant as evidenced by the effects of changing feed stock (oil or natural gas) prices on product prices. For nuclear power plants, capital costs predominate; fuel-related costs are only about $10 \%$ of the cost of their product electricity. The consequent preference to run at high rates is the basis for considering nuclear power plants to provide base-load generation only. Examination of the French power grid demonstrates that the constraint is more one of economics than of technological limits: with $70 \%$ of its power coming from nuclear plants, plants in that grid must be able to operate at reduced rates to accommodate daily and seasonal changes in demand. The future use of hybrid energy systems will require a new paradigm for designing and operating large process plants, one that recognizes flexibility of operating rate as an important objective..

\subsection{Diurnal Load-following}

Because methods do not exist to store electricity at the scale necessary for grid stabilization, gridwide demand and power generation must be constantly matched to within tight limits. This section and the next discuss the characteristics of the load-following required to compensate for both diurnal changes in demand and the variable generation rates of renewable wind- or solar-based generation methods. The difference at any instant between time-varying total electrical demand and time-varying renewable generation is the time-varying amount of power required from all of the grid's other available forms of generation including hybrid systems.

Electrical demand (also called load) follows a regular diurnal pattern. Demand peaks in the afternoon and early evening with a second peak in the morning during the colder months. Total demand is slightly lower on weekends compared to weekdays. Illustrative hourly data for Wyoming was not available, so Figure 10 shows three representative weeks of power demand from the Midwest Independent System Operator. The decrease at night is $15-40 \%$ of the daytime peak demand, typically about $30 \%$, and lasts for about eight hours from 10 PM until 6 AM. Because these demand curves represent many thousands of users, they have a smooth, predictable shape that changes over a time scale measured in hours. 


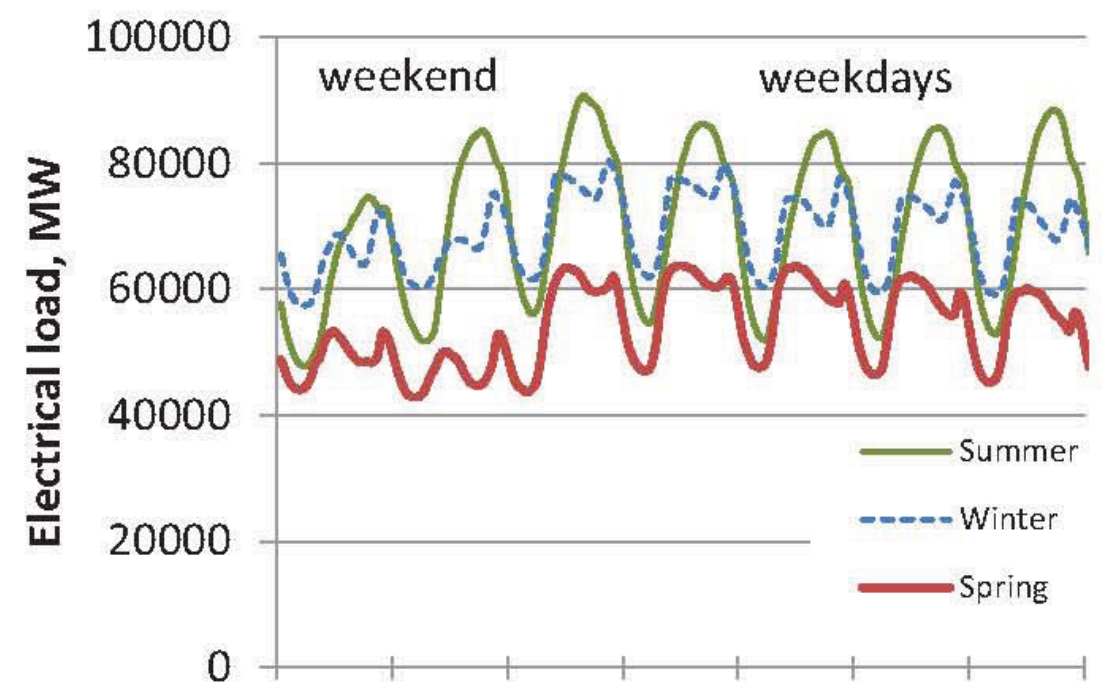

Figure 10. Three weeks of electrical demand data [Midwest Independent System Operator 2012]

The average daily demand also changes with the season. Figure 11 shows several years of daily peak demand data from three regions around the western U.S. The notable feature is the large difference in peak demand at different times of the year.

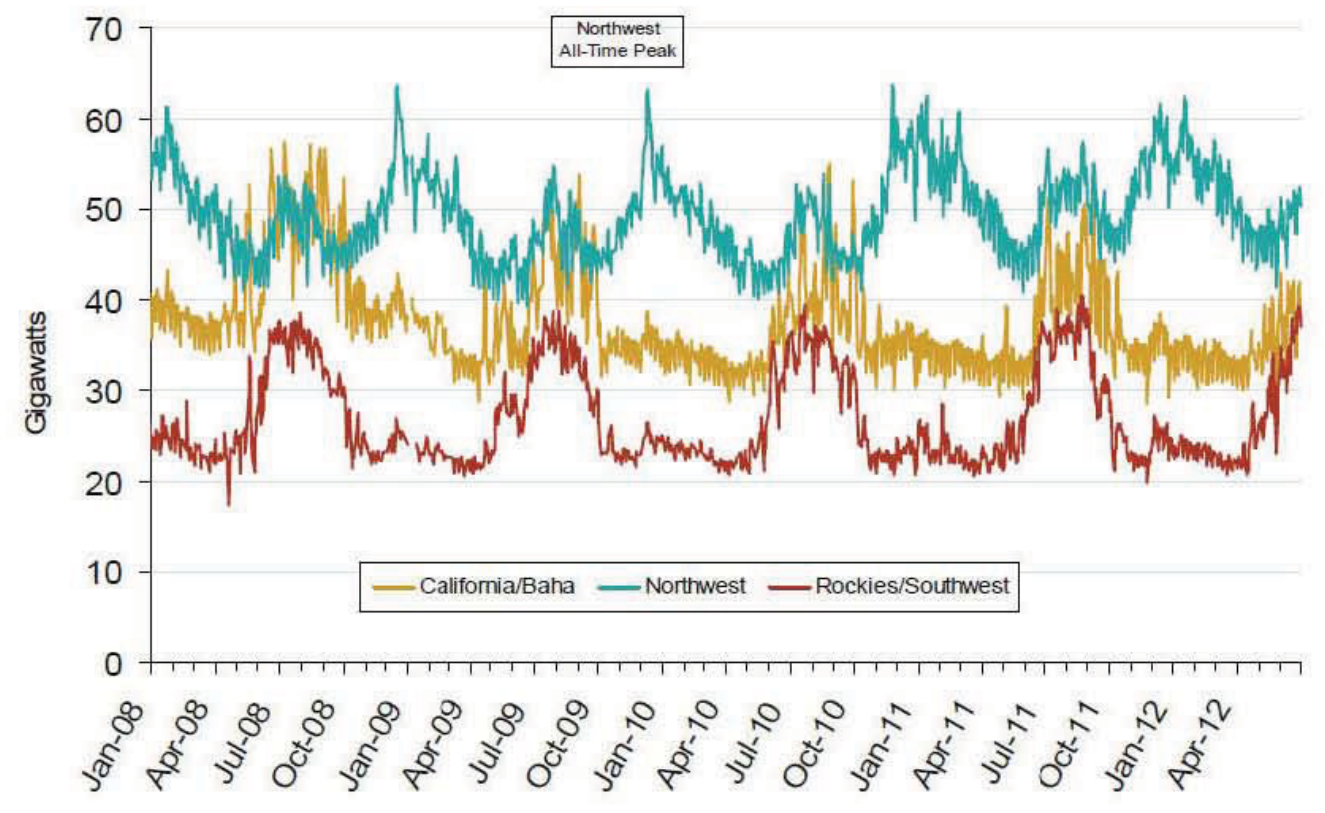

Notes: Data does not include weekends and holidays. Some data for 12/31/2008 - 1/9/2009 are not available from WECC Source: Derived from WECC Daily Report data available at htto://weco.biz

Uodated: Julv 12. 2012

Figure 11. Annual trends of daily peak power demand. Rockies/Southwest region includes Wyoming, Colorado, New Mexico, and Arizona. [FERC 2012]

The daily and seasonal variations in demand are large enough that they cannot be met by simply reducing operating rates on some or all of the generating plants. Some of them must be shut down or put into a warm standby state until demand recovers. For the seasonal swings, the periods on and off can be measured in months of duration. For the diurnal swings in demand, these shutdowns can last from one to twelve hours depending on when, in the sequence of all the units that will be shut down, a given unit is 
selected. This selection is typically done on the basis of each generator's cost of power production: the most expensive units are turned off first and turned back on last.

\subsection{Renewable (Wind/Solar) Energy's Variability}

Wind, solar photovoltaic, and solar thermal generation also have variability, but it is less regular and predictable than seasonal or diurnal variations in demand. Wyoming has excellent potential for wind generation, less so for solar-based technologies, so the remaining discussion will focus on wind although the concepts do apply to solar. Figure 12 shows projected wind generation potential across roughly the southeast quarter of Wyoming [NREL 2012]. The dataset containing these estimates was based on local weather results interpolated using topographic information. Red symbols indicate over $40 \%$ availability, an excellent result. In many locations around the nation 30\% availability (orange and yellow symbols) is considered good. Availability represents the total annual amount of generation in megawatt-hours compared to the amount if the turbine ran at $100 \%$ output all year.

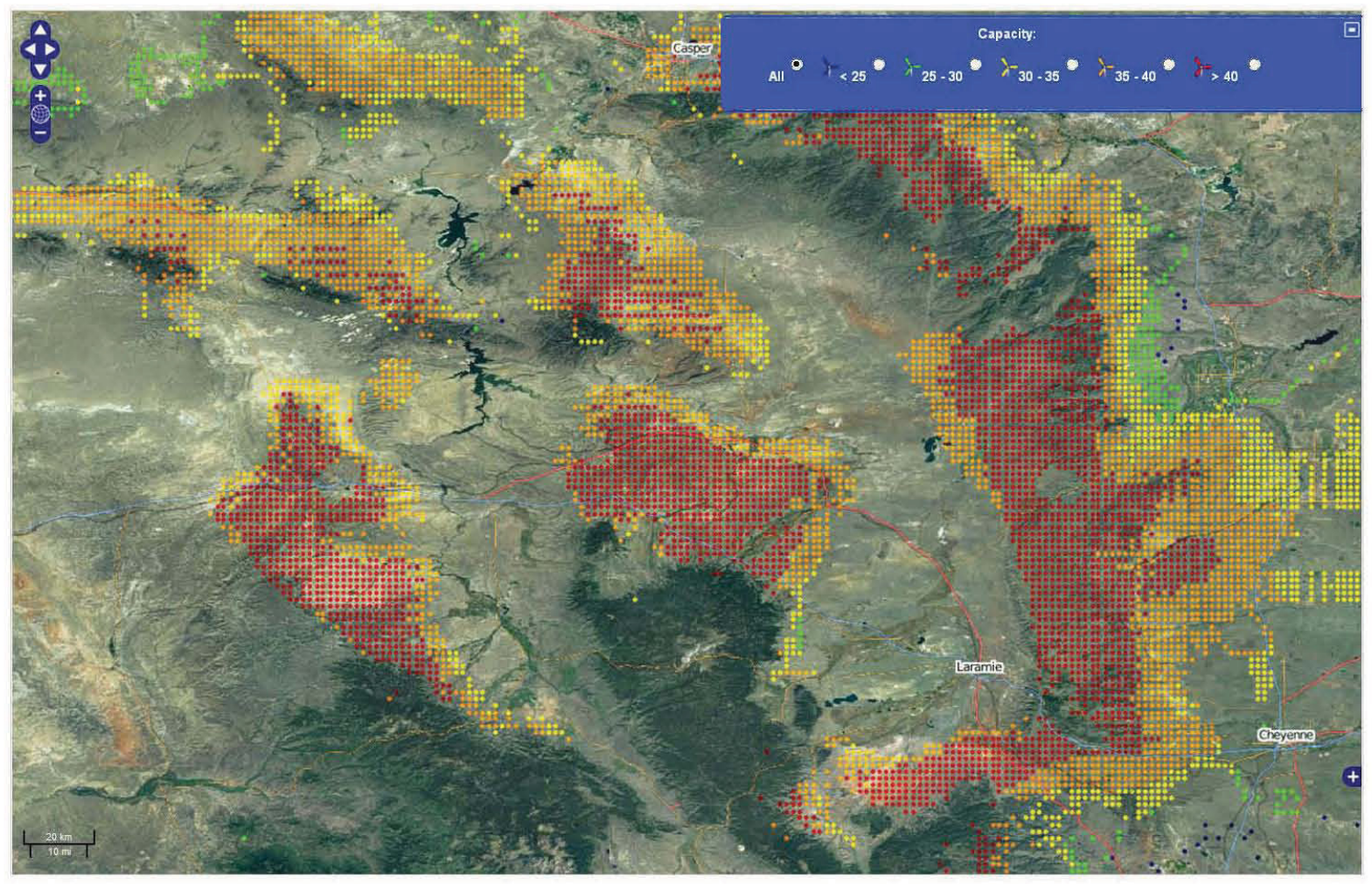

Figure 12. Map of wind generation potential in the southeast quadrant of Wyoming.

Projected generation rates for one week for a wind farm at the center of Figure 12 are shown in Figure 13. There are periods of high or low output that last for days, but when the generation rate changes it can take only an hour or two. There are also periods of intermediate levels of generation. A wind farm with a large number of turbines spread over several miles would tend to average out the fastest and largest transients in the turbines' individual outputs. To reduce - but still not eliminate - variability that is on the scale of a day or more requires that contributing wind farms be spread over an area comparable to the size of a weather front, several hundred miles. Consequently, to be able to handle the unavoidable transients in wind generation a power grid will have rapid-response generators typically powered by gas turbines. The amount of such generation that is normally available in a power grid to handle other transients can also address the variability of an amount of wind generation equal to about $25 \%$ of the system's generation capacity (the specific value depends on the grid's demand and generation characteristics, including the range of generation types available). A future hybrid energy system able to change its electrical output significantly within an hour would also be able to help mitigate these wind-caused fluctuations. 


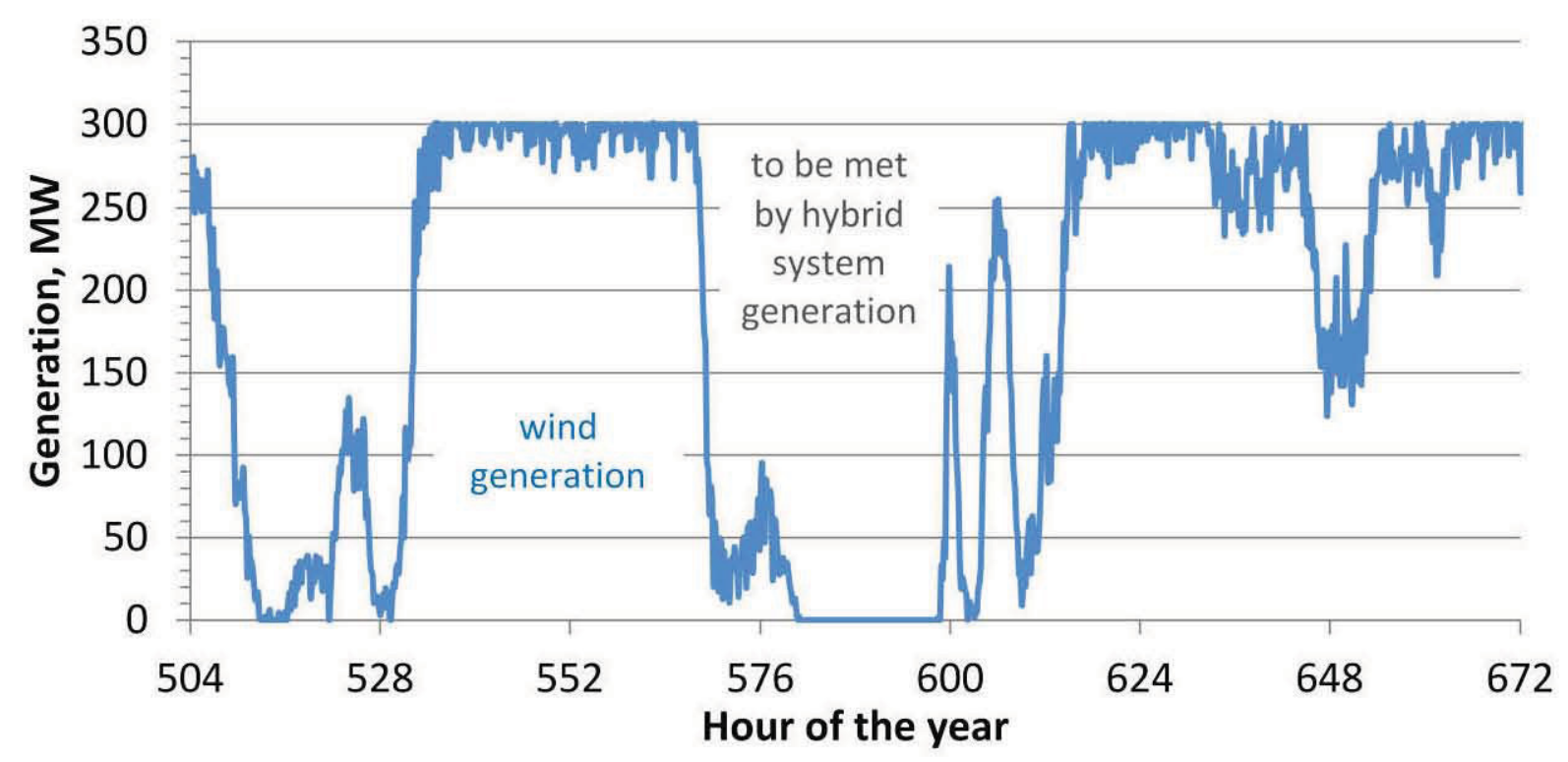

Figure 13. Example output of $300 \mathrm{MW}$ of wind turbines over seven days at the end of January.

\subsection{Hybrid System Operating Strategy}

\subsubsection{Constant Output Operation}

There are at least two ways to operate auxiliary types of power generation such as a hybrid energy system to smooth the variability of wind generation. In the first and conceptually simplest, the hybrid system and the wind farm are operated together to produce a combined electrical output that is constant, essentially mimicking base load generation. In Figure 13, this would correspond to making $300 \mathrm{MW}$ at all times, or as close to this objective as possible. This type of operation would allow the combined wind/hybrid system to replace a base load coal-fired power plant that was shut down by obsolescence or to avoid the cost of future $\mathrm{CO}_{2}$ capture requirements or emissions penalties.

A difficulty with this approach is that because of wind's low availability, typically $30-45 \%$ for regions considered attractive, the hybrid system must generate power for the balance of the operation, or $55-70 \%$ of the total energy generated. This in turn means that the primary heat source of the hybrid system delivers heat to the synfuel or chemical plant only when the wind blows, $30-45 \%$ of the expected annual total, and during some of that time only reduced heat delivery is available. This level of operation would be uneconomical for the process plant because of their generally high capital costs (although they are not as high as for a nuclear reactor). It also has only a modest effect on reducing $\mathrm{CO}_{2}$ emissions.

One answer to this problem is to always supply a specified minimum amount of heat to the process plant so its operating rate might vary between, for example, 70 and $100 \%$ as the need to offset wind fluctuations changes. This leads to exceptionally large process plants coupled to relatively small wind farms, both outside of desirable ranges. Alternatively, an auxiliary fossil-fired steam generator could provide heat to the process plant when nuclear heat is not available. However, it would have to run 55$70 \%$ of the time, largely countering the $\mathrm{CO}_{2}$ emission advantages of a nuclear-based hybrid system.

\subsubsection{Operation to Reduce Only High Frequency Variability}

Another strategy is to address only the problematic high frequency components of wind's variability. Power grids are well adapted for handling the diurnal variations in demand, so wind variability on that time scale can be handled similarly using the same equipment as long as the wind variability has a rate no more than about equal to the diurnal cycling of demand, typically about $30 \%$ of the daily peak over six hours or $5 \%$ per hour. In this operating mode, by switching its heat between the power system and the 
process plant, the hybrid energy system generates power so the total of wind plus the hybrid system output does not change faster than a specified rate. This is illustrated in Figure 14, where the difference between the two curves equals the amount of hybrid system generation. The combined power flowing to the grid, the black line, is noticeably smoother, making large changes only over a period of hours so the grid operators have time to respond.

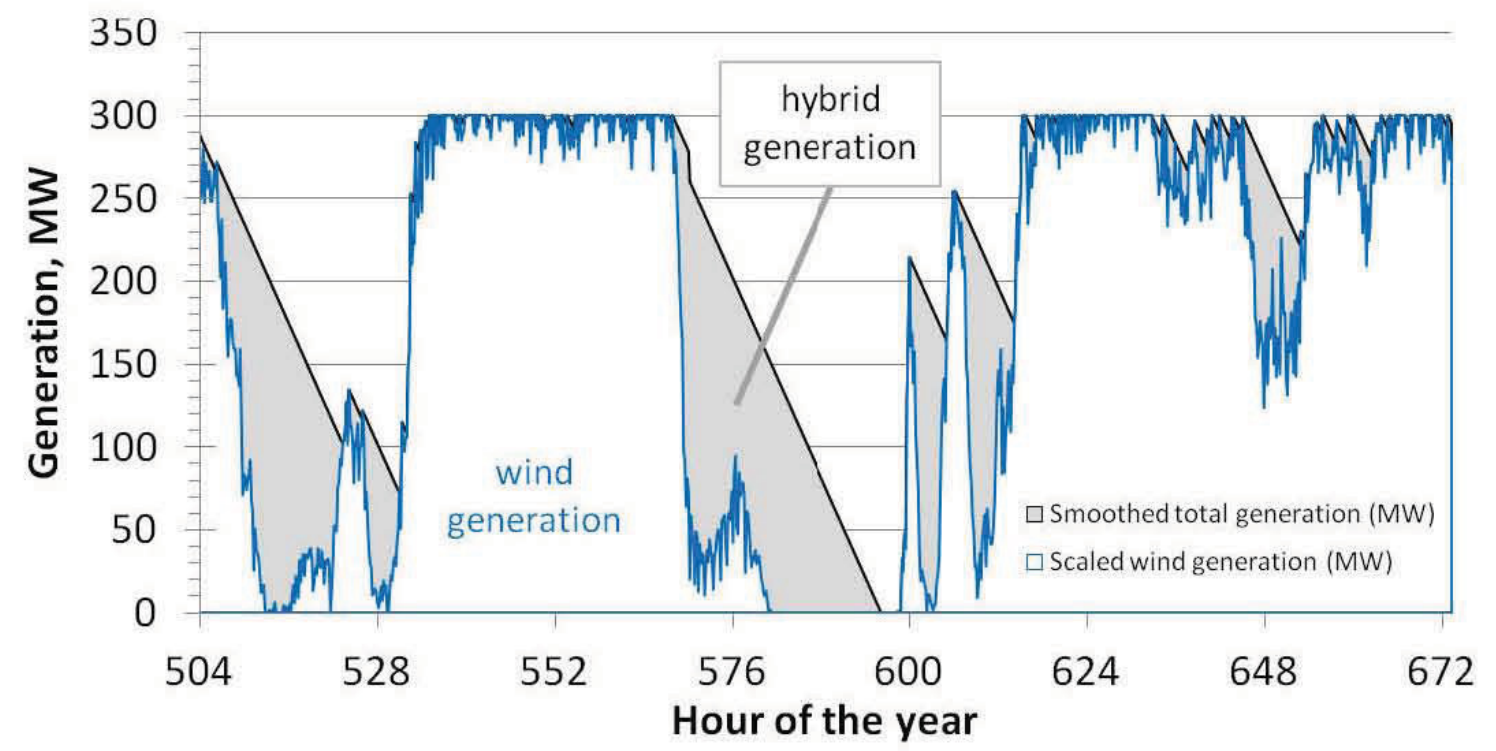

Figure 14. Hybrid system operation to smooth but not eliminate wind's variability.

The ability of the hybrid system to compensate for rapid changes in wind power output depends on how fast steam can be switched between the power and process plants, not on how fast the primary heat source can respond to a transient. As can be seen during the rapid wind generation drop at about hour 570 in Figure 14, the hybrid system output rises rapidly from zero to moderate the wind's drop. If the hybrid system's maximum power output is lower than the capacity of the wind farm there is a possibility of hitting that maximum, after which the combined output falls at the same rate as the wind generation rate falls. This can be seen at hour 570 between 280 and $260 \mathrm{MW}$ of generation. This situation might occur if a hybrid system based on a small modular reactor of a few hundred megawatts electrical capacity was paired with a large wind farm.

The response to a rapid rise in wind generation is different, as seen at about 530 hours. The hybrid energy system output has dropped to zero and cannot go negative, so the rapid rise of wind generation increases the combined output at the same high rate. This situation is more easily handled by the grid than is a rapid drop in generation, with one option being to curtail some of the wind generation to reduce the rate of increase of wind farm output. Another option is to implement some form of predictive control to anticipate rapid increases in wind generation and begin compensating pre-emptively.

This operating strategy greatly improves overall economic performance. The hybrid energy system now generates only the power corresponding to the area between the curve for wind generation and that for smoothed total generation. The thermal output corresponding to the area above the latter line up to the maximum output of $300 \mathrm{MWe}$, rather than being used for additional power production, now is available to send to the process plant as heat. In the full-year simulation that generated the week of results shown in Figure 14, there is $300 \mathrm{MW}$ of wind capacity, $240 \mathrm{MWe}$ of hybrid system generation capacity, and a maximum allowable ramp rate downward of $10 \mathrm{MWe}$ per hour. The ramp rate upward is not constrained for the reason described earlier. Over the whole year, wind generates $42.8 \%$ of its capacity. The hybrid system generates power, rather than sending heat to the process plant, with $19.7 \%$ of its annual output, much lower than the $57.2 \%$ it would have supplied under the constant output strategy. Because of the 
ability to split heat between the two alternatives, this new performance is not the same as making only power for $19.7 \%$ of the hours in a year. Much of the time the heat source supplies energy to both products.

Most important for overall system economics, however, is that now the nuclear primary heat source sends $80.3 \%$ of its heat to the process plant, allowing synfuel production for a much greater fraction of the time. In addition, the combined electrical output of the wind and hybrid systems corresponds to $58.6 \%$ availability over the course of a year. The $15.8 \%$ availability increase over wind alone improves the economics of transmission lines that might carry this combined power output to customers outside of Wyoming.

While only one annual performance result is reported here, the value of this operating strategy over the constant-output alternatives is apparent. Figure 15 shows that the amount of hybrid system output required to moderate wind's variability is a strong function of the acceptable rate of output drop. At an allowable ramp rate of $20 \mathrm{MW}$ per hour, small compared to $300 \mathrm{MW}$ total capacity, only $11.2 \%$ of the hybrid system's output goes to wind moderation. The synfuel plant receives nuclear heat the other $88.8 \%$ of the time, an amount similar to its own availability after allowing for planned and unplanned shutdowns. The specific operating parameters that might be used in a real system are subject to much further refinement and optimization to accommodate not only internal design tradeoffs but also the characteristics of the wind generation site and the local power grid.

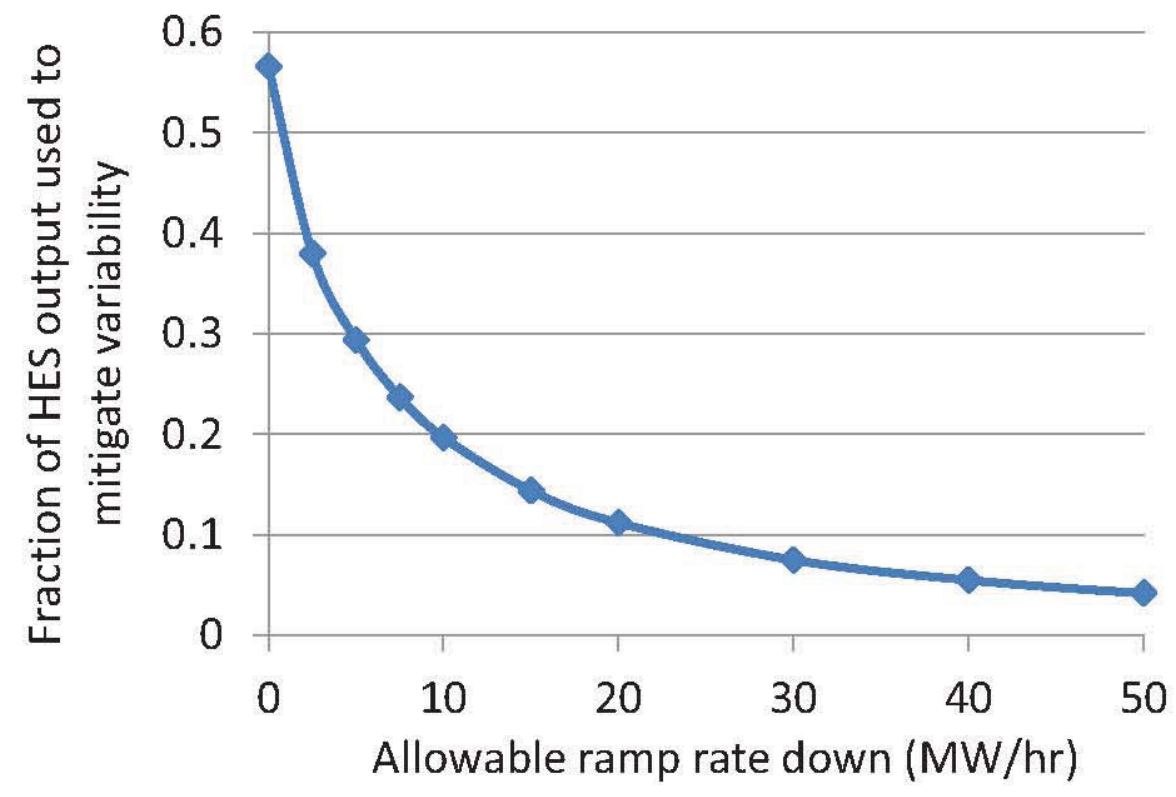

Figure 15. Allowing modest variability in wind farm output greatly reduces the demand for energy from the hybrid system's nuclear reactor. Wind farm capacity is $300 \mathrm{MWe}$.

\subsubsection{Direct Use of Wind Energy in Processes}

This report primarily addresses wind's variability by using hybrid energy systems to control the high frequency fluctuations and diverting the power plant's heat supply to another use - synfuel - when it is not needed for power generation. It is also conceivable to use wind power directly in a process adapted for such a variable input. Because wind energy is delivered as electricity, not heat as usually used in chemical processes, the alternatives are more limited because of the energy form itself as well as the lack of storage methods for it. Electrolysis of water to make hydrogen and oxygen has been frequently proposed, with more emphasis on the hydrogen as a fuel (for engines), energy storage medium (with fuel cells), or refining feed stock (for upgrading heavy or sour petroleum or as an adjunct to coal gasification) 
than on the oxygen for which it is more difficult to find users at the scale of its generation. Electrolysis systems could easily follow transients in power availability. However, if the need is to make hydrogen rather than to use wind power, industrial experience shows that methane steam reforming is preferred over electrolysis because it can be done easily at large scale and is less expensive, especially with the expected low future price of natural gas.

One possible use for oxygen from time-varying, wind-powered electrolysis, especially if $\mathrm{CO}_{2}$ emission limits or penalties come into effect, is oxycombustion of coal or natural gas in power plants. This process uses essentially pure oxygen to make a flue gas of concentrated $\mathrm{CO}_{2}$ - but no nitrogenwhich can be compressed and sent directly to storage sites or used for enhanced oil recovery (EOR).

Somewhat similarly, wind power could be used to supply power to a cryogenic air separation unit to make streams of oxygen for oxycombustion and nitrogen for large scale purposes including ammonia production or EOR. While some EOR operations currently use nitrogen from dedicated air separation plants this application, although large and valuable, is ultimately limited by the finite economically recoverable residual oil content of a region's petroleum fields. Whether an air separation unit can be adapted to operate well at frequently varying rates is not known. The cryogenic distillation column and complex cold recovery systems in an air separation unit make this seem difficult. The oxygen needed from an air separation unit to retrofit oxycombustion on a $700 \mathrm{MW}$ coal-fired power plant is analyzed in Section 4.3.

Time-varying wind energy might also be used to produce clean water from currently unusable sources. Desalination to purify low quality water for potable use is another process gaining more attention in recent years. There are a number of desalination techniques, some based on heat input, others using electrical power and therefore suitable for use with wind energy. Reverse osmosis which pumps water through membranes at high pressure is perhaps the best known example of the latter. This technology could be readily adapted for transient operation. However, desalination is expensive for making drinking water, about $\$ 1$ per cubic meter of potable water, and unaffordable for industrial or agricultural water. Operating on a part-time basis would further aggravate this cost problem.

In all of these processes, the ability to store the immediate product (hydrogen, oxygen, nitrogen, carbon dioxide, or water) is important to its usability in downstream processing. Storing gases at the quantities required for integration with variable power generation has been done, usually light hydrocarbons (for petrochemical feed stocks) in underground caverns solution-mined in salt domes. EOR itself is a form of gas storage, albeit with no intent to recover the gas. The availability of suitable salt domes or the usability with these gases of natural gas wells, including hydraulically fractured shale gas wells in very low permeability formations, will be a major factor in whether these processes can be used at any significant scale in Wyoming.

\subsection{Feasibility of Dynamic Operation of a Chemical Process}

Large chemical process plants, for instance those making commodity chemicals or refining petroleum, are designed to run at steady high rates to obtain well-optimized performance and good utilization of a large capital investment. This is known as continuous operation. However, it is not the only possible way of running a chemical process. In fine chemicals and pharmaceutical manufacturing, batch operations are common. Batch processing involves mixing chemical reagents in a vessel, heating the mixture, and allowing sufficient time for the desired reaction to occur. Throughout such a process, the temperature, pressure, and composition of the batch can be continually changing. Hybrid systems require an intermediate dynamic operating mode in which material is continually pumped through the process (not necessarily at a steady rate) while the temperature and pressure in each vessel are adjusted to maintain the proper amount of reaction or separation. In the limit of having the feed flow cycle fully on and off at regular intervals, this operation approaches batch operation.

Because conventional continuous processes for making commodity chemicals or synthetic fuels are highly developed, processes for dynamic operation should be adapted from them. It is outside the scope of 
this report to explore how this might be done either generally or for specific processes; such work could easily become a major research program by itself. However, to establish the conceptual feasibility of operating chemical processes dynamically, those that could be easily adapted are described here.

- Chemical processes handling gases (rather than liquids or solids) treat the process stream for a short length of time, less than a minute, in each reaction or separation vessel. This is because gases have low density and therefore occupy a large volume for a given weight of material, so vessels of reasonable size can hold only a few seconds worth of the feed stream. This in turn means that as the inlet conditions dynamically change over minutes or hours and the temperature and pressure of the equipment are adjusted accordingly, the material in the vessel sees only a few seconds of essentially constant conditions. Further, material processed at one temperature and pressure is not mixed in the vessel with material processed at other conditions that might not have the same composition. Consequently, gas phase processes should be relatively easy to convert to dynamic operation. Some pertinent examples include steam methane reforming to turn natural gas into synthesis gas, the watergas shift reaction that increases the amount of hydrogen in synthesis gas, and the conversion of synthesis gas into a variety of chemicals such as methanol.

- Some chemical reactors perform conversions that go to a certain, fixed final composition which is dependent on temperature and pressure. The chemical compounds in the system do not react any further even if more time is allowed. These are known as equilibrium reactions and are contrasted with kinetically limited reactions which continue to react if more time is allowed. Equilibrium reactions, not being affected by the time allowed in the reactor, are well suited to the varying rates of a dynamic system. Even if the flow rate through them goes to zero, by holding the reactor at the same temperature and pressure it will be ready to produce the same product composition immediately when flow returns. Examples of equilibrium reactions include the three already cited as gas phase reactions, ammonia synthesis (also gas phase), and some kinds of coal gasification (a gas-solid reaction with longer reaction times).

- Processes with steps that handle liquids and solids are not well suited to dynamic operation because, in general, they contain a large amount of material compared to the flow rate through them. Uniformly changing the temperature of a large amount of material cannot be done quickly, so it would be difficult to maintain the process conditions at the optimal values as the feed conditions change over time. In addition, the large amount of material means that compositions corresponding to conditions in the recent past are mixed with current compositions, and these may not be the same. Examples of these less desirable processes or reactions include coal gasifiers, slurry column reactors as in Fischer-Tropsch synthesis of synthetic liquid fuel, and distillations to separate or refine liquid chemical products or synthetic fuels.

Chemical processes typically contain a number of reaction and separation steps. If only one or two are problematic for dynamic operation while the others would be acceptable, the overall continuous process might still be adaptable. This would be possible if the stream(s) feeding the problematic step can be condensed into a liquid that is stored at the plant site. While the liquid flow into the storage tank might be time-varying, the feed from it to the non-dynamic process steps could be steady. The storage tank(s) would have to be large enough to compensate for perhaps several days of high or low rate dynamic operation reflecting an extended period of high or low wind generation rates.

The process proposed in this study, reforming of natural gas to syngas followed by methanol synthesis then conversion to gasoline, meets these criteria. Reforming is a gas phase equilibrium reaction. Methanol synthesis and the subsequent formation of dimethyl ether as a chemical intermediate are also gas phase equilibrium reactions. The gasoline synthesis reaction from dimethyl ether is done in a number of relatively small reactors operated in parallel, so when operating rates drop the proportionate number of those reactors can be bypassed, allowing the ones remaining in service to continue to operate at the their individual full design rate. The process includes a large distillation column to separate water from the crude methanol stream, but that crude feed is a condensed liquid that can be stored in a surge tank to 
allow a steady flow to the distillation column. Although highly dynamic operation of this system has not been tested, there are no evident problems that would prevent it.

\subsection{Economics of Transient Operation}

One use of a dynamic hybrid system is to facilitate the use of variable renewable resources, in this case wind. For this to happen through market mechanisms, wind generation must have a premium value greater than the value of other forms of generation and there must be a way of sharing this premium with the other participants required to build and operate a hybrid energy system. It would be impractical to attempt analysis of a number of specific hybrid system configurations, each with a range of design and operating conditions, to identify the value of their operation. It would also not provide a logical formulation of what fraction of the overall benefit should be credited to each process unit.

Instead, it can be recognized that a generalized hybrid system configuration such as in Figure 3 is composed of a conventional thermal power plant (nuclear or fossil-fired) that can periodically send some or all of its heat to a conventional type of synthetic fuel plant. This thermal connection between the two plants is a simple and natural point to establish a transfer price for the thermal energy in the system. This discussion covers one way this might be done.

\subsubsection{Valuation of Wind Generation}

The operation of electrical power markets is complex. Prices vary on an hourly or faster basis, changing at each time point with total demand and the availability of generation capacity. To create a known and reliable price structure and an incentive for developers to build wind generation capacity, several methods have been used. These include

- Feed-in tariffs that pay a known amount to the wind generation facility for each kilowatt-hour delivered to the grid. These payments last for 15-20 years to provide stability to allow financing of the wind project, although they can change according to an established schedule. The tariff can represent the total payment to the generator, in which case it will be near or above the average price of electricity, or it can be a smaller fixed premium which the generator receives in addition to the market price for electricity [Couture et al. 2010]

- Renewable portfolio standards, established individually by each state, which mandate that power utilities obtain a specified fraction of their power (typically $15-33 \%$ in western states) from renewable sources by a certain year (2015-2025 in those same states) [DSIRE 2010]. For every kilowatt-hour below the target, the utility must pay a penalty of 1 to 5 cents $/ \mathrm{kWh}$. In California, the target is being increased to $33 \%$ renewable by 2020 (with minimum $1 \%$ annual increases) with a penalty of 5 cents/kWh for non-compliance [CPUC 2012].

- A wind energy production tax credit of 2.2 cents $/ \mathrm{kWh}$ that is available from the U.S. government. It is scheduled to expire at the end of 2012. Its extension has been proposed but is not currently settled.

The overall effect of these incentives is that wind generation indeed has a premium value in economic, not just social, terms. This is a consequence of governmental regulations motivated by the social returns and therefore is subject to change at any time. The amount of the value premium varies with purchaser, location, duration, quantity, and other factors but would be expected to be $1-5$ cents $/ \mathrm{kWh}$ (or $10-50 \$ / \mathrm{MWh}$ ). In turn, part of this premium value might be spent by the wind-generating entity to reduce its output's variability, allowing an increase in the amount of wind generation that might be purchased by the power grid.

Wind generation has two characteristics different from fossil-fired generation that could be sources of value. The first of these is that there is no $\mathrm{CO}_{2}$ emission associated with wind generation (although construction of wind farms might have nonzero emissions). This value can be realized as a cost savings compared to penalties, taxes, or required capital expenditures tied to combustion of coal or natural gas and it is considered in this manner in Chapter 4. 
The second benefit is that wind (and solar) generate electricity directly rather than through a heatdriven power cycle. They do not require cooling water to do this, in contrast to fossil-fired plants which reject 50-65\% of their heat input to the environment via cooling water systems. In an arid region such as Wyoming, the reduced demand for cooling water can be significant. For example, a 250 MWe capacity wind farm with $35 \%$ availability would produce $87.5 \mathrm{MWe}$ averaged over a year. A coal-fired power plant with the same generation (ignoring dispatchability issues to deal only with total annual generation) and $35 \%$ thermal efficiency would reject $162.5 \mathrm{MW}$ of thermal energy to the environment. In an evaporative cooling system this would consume 1110 gallons per minute of water solely for make-up. The savings by using wind generation equals 1800 acre-feet of water annually, an amount that could irrigate about one square mile of land or supply the potable water needs of a town of 16,000 persons. The value of water rights for this level of usage, especially for municipal use, would depend greatly on the circumstances of where that usage might be and what alternative water supplies exist there.

\subsubsection{Cost of Hybrid Heat as a Co-product of Wind Generation}

With wind power selling at a policy-driven premium, there is an incentive for wind generation developers to team with hybrid energy system developers to produce a combined power output that is more attractive and more usable in large amounts by utilities subject to a Renewable Portfolio Standard. This teaming will include sharing of the wind energy premium with the hybrid system as a whole, using it to offset or cross-subsidize the cost of heat delivered to the synthetic fuels plant. This shared fraction of the wind energy premium is assumed to be distributed in its entirety to the synfuels plant because the power plant operator, especially a nuclear plant operator, receives economic benefit simply from being able to run at full rates at all times. This arrangement will however depend on the contractual structure negotiated among all the participants.

Using the same hybrid configuration and wind data used to generate Figure 14, the value of heat cross-subsidy for a modest wind premium of $1.5 \mathrm{cent} / \mathrm{kWh}(\$ 15 / \mathrm{MWh})$ paid to the hybrid system can be determined. The amount of premium collected during the $42.8 \%$ of wind generation availability is applied to the $80.3 \%$ of its thermal output that the $240 \mathrm{MWe}$ hybrid system sends to the synfuel plant. The result is a potential cross-subsidy of $\$ 3.20$ per $\mathrm{MWh}$ of thermal energy. If the wind energy premium paid to the hybrid system is greater than $\$ 15$ per MWh this potential subsidy increases proportionately.

This value is significant compared to the cost of heat that the process plant would otherwise either buy from a co-generation facility or produce itself in a boiler or furnace system. For the co-generation case, electricity production costs in the typical range of $\$ 50$ to $\$ 100$ per MWh correspond, via the plant's thermal efficiency, to $\$ 17$ to $\$ 50$ per MWh thermal for heat diverted to a process plant. In particular, new nuclear heat is estimated at $\$ 19.20$ per MWh based on projected nuclear power costs [IEA 2010]. The nuclear heat cost is assumed to be same whether designed for power generation or for co-gen process heat application because, in the second application, the cost savings of smaller turbines and cooling tower would be offset by the cost for a large high pressure intermediate heat exchanger to isolate the nuclear and chemical facilities' steam systems from each other.

For heat production in a dedicated furnace or boiler typical of a chemical plant, natural gas at $\$ 4$ per MMBTU burned in a furnace with $85 \%$ efficiency delivers heat for a fuel cost (no capital or operating costs) of $\$ 16.06$ per MWh, while coal at $\$ 20$ per ton and $90 \%$ efficiency generates heat at $\$ 4.41$ per $\mathrm{MWh}$. Adding a potential cost for $\mathrm{CO}_{2}$ capture and disposal of $\$ 30$ per ton $\mathrm{CO}_{2}$ and for generation derating of $10 \%$ (natural gas) and $20 \%$ (coal), the costs for fuel alone rise to $\$ 25.60$ and $\$ 21.63$ per $\mathrm{MWh}$, respectively, not including the associated capital costs. Over a conventional (without $\mathrm{CO}_{2}$ capture) boiler's lifetime, fuel costs represent $96 \%$ of total costs, compared to capital $3 \%$ and operations and maintenance 1\% [IES-ETSAP 2010].

For heat supply costs of $\$ 19-26$ per MWh a savings of $\$ 3.20$ per MWh thermal, possibly more, by using hybrid system heat would be significant. Further, using nuclear heat would obviate the risk of unpredictable future costs for boiler fuel. This provides incentive for a synfuel plant to participate in a hybrid energy complex even if it means a somewhat reduced average operating rate. The cost difference 
between nuclear heat cross-subsidized by the wind premium and either of the conventional fossil-fired cases with the added costs of $\mathrm{CO}_{2}$ capture is substantial. It should encourage in-depth review of that option for new plants when the likelihood of mandatory large $\mathrm{CO}_{2}$ emission reductions is better known. Exactly how this sharing of economic benefits will occur in practice is unknown because many aspects of this concept are at this speculative: how hybrid systems' internal economics will work between partner organizations, mow much value results can actually be realized by addressing wind's variability, and how government-decreed drivers for wind usage might change over time. 


\section{EVALUATION OF PROPOSED HYBRID SYSTEMS 4.1 Process Description of Hybrid Synfuel Cases \\ 4.1.1 Comparison of Conventional Fossil Energy Options for Synfuels}

There is a choice of two primary feed stocks (coal and natural gas) to create syngas and two processes to convert that syngas to marketable liquid transportation fuels. The market analysis in Chapter 2 identified gasoline from natural gas as the preferred choice. This chapter discusses how the chemical conversion would be done in a hybrid energy system. It starts with a review of the major synfuel process alternatives to validate the market-based choice on the alternative basis of technical advantages.

The four possible process configurations are

- Natural gas reforming to methanol to gasoline

- Natural gas reforming to Fischer-Tropsch diesel

- Coal gasification to methanol to gasoline

- Coal gasification to Fischer-Tropsch diesel

All four of these individual processes have been built and operated at commercial scale. Figure 16 shows a natural gas to methanol to gasoline plant that was built and operated by Exxon in the 1980s. Shell has built natural gas to Fischer-Tropsch diesel plants in Malaysia and Qatar. Sasol also built a natural gas to Fischer-Tropsch diesel plant in Qatar. A coal to methanol to gasoline plant was built by JAMG in Shanxi Province, China. Sasol built and has continuously operated coal to Fischer-Tropsch diesel plants in South Africa since the 1950s.

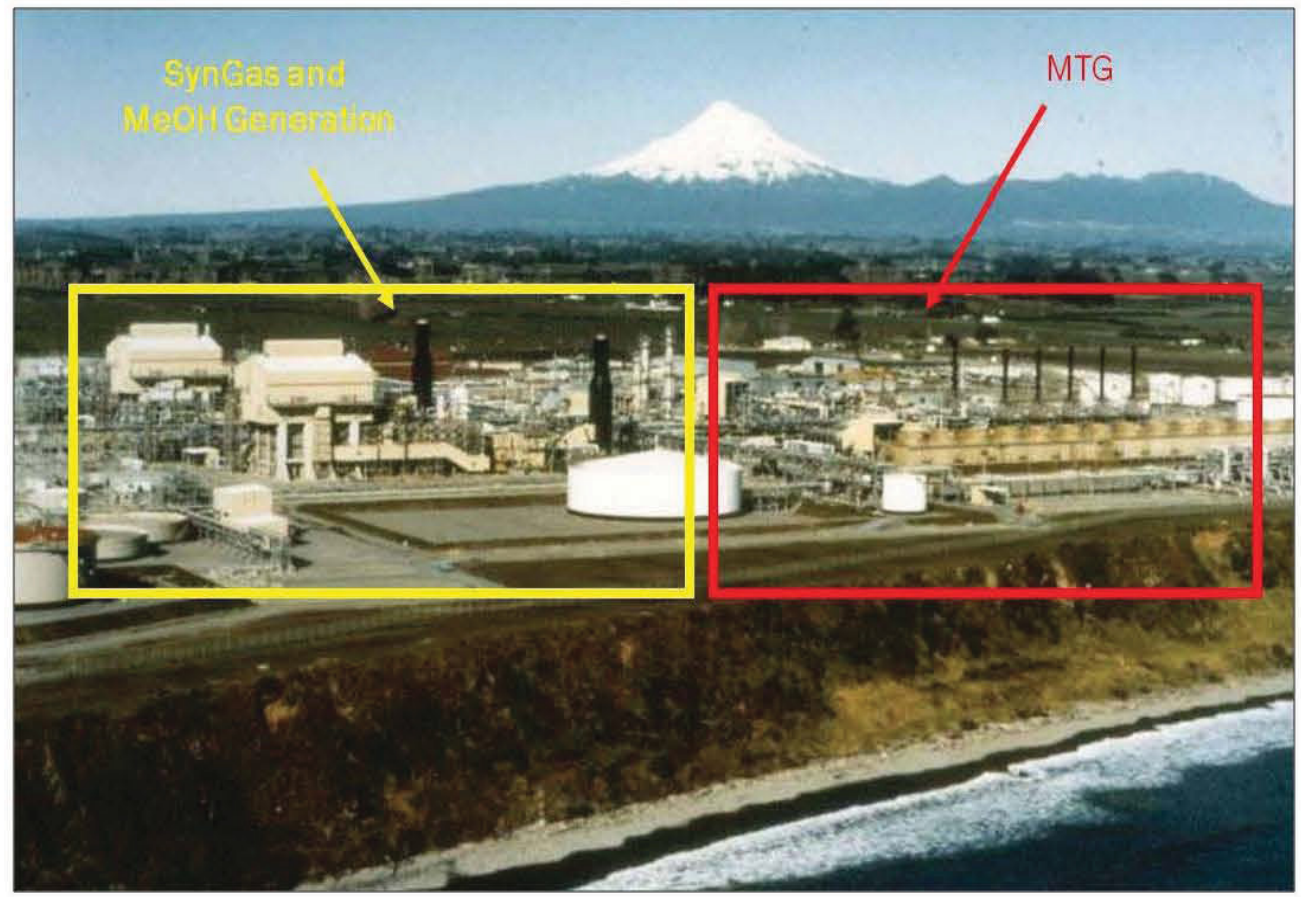

Figure 16. Natural gas to methanol to gasoline plant in Montunui, New Zealand. 
Table 7. Selected previous results for fossil energy only cases.

\begin{tabular}{|c|c|c|c|c|}
\hline \multirow{2}{*}{$\begin{array}{r}\text { Feed stock: } \\
\text { Product: }\end{array}$} & \multicolumn{2}{|c|}{ Natural Gas } & \multicolumn{2}{|c|}{ Coal } \\
\hline & Gasoline & FT Diesel & Gasoline & FT Diesel \\
\hline $\begin{array}{l}\text { Natural gas feed rate, } \\
\text { MMSCF/day }\end{array}$ & 288 & 428 & & \\
\hline Assumed gas cost, \$/MMBTU & 4.50 & 4.50 & & \\
\hline PRB coal feed rate, ton/day & & & 31,100 & 36,300 \\
\hline Assumed coal cost, $\$ /$ ton & & & 10.50 & 10.50 \\
\hline Water consumed, gpm & 8,700 & 12,900 & 15,900 & 23,700 \\
\hline $\begin{array}{l}\text { Liquefied petroleum gas, } \\
\text { barrels per day }\end{array}$ & 5,300 & 3,240 & 8,200 & 2,000 \\
\hline $\begin{array}{l}\text { Gasoline or (in FT cases) } \\
\text { naphtha, barrels per day }\end{array}$ & 33,500 & 12,200 & 52,243 & 12,700 \\
\hline Diesel, barrels per day & 0 & 34,600 & 0 & 35,200 \\
\hline Net power production, MW & -98 & 60 & -462 & 103 \\
\hline $\mathrm{CO}_{2}$ captured, $\mathrm{MMSCF} /$ day & 0 & 0 & 530 & 583 \\
\hline $\mathrm{CO}_{2}$ vented, $\mathrm{MMSCF} /$ day & 49 & 124 & 25 & 262 \\
\hline Total capital investment & $\$ 1.7$ billion & $\$ 2.0$ billion & $\$ 5.6$ billion & $\$ 5.9$ billion \\
\hline Required fuel sales price ${ }^{*}$ & $\$ 1.49 /$ gallon & $\$ 1.38 /$ gallon & $\$ 1.73 /$ gallon & $\$ 1.66 /$ gallon \\
\hline $\begin{array}{l}\text { Internal rate of return with } \\
\text { gasoline at } \$ 2.58 / \text { gallon or } \\
\text { diesel at } \$ 2.72 / \text { gallon }\end{array}$ & $37.8 \%$ & $57.4 \%$ & $26 \%$ & $30 \%$ \\
\hline
\end{tabular}

An earlier study for the Wyoming Business Council [Boardman 2011] compared these four processes using detailed ASPEN process simulations and a discounted cash flow analysis. Selected results from this study are presented in Table 7 . The natural gas-based processes are more economically attractive than the coal-based processes despite their higher feed and fuel costs because of their much lower capital cost. If future natural gas prices are much higher than current prices, coal gasification might become the preferred means for producing syngas.

The rates of return in Table 7 show that converting natural gas to Fischer-Tropsch diesel is more economically attractive than making gasoline. For this study, however, the preferred approach is natural gas to methanol to gasoline. Regional demand for gasoline is higher than for diesel. In addition, the Fischer-Tropsch process creates a substantial naphtha byproduct stream. Naphtha consists of hydrocarbons in the gasoline boiling range that, because of their molecular structure, have a very low octane value and therefore are not well suited for use in gasoline. Marketing of naphtha in the region is expected to be problematic, although shipment to Alberta for use as an oil sands bitumen diluent is a possibility. In contrast to its low value in fuels, Fischer-Tropsch naphtha is a good feedstock for ethylene and propylene production (the feedstocks for polyethylene and polypropylene plastics) but natural gas liquids are strong competitors for this market. Most ethylene/propylene producers are on the Gulf Coast so a Wyoming Fischer-Tropsch plant would face additional shipping charges on a low value commodity.

\subsubsection{Nuclear Integration Options}

Flow sheets for all four processes for the conversion of natural gas or coal to gasoline or diesel were examined to identify opportunities for integrating nuclear energy. Some of the technical issues in doing 
this integration are discussed in more detail in Appendix A. With the approach of this report of examining nuclear heat purely on the basis of its temperature or delivery rate, there was no need to specify what particular reactor was used. Nuclear heat at temperatures of 300 and $500{ }^{\circ} \mathrm{C}$ proved to have the same uses; there was no advantage to the hotter of these sources. Nuclear heat at $800^{\circ} \mathrm{C}$ can be used differently and this is covered in a complementary report on high temperature gas reactors. The results of this examination did not change the preference for steam reforming natural gas followed by methanol synthesis and a methanol to gasoline process.

The integration scheme using $300{ }^{\circ} \mathrm{C}$ heat from a light water reactor is partially illustrated in Figure 17. Figure 17A shows the conventional configuration with a natural gas-fired furnace providing the energy to preheat the reformer feeds and the reformer effluent being used to generate steam. In the nuclear-integrated hybrid case (Figure 17B), hot effluent gas from the autothermal reformer provides heat for the primary reformer, eliminating the need for the reformer furnace and its natural gas consumption. Most of the purge gas conventionally burned in this furnace is instead recycled as feed to the reformer, using its carbon content to increase the production of syngas at a fixed natural gas feedstock rate. A relatively small fuel gas stream is still burned to make steam; this is necessary to provide a purge point to control the inert gas build-up in the system. Although concerns have been raised about metal dusting (carburization) in the heat exchange train because of the high carbon content of the synthesis gas, use of higher alloys containing chromium, nickel, or silicon can address this type of corrosion. This process configuration under the name gas-heated reforming has, according to their web sites, been offered and built commercially by a variety of process technology vendors including KBR, Haldor Topsoe, Linde, and Davy.

Because the heat in that reformer effluent stream is, in the gas-heated reformer system, used to preheat the reformer feeds, another way is needed to generate steam as a chemical feed to the primary reformer as well as for other process heating. In the proposed hybrid energy system, that source is a light water nuclear reactor. Its $300^{\circ} \mathrm{C}$ temperature is high enough to generate high and medium pressure steam; the small usage in the conventional system of very high pressure steam for process heating can be met by high pressure steam (with larger heat exchangers because of its lower condensing temperature; the process temperatures are below high pressure steam's temperature) and by dropping the operating pressure, hence temperature, of the one small distillation column that was above that temperature..

A.
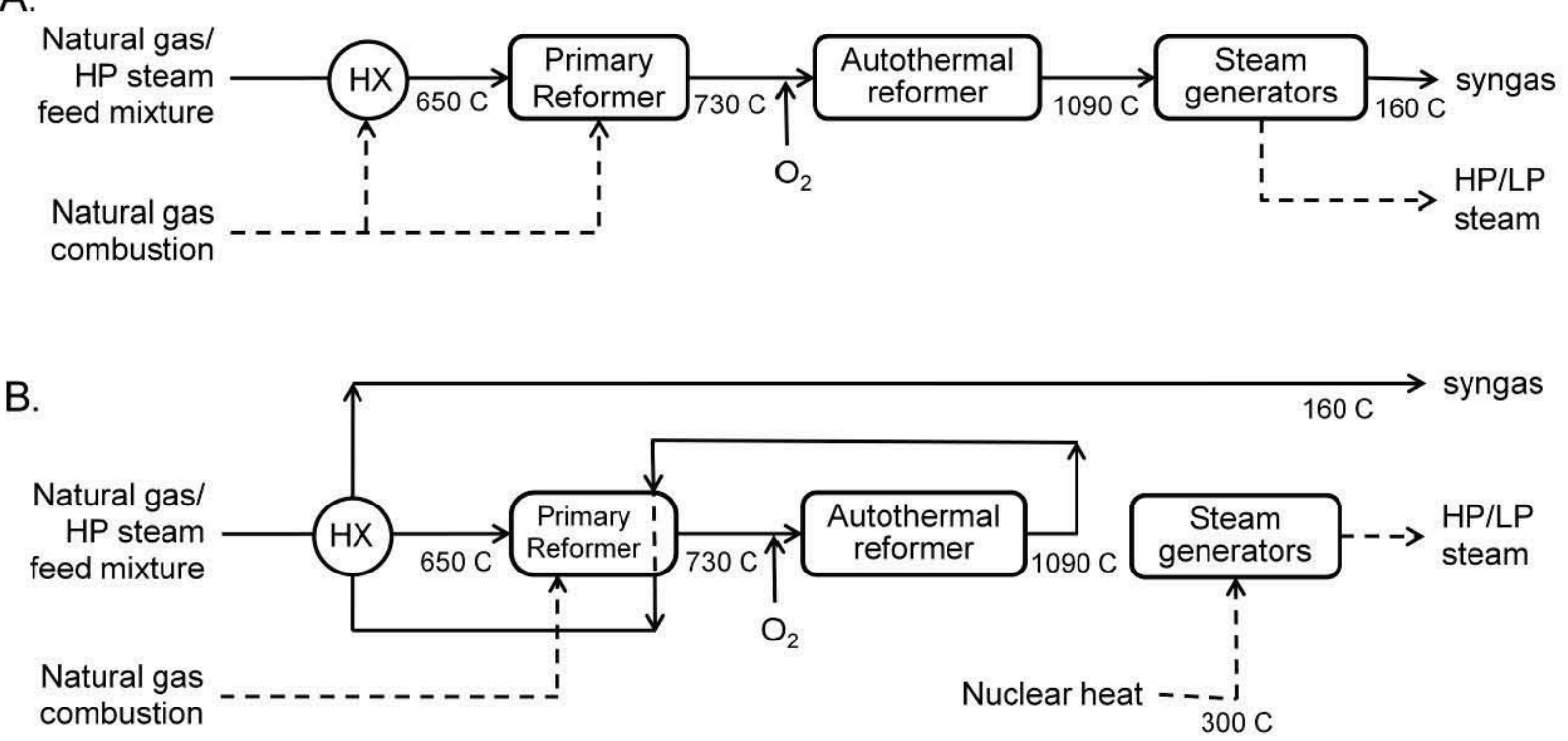

Figure 17. Reconfigured reformer section of a nuclear-integrated natural gas to gasoline plant. HX represents a train of heat exchangers. 
This process configuration has been previously studied by INL [Cherry 2012]. An unpublished INL ASPEN simulation of the nuclear-integrated natural gas to methanol to gasoline process produced the second column of results in Table 8. Compared to the conventional natural gas to methanol to gasoline plant, natural gas consumption is reduced by $15 \%$. Direct $\mathrm{CO}_{2}$ emissions are reduced over $97 \%$ since $\mathrm{CO}_{2}$ emissions for the conventional case were primarily from the reformer furnace.

Table 8. Comparison of cases for natural gas to methanol to gasoline.

\begin{tabular}{|c|c|c|c|c|c|}
\hline & $\begin{array}{l}\text { Conventional } \\
\text { NG to gasoline } \\
\text { process }\end{array}$ & $\begin{array}{l}\text { Nuclear } \\
\text { assisted }^{\mathrm{a}}\end{array}$ & $\begin{array}{l}\text { NGCC hybrid - } \\
\text { balanced synfuel } \\
\text { and power }\end{array}$ & $\begin{array}{l}\text { NGCC hybrid - } \\
\text { max. power, } \\
\text { no synfuel }\end{array}$ & $\begin{array}{l}\text { NGCC hybrid - } \\
\text { max. synfuel, } \\
\text { min. power }\end{array}$ \\
\hline $\begin{array}{l}\text { Natural gas feed rate, } \\
\text { MMSCF/day }\end{array}$ & 86 & 73 & 102 & 29 & 92 \\
\hline Water consumed, gpm ${ }^{\mathrm{e}}$ & 2,597 & 1,732 & 1,732 & 0 & 1,732 \\
\hline $\begin{array}{l}\text { High pressure steam } \\
\text { from light water reactor } \\
\text { or NGCC plant, ton/day }\end{array}$ & 0 & 3,315 & 3,315 & 0 & 3,315 \\
\hline $\begin{array}{l}\text { Liquefied petroleum } \\
\text { gas, bbl/day }\end{array}$ & 1,582 & 1,577 & 1,577 & 0 & 1,577 \\
\hline Gasoline, bbl/day & 10,000 & 10,000 & 10,000 & 0 & 10,000 \\
\hline $\begin{array}{l}\text { Net electric power } \\
\text { produced, MW }\end{array}$ & -29 & +132 & +98 & +200 & +14 \\
\hline $\begin{array}{l}\mathrm{CO}_{2} \text { vented, } \\
\mathrm{MMSCF} / \text { day }\end{array}$ & 15 & 0.4 & 29.5 & 29.1 & 19.4 \\
\hline \multicolumn{6}{|c|}{$\begin{array}{l}\text { a. With natural gas to gasoline plant at full capacity. Assumes } 600 \mathrm{MW} \text { thermal light water reactor with } 33 \% \text { thermal to electric } \\
\text { conversion efficiency. }\end{array}$} \\
\hline \multicolumn{6}{|c|}{$\begin{array}{l}\text { b. With NGCC and natural gas to gasoline plants at full capacity. All steam exiting first steam turbine in NGCC plant is fed to } \\
\text { natural gas to gasoline plant. }\end{array}$} \\
\hline \multicolumn{6}{|c|}{ c. NGCC plant operating at full capacity. Natural gas to gasoline plant shut down. } \\
\hline \multicolumn{6}{|c|}{$\begin{array}{l}\text { d. With gas turbine at } 30 \% \text { of rated power output, but same steam rate to natural gas to gasoline plant. Natural gas to gasoline } \\
\text { plant at full capacity. }\end{array}$} \\
\hline
\end{tabular}

For a plant that produces 10,000 barrels per day of gasoline, the light water reactor provides 3,315 short ton/day $\left(125\right.$ metric tonne/hr) of steam at $509^{\circ} \mathrm{F}\left(265^{\circ} \mathrm{C}\right)$ and $860 \mathrm{psia}(5.93 \mathrm{MPa})$. The total nuclear-derived heat transfer to the chemical processes is $81 \mathrm{MW}$, a quantity of steam that could easily be supplied by a small modular reactor. In fact, most proposed SMRs have thermal capacity larger than this and would be able to make additional electricity at all times. This $81 \mathrm{MW}$ of nuclear heat corresponds to only about half of the reduction in natural gas feed rate (13 MMSCFD) because the heating value of that gas feed rate change must be corrected for furnace efficiency (to get the amount of heat delivered) and for the nuclear case's higher product yield (hence less feed needed for the same gasoline production) because it recycles the lights purge stream to the reformer rather than burning it to make power.

Cooling water usage by the $10,000 \mathrm{bpd}$ synfuel plant is $1732 \mathrm{gpm}$, or $2794 \mathrm{acre}$-feet/year. This value should, to a first approximation, scale linearly with plant capacity. It does not include any water usage by the NGCC plant under the assumption that air-cooling would be used there and that incidental uses such as for boiler feed water makeup are not large in comparison to the cooling load.

Because the nuclear integration concept shown here affects the natural gas reforming section of the plant and not the conversion of syngas to liquid fuels, this integration concept could also be applied to a natural gas to Fischer-Tropsch diesel plant. 


\subsubsection{Integration with an NGCC Heat Source}

The integration of a light water, small modular nuclear reactor and a natural gas-to-methanol-togasoline plant is the preferred process configuration of this study. Such a system would have a large capital cost and, even though the synfuel, power generation, and wind farm steps are established technologies, would have risks associated with the integration of the nonnuclear components. Although light water reactor technology is well established for large power reactors, a small modular reactor using light water or any other technology will be a new system that as of now has not been licensed, built, or operated. It is also the single most expensive piece of the entire hybrid system.

It may be desirable, therefore, to start operation in phases, the first without the nuclear plant and using combustion-generated heat instead. This would allow testing of the integration aspects and validation of the economic performance of a hybrid system without the complexity introduced with a nuclear reactor. During this testing period the small modular reactor technology could continue through its own further design, licensing, and possible demonstration elsewhere in a conventional power application. When the nuclear reactor is ready for incorporation into the hybrid system, possibly further motivated by future taxes on $\mathrm{CO}_{2}$ emissions from the fossil heat source, a reactor could be retrofitted onto the rest of the hybrid system. This future conversion should be considered in the original design of the system.

For the original temporary heat source, a natural gas combined cycle plant would be appropriate because of its high thermal efficiency when making power, potentially well above $50 \%$, and the flexibility it offers in producing either power or heat. A simple gas-fired boiler producing only steam might also suffice in this use, but it would have only $33-38 \%$ thermal efficiency when making power because it operates a Rankine power cycle. This lower efficiency implies greater costs for fuel and $\mathrm{CO}_{2}$ emissions. The NGCC integration shown Figure 18 is a modification of a more conventional NGCC plant design [Chou et al. 2011]. The NGCC plant consists of a gas turbine, a heat recovery steam generator (HSRG), and a single steam turbine in which the temperature, $1050^{\circ} \mathrm{F}\left(566^{\circ} \mathrm{C}\right)$, and pressure, $2415 \mathrm{psia}(16.65$ $\mathrm{MPa}$ ) of the steam from the HSRG are reduced to the temperature and pressure to be provided by the light water reactor. The NGCC plant would be sized such that the effluent from the first stage steam turbine nominally matches the rate that steam is required in the synfuel plant. This analysis is based on energy balances only, not performance rating of particular pieces of equipment, so reduced gas turbine performance at Wyoming's altitude, hence lower air pressure, is not a problem here. However, it will have to be considered during design of a plant.

The first NGCC integrated case shown in the third column in Table 8 assumes that both the NGCC plant and the natural gas to gasoline plant operate at full capacity. In this case, the gas turbine produces 120.2 MW of electrical power. Assuming that the steam turbine and electrical generator are $80 \%$ efficient, power produced by the first stage of the steam turbine, the only one with significant steam flow, is 19.2 MW, for a combined power output of $139.3 \mathrm{MW}$. The natural gas to gasoline plant produces some electric power but its consumption of power is much greater, so the plant has a net $41.2 \mathrm{MW}$ of electric power consumption. When combined with the NGCC plant, this makes $98.2 \mathrm{MW}$ of power available for export. 


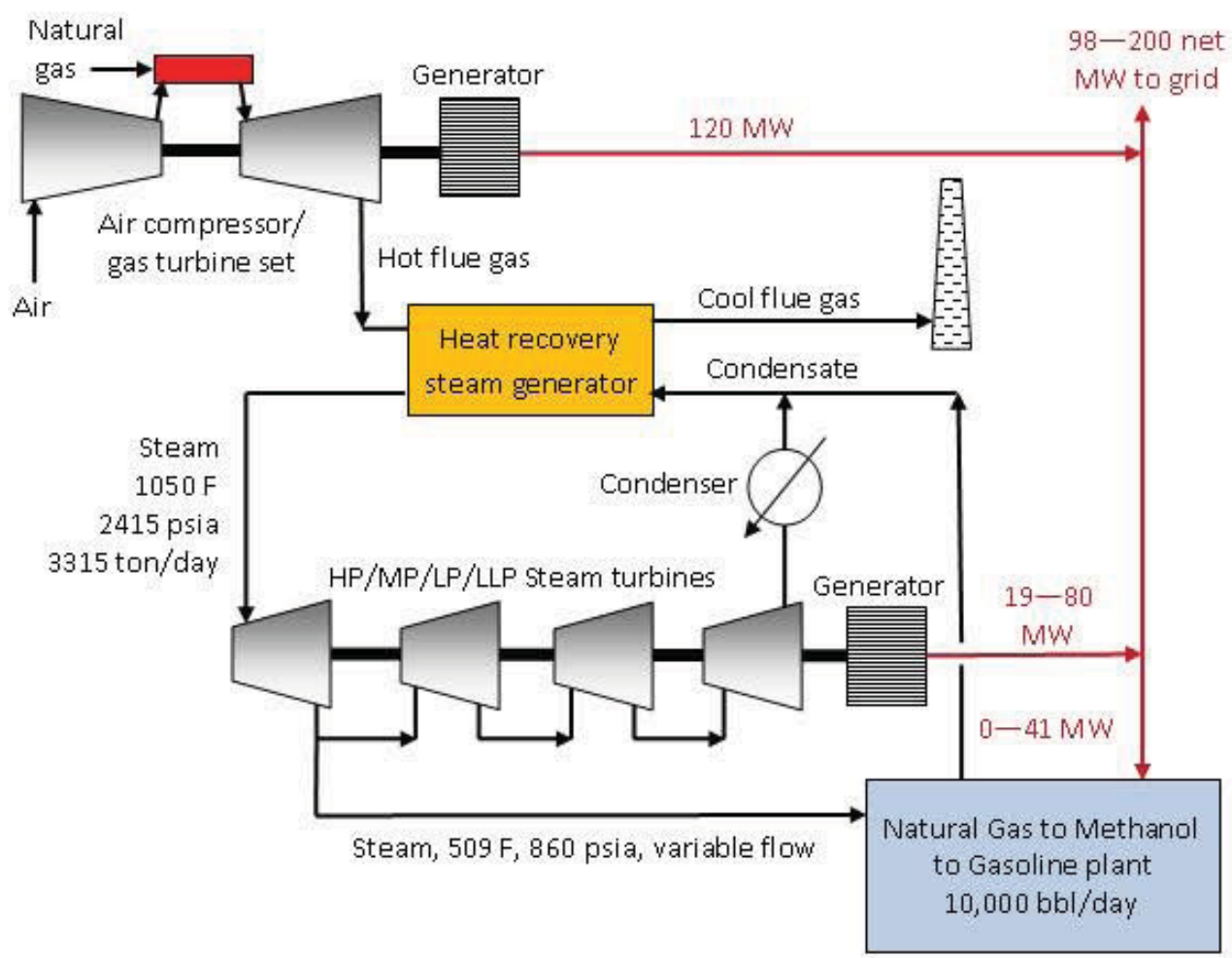

Figure 18. A natural gas combined cycle plant serves in place of the nuclear reactor prior to construction of the nuclear reactor.

The second NGCC case in Table 8 puts all the system energy towards electricity production, generating $200 \mathrm{MW}$. These outputs of $98-200 \mathrm{MWe}$ are comparable to a single medium to large wind fam of 50-100 turbines. The third NGCC case generates steam at full rate for the synfuel plant, but attempts to minimize power production from the gas turbine. This might be done when the associated wind farm is producing maximally. Because the gas turbine is part of the combustion system, it cannot be completely shut down. The table assumes that it can be tumed down to $30 \%$ output, perhaps by bypassing a large fraction of the combustor gases around it. Without the gas turbine removing energy from the hot gas, its temperature could be quite high and would be a matter of design concern when the operating range of this system is ultimately determined.

The original NGCC-based design [Chou et al. 2011] for 30,223 bpd of gasoline and 9251 ton/day of steam production was scaled to $10,000 \mathrm{bpd}$ using the six-tenths exponent rule to give an estimated capital cost of the NGCC plant of $\$ 226$ million.

\subsubsection{Recommended Load-following Strategies}

Nuclear power plants have high capital costs and low variable operating costs, so constant operation at full capacity is normally expected. With a nuclear-integrated hybrid energy system, the preferred loadfollowing strategy is to vary the operating rate of the natural gas to gasoline plant. This allows the net power production to vary from $132 \mathrm{MW}$, corresponding to full capacity operation of the natural gas to gasoline plant, to $200 \mathrm{MW}$, which corresponds to stopping synfuel production.

For an NGCC-integrated hybrid energy system, the capital cost of the natural gas to gasoline plant is greater than that of the NGCC plant. Therefore, there is an incentive to operate the natural gas to gasoline plant at full capacity, and vary the power output of the NGCC plant. A comparison of the first and third NGCC-integrated cases in Table 8 shows that net power output can be varied from $14 \mathrm{MW}$, corresponding to a low power output from the NGCC, up to $98 \mathrm{MW}$, corresponding to full output from the NGCC. 
Table 8 assumes a $200 \mathrm{MW}$ electric power rating for both the nuclear and the NGCC power plants. Because of their different load-following strategies constrained by economics which allow turndown of the gas turbine system but not the nuclear reactor, replacing the NGCC power plant with a nuclear power plant increases the net power output from 14-98 MW to $98-200 \mathrm{MW}$. If the $200 \mathrm{MWe}$ NGCC plant were replaced by a $100 \mathrm{MWe}$ nuclear plant, then the net power output would be similar, eliminating the need for additional power transmission capacity from the site of this possible first plant.

\subsection{Financial Evaluation of Hybrid Synfuel Cases}

\subsubsection{Cost Calculation for the Conventional Gas-to-MTG Plant}

The economic performance of the four design cases just discussed is determined in this and the next several sections. To reiterate, the cases are

- a conventional, nonnuclear natural gas to gasoline plant as the reference plant based on current technology,

- a natural gas to gasoline plant that uses a light water small modular nuclear reactor in steady state cogeneration mode to supply process heat and electricity,

- the same plant configuration as case 2 but operated in dynamic hybrid fashion, diverting a fraction of its heat output as electricity to a wind farm to reduce the variability of its generation at the cost of somewhat lower synfuel production, and

- the same operating strategy as case 3 , but with the small modular reactor replaced by a natural gasfired combined cycle plant to produce heat and electricity.

This last case has a much lower capital cost and no need for NRC licensing. It is therefore a lower risk system that could be built and operated much sooner than a nuclear system.

Figure 19 presents the internal rate of return for operation of a conventional nonnuclear natural gas to gasoline process under these assumptions as a function of gasoline selling prices at different natural gas prices. Each $\$ 2$ per MMBTU increase in the price of natural gas requires a $\$ 0.43$ per gallon increase in the selling price of gasoline to maintain the same return. This selling price is at the factory gate and does not include distribution costs, dealer markups, or taxes which add $\$ 0.75-1.00$ per gallon.. The historic proportionality of gasoline production cost to the cost of crude oil is shown in the figure. The likelihood of obtaining the highest returns shown corresponds to the likelihood of oil prices above $\$ 140 / \mathrm{barrel}$.

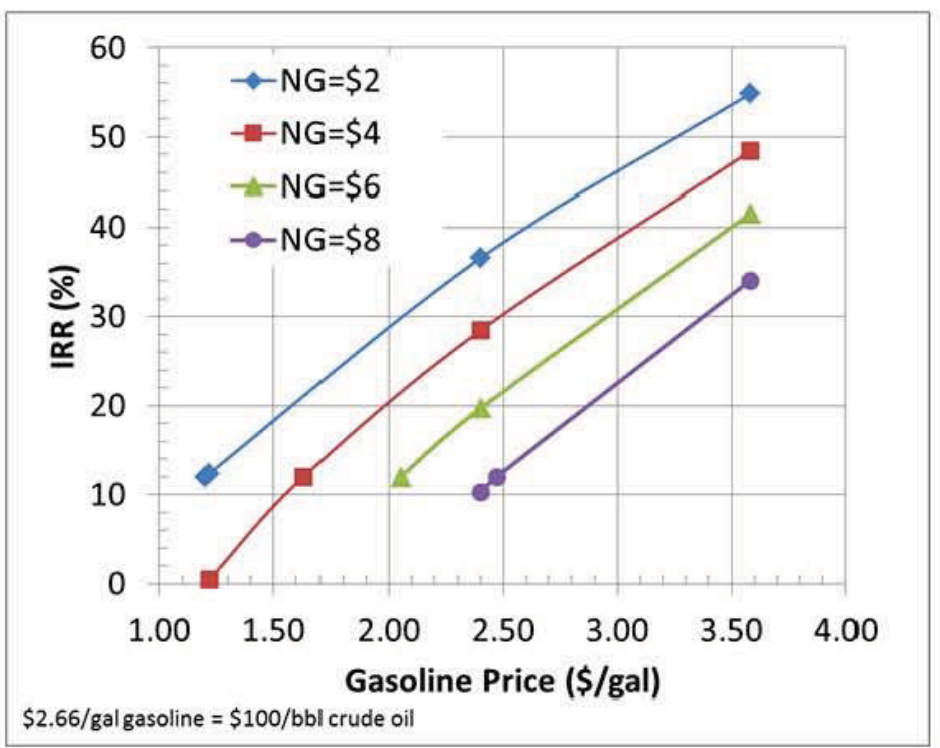

Figure 19. IRR vs. gasoline selling price for the conventional natural gas-to-MTG plant. 


\subsubsection{Cost Calculation for the Steady State Nuclear-integrated Gas-to-MTG Plant}

\subsubsection{Assumptions for the Modified Plant}

The nuclear-integrated gas-to-MTG plant has the same plant capacity as the conventional gas-toMTG plant, 10,000 bbl/day gasoline production. Because of the nuclear heat source, the 8.6 MMSCFD of natural gas used for providing heat to the primary reformer in the conventional case (Appendix B-1) is not required. In addition, the new case includes recycle of purge gases from the synthesis sections into the reformer so their carbon value can be recovered as more syngas, rather than being burned to generate heat which in the new case comes from the nuclear system.

The conventional gas-to-MTG process, although a net power importer, generates approximately 19 MW of electricity from the steam produced by the hot secondary reformer effluent (scaled from results in [INL 2010]). In the light water nuclear-heated system, that effluent preheats the reformer feeds with the process steam now being made by nuclear heat. The amount of steam made is set by how much the process needs, not by the large amount of heat to be removed while cooling the reformer effluent, so there is little excess steam to be used for power generation. However, the total electricity consumed by the plant, neglecting the small power reduction because no feed of combustion air is needed in the nuclear case, is approximately the same in both cases. The result is that the net electricity needed is $41.2 \mathrm{MW}$ for the nuclear-integrated case rather than $29 \mathrm{MW}$ required in the conventional case (scaled-down numbers from [INL 2010]). The smaller steam turbine needed in this scenario reduces the capital cost for the synfuel plant by about $\$ 10$ million when it is integrated with a nuclear reactor (which is costed separately). These changes were incorporated into the economic model to calculate the IRR for the nuclear-assisted case.

\subsubsection{Cost Estimates for Nuclear Electricity and Heat}

The integration of the nuclear plant with the rest of the hybrid energy system is through the supply of heat and power. Many independent sources have estimated the cost of producing electrical power using nuclear reactors. At the level of this analysis, there is no need to recreate those results. Table 9 shows several estimates for the levelized cost of electricity produced by nuclear technology, coal, natural gas and onshore wind. The levelized cost of power is the fixed value at which all the plant's electrical output over its economic lifetime must be sold to cover all construction, operating, and other costs and to produce the required financial return (an example calculation appears in Appendix B-2). This cost of electricity can be used to estimate the cost of heat from the same system by using the overall thermal efficiency of a nuclear plant, typically $33-34 \%$ for a light water reactor, to equate the cost of producing one unit of power to the cost of producing the three units of heat used to make that power. As long as the nuclear system is paid for one unit of power or the equivalent amount of heat at the rate determined by the levelized cost calculations, its costs including a return to the project owners will be covered. 
Table 9. Estimates for the levelized costs of electricity based on literature data.

\begin{tabular}{|c|c|c|c|c|c|c|}
\hline \multirow[b]{2}{*}{ Source } & \multicolumn{6}{|c|}{ Levelized cost of electricity (cents/ $\mathrm{kWh}$ ) } \\
\hline & Nuclear & Coal & Coal-CCS & NG & NG-CCS & Wind (onshore) \\
\hline $\begin{array}{l}\text { Calculation based on INL } 2009 \text { and INL } 2012 \\
\text { (Appendix B-2) }\end{array}$ & 4.5 & & & & & \\
\hline $\begin{array}{l}\text { 1,300MWe Generation III thermal reactor } \\
\text { [INL 2009] }\end{array}$ & 3.1 & & & & & \\
\hline OECD [OECD 2010] & $5.0-8.2$ & & & & & \\
\hline EPRI [NEI 2012] & $7.6-8.7$ & $5.4-7.3^{1,2}$ & $8.5-10.5^{1.3}$ & $4.9-7.9^{2,11}$ & $6.8-10.9^{3}$ & $7.3-13.4^{3}$ \\
\hline MIT [NEI 2012] & $6.6-8.4$ & 6.2 & $8.3^{4}$ & 6.5 & $7.5^{4}$ & \\
\hline EIA $[\text { NEI } 2012]^{5}$ & $10.97-12.14$ & & $12.63-15.45$ & $6.0-7.41$ & $8.08-10.4$ & $9.7-11.54$ \\
\hline NRC [NEI 2012] & $6.0-13.0$ & $5-9$ & $9-15$ & & & $4-10$ \\
\hline NEI [NEI 2012] & $8.4-9.1$ & $7.5^{7}$ & $10^{7}$ & $5.6-7.0^{8}$ & $7.4-8.8^{8}$ & \\
\hline NEA [NEA 2010] & $4.9^{6}$ & $7.5^{6,9}$ & $6.8^{6}$ & $7.7^{6,10}$ & $9.2^{6,10}$ & $4.8^{6}$ \\
\hline \multicolumn{7}{|l|}{ 1: includes PC and IGCC } \\
\hline \multicolumn{2}{|l|}{ 2: projected for 2015} & \multicolumn{5}{|c|}{ 8: NGCC, assuming $\$ 4$ and $\$ 6$ as natural gas cost } \\
\hline \multicolumn{2}{|l|}{ 3: projected for 2025} & \multicolumn{5}{|l|}{ 9: IGCC } \\
\hline \multicolumn{2}{|l|}{$4: \$ 25 / \mathrm{tCO} 2$} & \multicolumn{5}{|l|}{ 10: CCGT } \\
\hline \multicolumn{2}{|l|}{$5: 2009 \$$ for plants entering service in 2016} & \multicolumn{5}{|l|}{ 11: NGCC } \\
\hline $6: 5 \%$ discount rate & & & & & & \\
\hline
\end{tabular}

These power cost estimates have a wide range, about a factor of three, because of different assumptions regarding plant size, capital cost, financial parameters including the year into which the costs are projected, plant availability, operating costs, contingencies, first-of-a-kind or $\mathrm{n}^{\text {th }}$-of-a-kind technologies, etc. The estimates for the levelized cost of electricity generated from nuclear energy range from 3 to 13 cents $/ \mathrm{kWh}$ with most in the range 6 to 9 cents $/ \mathrm{kWh}$. Small modular reactors, because of their new technology and lack of economies of scale, are expected to be at or beyond the upper end of the range, especially if used as single or dual units rather than in larger numbers at each site. The costs given are competitive with electricity generated by onshore wind or fossil fuel plants, particularly if carbon dioxide capture and sequestration is required in the future (Figure 20). The levelized costs of electricity generated by nuclear plants and onshore wind both have a wide range but are comparable.

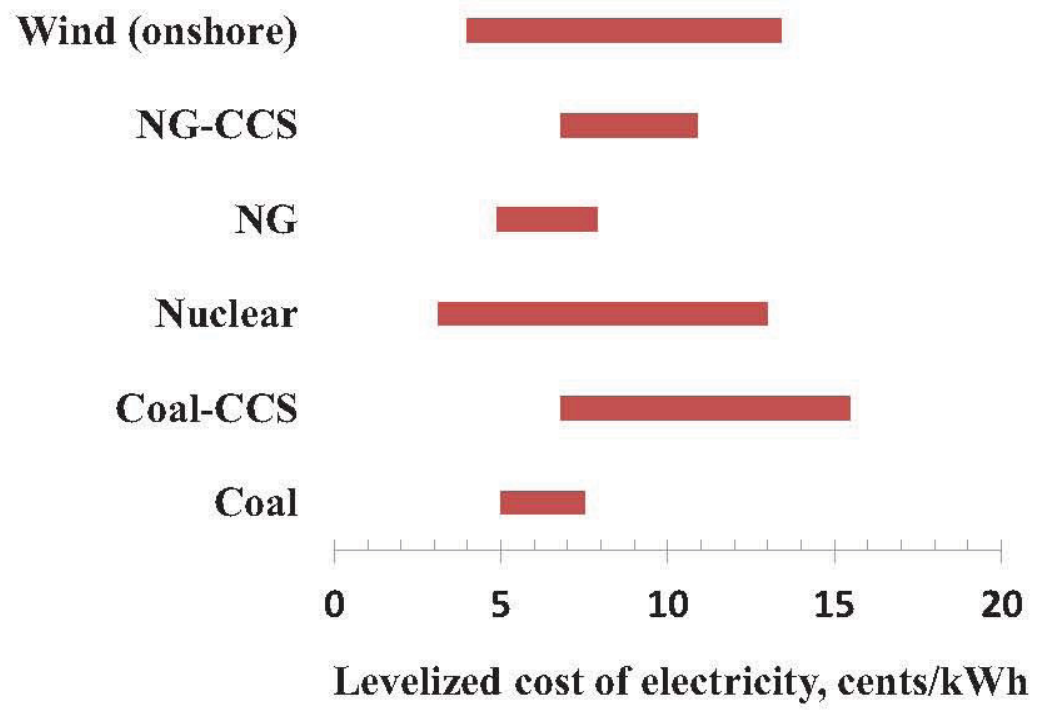

Figure 20. Ranges of levelized costs of electricity for coal, gas, nuclear and onshore wind power plants. 
Based on the range of estimated costs, the financial analysis uses three alternative prices for the levelized cost of nuclear electricity: 4,8 , and 12 cents $/ \mathrm{kWh}$. Assuming $33 \%$ efficiency for the Rankine cycle used with light water reactors, these values are equal to $1.32,2.64$, and 3.96 cents $/ \mathrm{kWh}$ thermal energy. Because the levelized cost of electricity calculations assume base load operation and high availability of the nuclear power plant, for these heat costs to be valid the reactor must operate at high rates and almost continually whether producing power, heat, or a combination of them.

\subsubsection{Economic Comparison of Conventional and Nuclear-integrated Natural Gas-MTG Processes}

Figure 21 shows IRR versus gasoline selling prices for natural gas prices of 4 and 8 \$MSCF, respectively. The data indicate that the nuclear-integrated cogeneration case is generally competitive with the conventional case over a range of nuclear heat prices which can be extrapolated if nuclear heat from a single small modular reactor is more expensive than shown. This result occurs because the cost of energy for process heat is not the major component of final product cost. At the level of a $12 \%$ IRR, the nominal minimum attractive case, differences in the cost of nuclear heat lead to relatively small differences in the required gasoline selling price. All cases have attractive returns at gasoline prices above about $\$ 1.70$ per gallon or $\$ 2.30$ per gallon with natural gas prices of 4 or 8 \$MMSCF respectively.

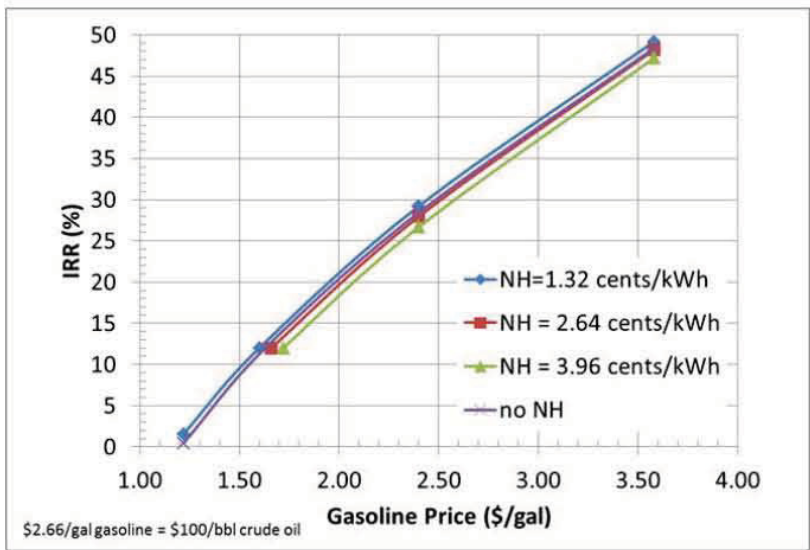

(a)

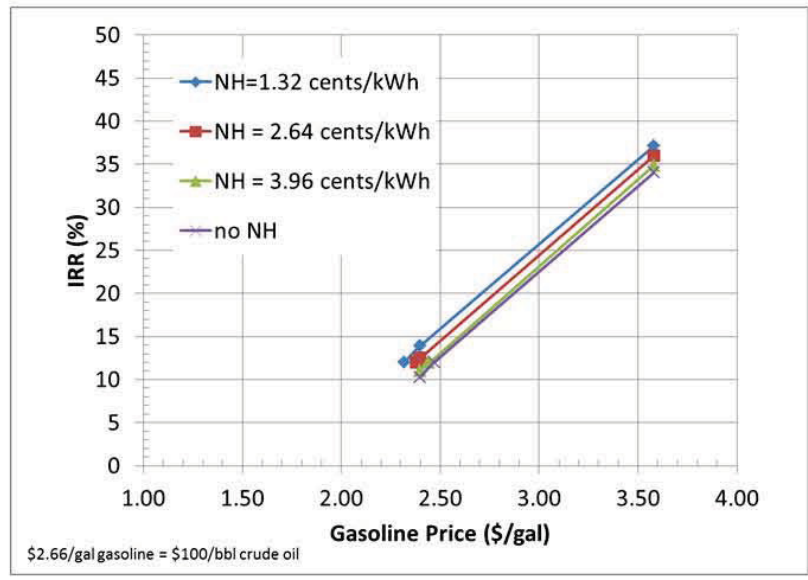

(b)

Figure 21. IRR vs gasoline selling price for different nuclear heat $(\mathrm{NH})$ costs, at a natural gas price of \$4/MSCF (a) and \$8/MSCF (b).

\subsubsection{Hybrid System Supplying Both Heat and Variability-Reducing Power}

The previous section evaluated a nuclear-integrated natural gas-to-MTG plant with the chemical plant operating at steady state, i.e., always receiving nuclear heat and running at full rates. This section considers a hybrid system in which the nuclear plant also provides electricity to the electric grid to compensate for the variability of a wind farm. In this scenario the natural gas-to-MTG plant will not receive steam constantly, but only at times the electricity is not required to address wind's variability. Chapter 3 describes such a system further and gives estimates under different assumptions of what percentage of the nuclear heat output is sent to the chemical plant

In determining the economics of such a system, the fraction of its thermal output that the nuclear reactor sends to power production to stabilize wind output sets the fraction of output that the synfuel plant does not manufacture. This is equivalent to availability, although reduced availability is usually attributed to mechanical or operations problems. The availability of the conventional plant was assumed to be $92 \%$ and this value is retained for the baseline mechanical availability. In addition, the loss of availability attributable to smoothing wind generation (see Figure 15) must be incorporated. Adroit scheduling based 
on weather forecasts and projected wind farm operation would conduct some part of the synfuel plant's planned shutdowns for minor maintenance during periods when no heat will be coming from the nuclear plant. If the tolerable rate of change of the combined wind and nuclear electricity output of the example system is 10 MWe per hour (see Chapter 3),the nuclear plant would send $80.3 \%$ of its heat to the chemical plant. The other $19.7 \%$ sent to the wind farm would not necessarily subtract directly from the baseline $92 \%$ synfuel plant availability to give $72.3 \%$ annual availability; that would be the worst possible operation with no maintenance being done during these energy supply downtimes.

Bracketing the range of possible outcomes, Figure 22 shows data for 92,82 and $72.3 \%$ plant availability. As in the earlier cases gasoline prices of 2.00-2.50 dollars per/gallon produce acceptable returns, with higher availabilities producing better results. The results for $92 \%$ availability are slightly better than the conventional natural gas to gasoline case because the hybrid cases include recycle of purge gas to the reformer, decreasing the amount of natural gas feed needed. Lower values of synfuel plant availability require higher gasoline prices to achieve the same IRR.

It should also be noted that mitigating the variability of wind power generates a value which might be partially captured by the hybrid system. Chapter 3 calculates a potential cross-subsidy of $\$ 3.2$ per MWh thermal energy (or $0.32 \mathrm{cent} / \mathrm{kWh}$ ) assuming a wind premium of 1.5 cents per $\mathrm{kWh}$. Applying this subsidy to the assumed cost estimates for nuclear heat gives net costs of $1.0,2.32$, and $3.64 \mathrm{cents} / \mathrm{kWh}$. A cost for nuclear heat of 2.32 cents/kwh and a cost of natural gas of \$6/MSCF were assumed in Figure 22.

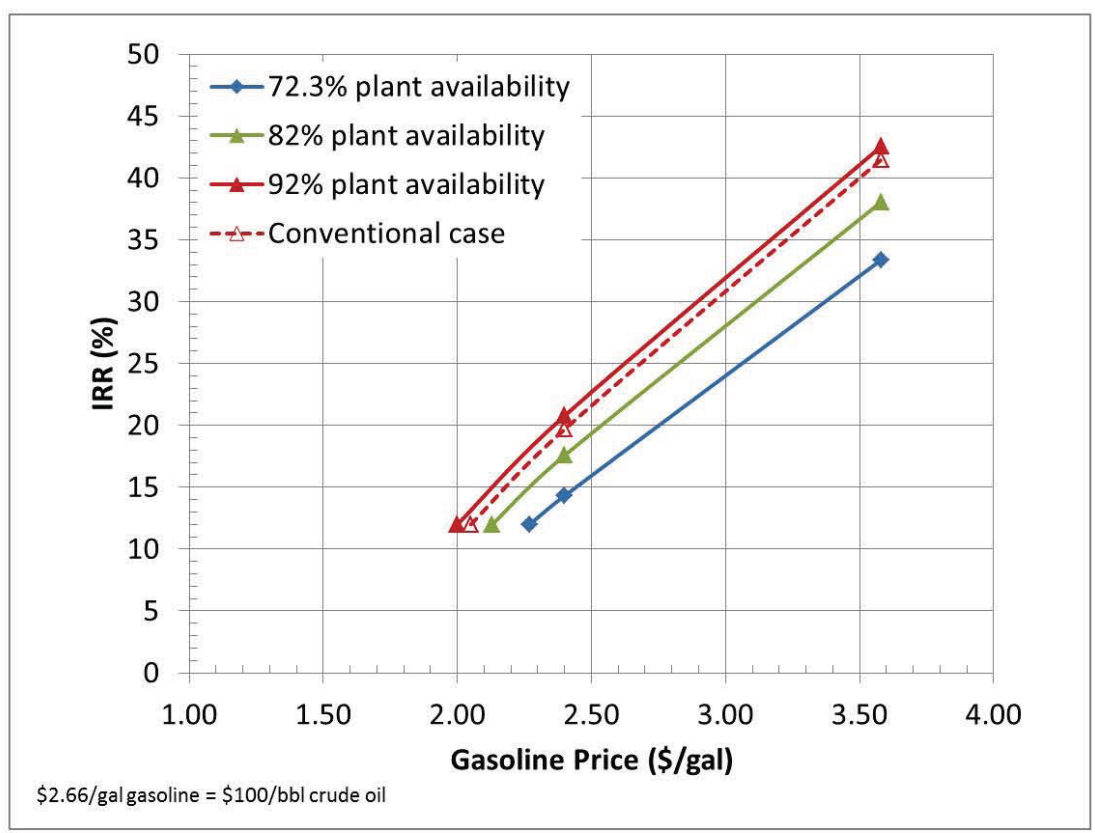

Figure 22. IRR versus gasoline price for different plant availabilities of a nuclear hybrid energy system (\$6/MSCF natural gas, 2.32 cents/kWh nuclear heat, 92\% plant availability for the conventional case).

\subsubsection{Cost Calculation for the NGCC-integrated Gas-to-MTG Plant}

This case represents a likely initial form of hybrid energy system. A nuclear-heated system involves a number of novel system interconnections as well as the use of a small modular reactor, none of which have been licensed or built. To simplify the design and operation of the overall project while allowing time, perhaps ten years, for the small modular reactor technology to reach commercial readiness and perhaps the lower costs of $n^{\text {th }}$ of a kind status, it might be attractive to build a hybrid energy system with natural gas-fired steam generation. This section evaluates the economics of that option.

A natural gas combined cycle (NGCC) plant without carbon sequestration can produce electricity at a predicted cost of about $6.8 \mathrm{cent} / \mathrm{kWh}$ on the basis of the cost estimates in Table 9 . This cost depends on 
the price of the natural gas. OECD 2010 estimates a levelized cost of electricity of $\sim 8$ cent $/ \mathrm{kWh}$ for a natural gas price of \$7.8/ MSCF. The Nuclear Energy Institute 2012 provides estimates for the levelized cost of electricity of $5.6 \mathrm{cent} / \mathrm{kWh}$ and 7.0 cent $\mathrm{kWh}$ for natural gas prices of $\$ 4 / \mathrm{MSCF}$ and $\$ 6 / \mathrm{MSCF}$, respectively. Based on this information this analysis assumes levelized costs of electricity of 5.6, 7.0 and $8.0 \mathrm{cent} / \mathrm{kWh}$ for natural gas prices of $\$ 4, \$ 6$ and $\$ 8 / \mathrm{MSCF}$, respectively.

These values can be used to predict the cost of the steam that the natural gas-to-MTG plant receives from the NGCC plant. To estimate these costs the efficiency of the power conversion cycle has to be evaluated. A representative value of thermal efficiency of an NGCC plant is $52 \%$, leading to heat costs at the heat recovery steam generator of $2.91,3.64$ and 4.16 cent $/ \mathrm{kWh}$, respectively. In the absence of a complete design of the turbine train, it is assumed that about $20 \%$ of the total power generated (in poweronly mode) is extracted from the first stage of expansion ahead of any reheat before the second stage turbine. The steam after the first stage, that is the steam that goes to the synfuel plant, is then worth only $80 \%$ of the highest steam price. This leads to values of $2.33,2.91$, and $3.33 \mathrm{cent} / \mathrm{kWh}$.

As this system facilitates wind generation there is an assumed $\$ 3.2$ per MWh heat cross-subsidy yielding cost estimates for the steam supplied by the NGCC of $2.01,2.59$ and $3.01 \mathrm{cents} / \mathrm{kWh}$ for the three natural gas prices used. The subsidy is small compared to the range of these estimates. When integrated with an NGCC plant, the chemical plant is expected to run at a nominal $82 \%$ availability as discussed for the nuclear hybrid system. The only difference is the cost of the thermal energy, 1.32-3.96 cents/ $\mathrm{kWh}$ for the nuclear-integrated case and 2.01-3.01 cents/kWh for the NGCC-integrated case, depending on the cost for natural gas. Figure 23 shows an economic advantage of the conventional, nonhybrid case over the NGCC-integrated case for all natural gas prices chosen. To understand this economic advantage the effects of synfuel plant availability are shown in Figure 24 . The data indicate that the lower plant availability is the main cause leading to the economic favorability of the conventional case. Slight differences between the conventional case and the NGCC case at $92 \%$ availability may be due to the several assumptions used to estimate the cost of the steam provided by the NGCC plant. The less attractive projection of NGCC economics should be weighed against the value of gaining experience operating a hybrid energy system and the value of enabling a future nuclear hybrid energy system.

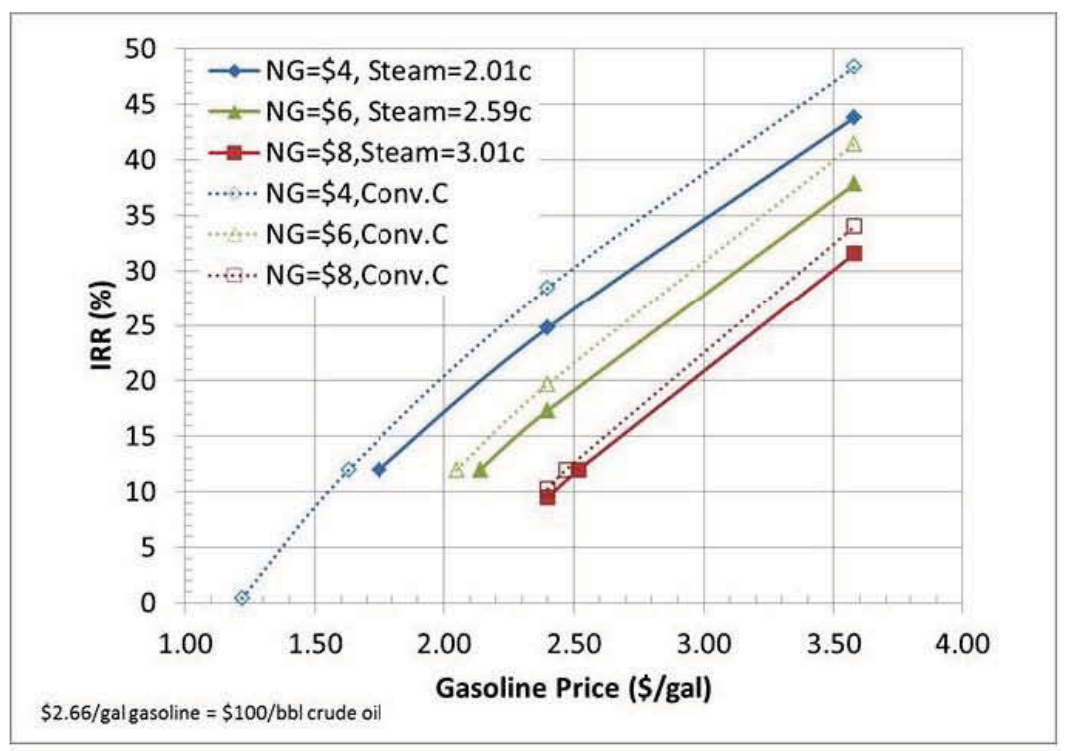

Figure 23. IRR versus gasoline price for different natural gas prices for the conventional case and the NGCC-integrated process. 


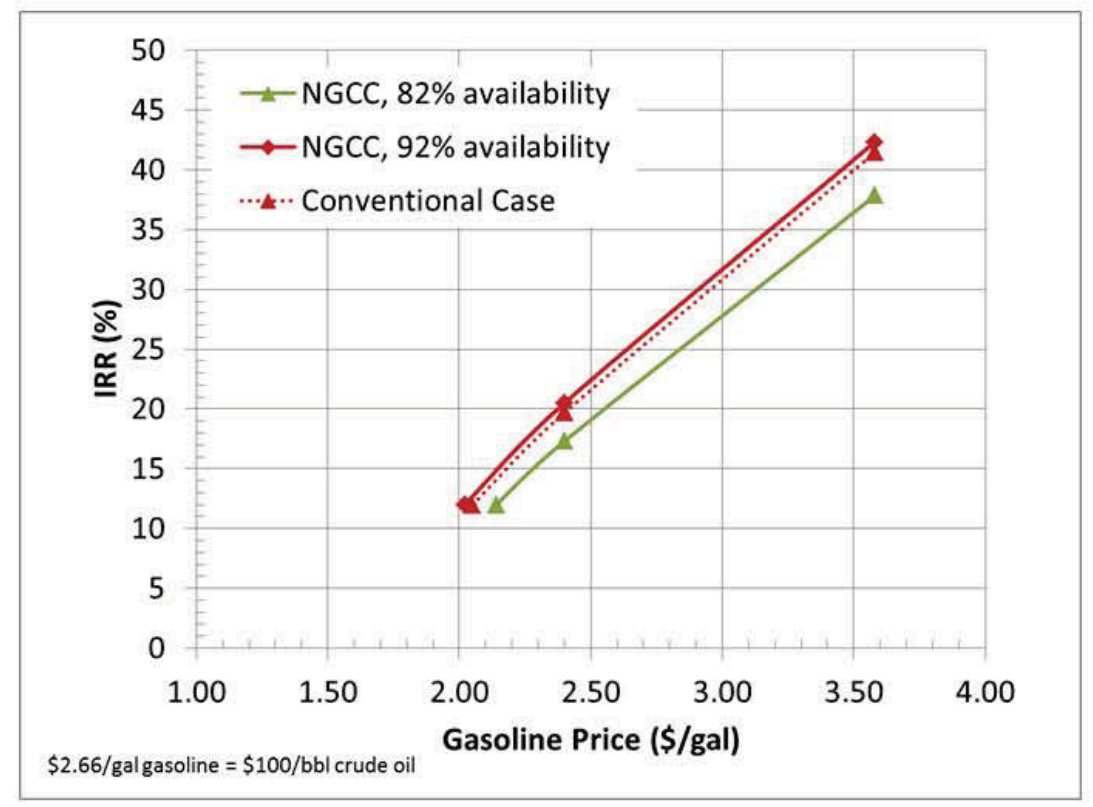

Figure 24. IRR versus gasoline price for the conventional case, the NGCC-integrated process assuming 92 and $82 \%$ plant availability (Natural gas price $\$ 6 / \mathrm{MSCF}$, cost of steam $2.59 \mathrm{cent} / \mathrm{kWh}$ ).

\subsubsection{Carbon Tax Considerations}

The previous sections evaluated the costs for the conventional, nuclear-assisted, nuclear hybrid and NGCC hybrid natural gas-to-MTG system in the absence of a possible tax or other penalty for $\mathrm{CO}_{2}$ emissions. This section analyzes the consequences of a carbon tax ranging from $\$ 25$ to $\$ 100$ per ton of $\mathrm{CO}_{2}$ on the $\mathrm{CO}_{2}$ released by the different natural gas-to-MTG plants (Table 10).

Table 10. Amount of $\mathrm{CO}_{2}$ released by the various systems.

\begin{tabular}{|c|c|c|c|c|}
\hline & $\begin{array}{c}\text { Conventional } \\
\text { case }\end{array}$ & $\begin{array}{c}\text { Nuclear-assisted } \\
\text { case }\end{array}$ & $\begin{array}{c}\text { Nuclear hybrid } \\
\text { case }^{\mathrm{a}}\end{array}$ & $\begin{array}{c}\text { NGCC-hybrid } \\
\text { case }^{\mathrm{a}}\end{array}$ \\
\hline $\mathrm{CO}_{2}$ [MMSCFD] & 16.5 & 0.4 & 0.356 & 19.4 \\
\hline $\mathrm{CO}_{2}[$ ton $/$ day $]$ & 834 & 22.2 & 19.8 & $951^{b}$ \\
\hline
\end{tabular}

Figure 25 shows the required gasoline selling price as a function of the carbon tax to obtain an IRR of $12 \%$ at an average natural gas price of $\$ 6$ per MSCF. The values for heat cost were derived in the previous sections. Figure 25 shows that the required gasoline prices are almost constant for the system utilizing nuclear heat since it emits only very small amounts of $\mathrm{CO}_{2}$. The conventional natural gas-toMTG plant and the NGCC hybrid plant show an increase in required gasoline selling price with increasing carbon tax, as expected. At carbon taxes above $\$ 35 /$ ton $\mathrm{CO}_{2}$ the nuclear hybrid system with availability of $82 \%$ becomes economically more attractive than the conventional case with $92 \%$ availability. The NGCC hybrid case is less economically attractive than the conventional case because of the resulting lower availability of the synfuel plant. Nonetheless, it is still a profitable enterprise at gasoline selling prices (at the factory gate) of $\$ 2.14-2.43$ per gallon depending on the carbon emission penalty. 


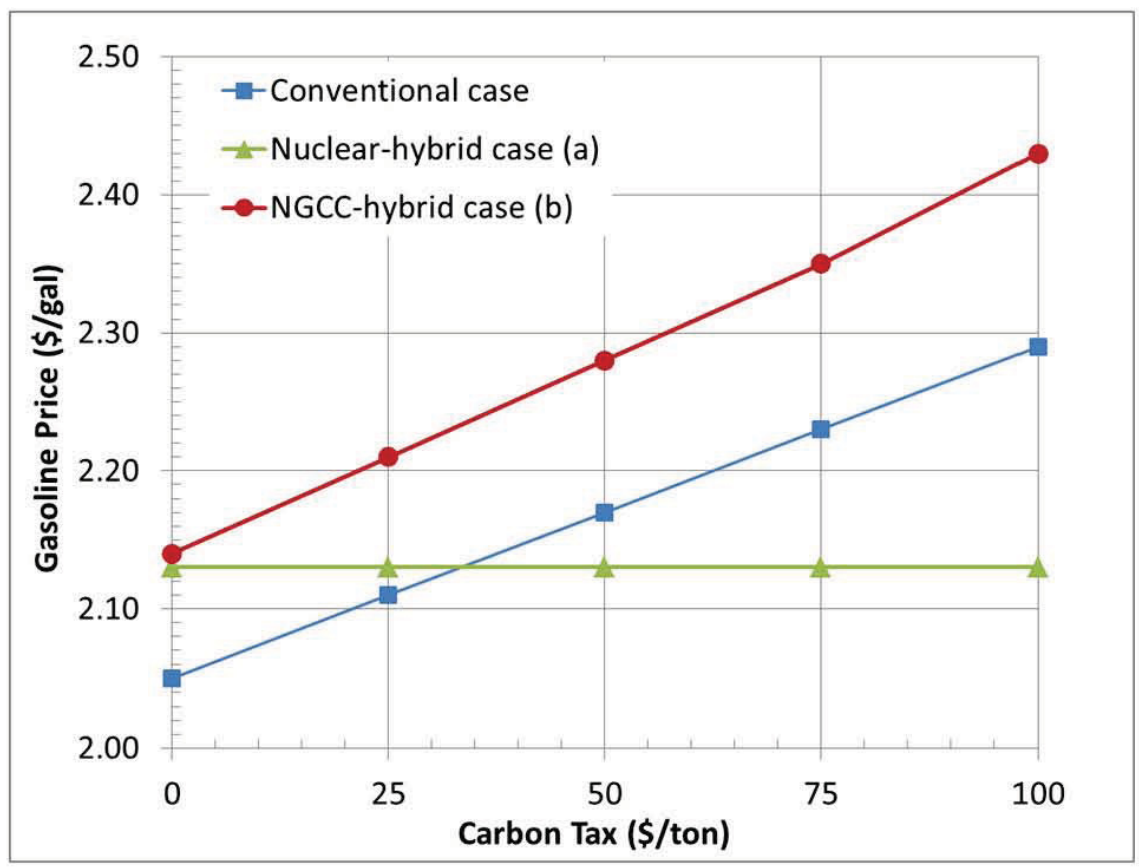

Figure 25. Gasoline price versus carbon tax for different hybrid energy systems. The plot assumes $12 \%$ IRR and \$6/MSCF natural gas. Operating conditions were (a) $82 \%$ plant availability, steam cost 2.32 cents $/ \mathrm{kWh}$, and (b) $82 \%$ plant availability, steam cost 2.59 cents $/ \mathrm{kWh}$.

\subsubsection{Summary of Economic Analysis}

The economic feasibility of four different design cases for a natural gas-to-MTG plant was evaluated:

- a conventional natural gas-to-MTG

- a nuclear-assisted natural gas-to-MTG process where nuclear heat is continuously supplied to the synfuel plant at full rate

- a nuclear hybrid system in which a fraction of the nuclear energy is used to provide electricity to the electric grid to mitigate the variability of a wind farm resulting in (1) a lower availability of the synfuels plant and (2) a potential cross-subsidy of $\$ 3.2$ per MWh thermal energy assuming a wind premium of 1.5 cents per $\mathrm{kWh}$

- a NGCC hybrid system where a fraction of the gas-fired energy is used to provide electricity to the electric grid to mitigate the variability of a wind farm resulting in (1) a lower availability of the synfuels plant and (2) a potential cross-subsidy of $\$ 3.2$ per MWh thermal energy assuming a wind premium of 1.5 cents per $\mathrm{kWh}$

The Internal Rate of Return was utilized to compare the economic performance of these systems. Table 11 presents the main results at a target IRR of $12 \%$, average natural gas price of $\$ 6 / \mathrm{MSCF}$, and price of nuclear heat of $2.64 \mathrm{cent} / \mathrm{kWh}$ for the nuclear-assisted case, $2.32 \mathrm{cent} / \mathrm{kWh}$ for the nuclear hybrid case (includes a wind premium) and $2.59 \mathrm{cent} / \mathrm{kWh}$ for the NGCC hybrid case (with a wind premium). 
Table 11. Natural gas-to-MTG economic results summary for an IRR of $12 \%$ and an average natural gas price of $\$ 6 / \mathrm{MSCF}$.

\begin{tabular}{|l|c|c|c|}
\hline & \multicolumn{3}{|c|}{ Required gasoline price, \$/gal } \\
\hline Technology & $\mathrm{No} \mathrm{CO}_{2}$ tax added & $\$ 50 /$ ton $\mathrm{CO}_{2}$ tax & $\$ 100 /$ ton $\mathrm{CO}_{2}$ tax \\
\hline Conventional MTG & 2.05 & 2.17 & 2.29 \\
\hline Nuclear-assisted MTG & 2.02 & 2.02 & 2.03 \\
\hline Nuclear Hybrid MTG & 2.13 & 2.13 & 2.13 \\
\hline NGCC-hybrid MTG & 2.14 & 2.28 & 2.43 \\
\hline
\end{tabular}

These results suggest that the production of gasoline from natural gas represents an economically attractive process taking into consideration that the average US gasoline price was between $\$ 3.3-4.0$ / gallon throughout 2011 (EIA 2012). The state of Wyoming could turn its natural gas into a valuable product, gasoline, utilizing a gas to liquid process. The estimated gasoline prices required to achieve an IRR of $12 \%$ in this study are competitive with current US gasoline prices, indicating that all of the alternative processes studied are economically viable options. The nuclear-assisted process which continuously provides heat to the natural gas-to-MTG plant represents the most desirable alternative system at higher natural gas prices or when carbon taxes are taken into consideration. The nuclear hybrid and NGCC hybrid plants increase in economic profitability with increasing synfuels plant availability suggesting that the allowable ramp rate while mitigating wind variability (see Figure 15) has to be optimized so heat can be provided to the natural gas-to-liquids plant as frequently as possible.

While Table 11 indicates that a conventional gas to liquids process is less expensive to operate than an NGCC-assisted hybrid system, the latter case has the value of demonstrating the integration of the nonnuclear parts of a hybrid system and allowing for future conversion to a nuclear-assisted hybrid system when that technology is ready and if carbon emission taxes become significant costs.

These results are dependent on what nuclear system is used and especially its costs as reflected in the levelized cost of electricity. Heat is needed at a modest temperature of only $300{ }^{\circ} \mathrm{C}$ and this is available from light water reactors or many other types. The only requirement for financial feasibility is that the levelized cost of electricity (or, actually, the levelized cost of heat) be acceptable and that the system be able to produce and deliver the $80-90 \mathrm{MW}$ of steam necessary for a $10,000 \mathrm{bpd}$ plant.

\subsection{Direct Use of Wind Energy for Oxycombustion}

Although there are significant technical issues to be resolved before wind energy might be used to drive a commercial-scale air separation unit, this section assumes success and estimates the size of an installation retrofitted onto a $700 \mathrm{MWe}$ coal-fired power plant.

In an oxycombustion system, essentially pure oxygen ( $>95 \%)$ is used to burn coal in a boiler. The resulting flue gas contains primarily carbon dioxide and water vapor, with trace amounts of other species derived from sulfur, nitrogen, and other contaminants in the coal. This flue gas does not contain the large fraction of nitrogen that results when air is used for the combustion. Consequently, when the flue gas is cooled and the water vapor condenses, a stream of high concentration $\mathrm{CO}_{2}$ is left. This can be compressed and sent to an enhanced oil recovery site or a permanent $\mathrm{CO}_{2}$ storage site. To prevent excessive temperatures in the boiler when using pure oxygen, part of the product $\mathrm{CO}_{2}$ is recycled there to absorb some of the combustion heat, analogous to the role that nitrogen plays in conventional boilers. This type of $\mathrm{CO}_{2}$ capture system avoids the equipment and operating costs of conventional amine systems.

A $700 \mathrm{MWe}$ coal-fired power plant with a typical value of heat rate (a measure of thermal efficiency) of $10,000 \mathrm{BTU} / \mathrm{kWh}$ burns about 9550 ton/day of Wyoming coal (heating value $8800 \mathrm{BTU} / \mathrm{lb}$ ). Oxycombustion of this amount of coal would require 12,500 ton/day of oxygen. Using a power 
requirement value of $1.42 \mathrm{MW} /\left(\mathrm{kg} / \mathrm{s} \mathrm{O}_{2}\right)$ for an air separation unit modeled in [Wood 2010],187 MWe is required for the cryogenic separation, primarily for compressing the air fed into the unit.

This power is assumed to be obtained from a wind farm rather than being taken from the power plant's own output. Because that wind power is variable, the air separation unit must be oversized so it can produce an average of 12,500 ton/day of oxygen, accounting for the fraction of time the wind farm is generating. While annual average wind availability can be $40 \%$ or more in some places in Wyoming, a year's worth of oxygen storage seems impractical. Instead, if 2-4 weeks is a more realistic amount of storage and long enough to average the weather reliably, then the allowable inventory swing plus the wind availability during the statistically worst 2-4 weeks of the year must be considered. Taking that availability as $30 \%$, the wind farm must have a capacity of $623 \mathrm{MW}$ to average $187 \mathrm{MW}$ over those $2-4$ weeks. This is nearly the size of the coal plant and is dedicated solely to powering the air separation plant.

This $700 \mathrm{MW}$ coal-fired plant and air separation unit would generate about 17,200 ton/day of $\mathrm{CO}_{2}$ and 41,100 ton/day of nitrogen which can also be used for EOR. Air separation plants dedicated to making nitrogen for EOR have been used for a number of years [Air Products 2012]. The combined amount of the two EOR gases, calculated on a molar (volume) basis rather than by weight, is equivalent to 81,800 ton/day of $\mathrm{CO}_{2}$ from this one combined facility. However, the nitrogen and carbon dioxide would be sold separately by the air separation and power plants. While the $\mathrm{CO}_{2}$ from the power plant would be produced at a steady rate, the nitrogen would be as variable as wind power generation and would require a large storage capacity.

Wyoming has about $6500 \mathrm{MW}$ of coal-fired power plants (Figure 2). If one third of that capacity (about three $700 \mathrm{MWe}$ plants) is retrofitted with oxycombustion systems to capture their $\mathrm{CO}_{2}$ while allowing continued operation, about $1900 \mathrm{MW}$ of wind generation capacity would be required. This would require $800-1000$ turbines in this service, although they need not all be new installations if existing wind turbines are used for this purpose. This amount of wind generation could be distributed across the state, supplying power to one central or several smaller air separation facilities which in turn supply the power plants. An oxygen distribution pipeline might let a central facility capture economies of scale. A pipeline system would also allow just one set of gas storage caverns to be located optimally to serve all the air separation and power plants.

This total amount of oxycombustion would generate 251,000 ton/day $\mathrm{CO}_{2}$ equivalents of EOR gas. The long term ability of Wyoming's oil reservoirs to utilize this much EOR gas, or even just the $\mathrm{CO}_{2}$ fraction of it since nitrogen can be released to the atmosphere, must be established. If there is sufficient use in oil fields, a pipeline network to distribute the nitrogen across Wyoming and to neighboring states (similar to the syngas and $\mathrm{CO}_{2}$ pipelines of section 2.3.3) might be justified.

There is not sufficient information to do a detailed economic analysis, but order of magnitude calculations show some promise for this idea. For a facility sized at 41,700 ton/day oxygen (to make 12,500 ton/day at $30 \%$ availability) for a $700 \mathrm{MWe}$ coal plant, capital cost in 2011 dollars of an air separation plant is $\$ 387$ million (scaled using six-tenths exponent rule and updated to 2011 costs using data from [NETL 2007]). Construction and operation of the wind farm and the oxycombustion unit on the power plant are considered to be separate activities whose effect on the air separation project can be represented by the price of the gases or power sold between the projects. Table 12 shows a cost breakdown. Although the current cost of $\mathrm{CO}_{2}$ for $\mathrm{EOR}$ is about $\$ 20 /$ ton, Table 12 uses $\$ 10 /$ ton under the assumption that the large amount of $\mathrm{CO}_{2}$ and nitrogen will depress the market price, especially if several of these air separation facilities are built. The net $\$ 78.4$ million of annual income offers an attractive $20 \%$ pretax simple return on the cost of the air separation plant. 
Table 12. Projected costs of air separation for oxycombustion

\begin{tabular}{|l|l|c|}
\hline \multicolumn{1}{|c|}{ Cost category } & \multicolumn{1}{|c|}{ Basis } & \multicolumn{1}{|c|}{$\begin{array}{c}\text { Annual revenue } \\
\text { (\$million) }\end{array}$} \\
\hline Capital changes & $12 \%$ of capital/year & $(46.5)$ \\
\hline Operations and Maintenance & $6 \%$ of capital/year & $(23.2)$ \\
\hline Power cost $\left(@ 1.42 \mathrm{MW}\right.$ per $\left.\mathrm{kg} / \mathrm{s} \mathrm{O}_{2}\right)$ & $\$ 100 / \mathrm{MWh}$ for wind power & $(147.4)$ \\
\hline Oxygen sales & $\$ 20 /$ ton & 82.5 \\
\hline Nitrogen sales for EOR & $\$ 10 /$ ton $\mathrm{CO}_{2}$ molar equivalent & 213.0 \\
\hline Net income & \multicolumn{2}{|c|}{} \\
\hline
\end{tabular}




\section{BUSINESS ISSUES}

A hybrid energy system, especially one powered by a novel type of nuclear reactor, is a complex system that must consider a variety of nontechnical regulatory and business issues. Some of these are identified and discussed in this chapter.

\subsection{Permitting: Air, Water, Wildlife, and Reactor Licensing}

Permitting of a hybrid energy system or small modular reactor in Wyoming will require a variety of state and federal permits or licenses. This section discusses the local, state, and federal permits that need to be considered to site a hybrid energy system and the licensing requirements for a small modular reactor connected to the hybrid energy system.

At the state level, the Wyoming Department of Environmental Quality (DEQ) is the agency with overall responsibility for the industrial siting, air quality (including NOx, SOx, and particulates, but not $\mathrm{CO}_{2}$ ), solid and hazardous waste, water quality, storm water management, and land quality permits needed. The state Engineer's Office issues permits to appropriate surface or ground water to meet the water requirements of the facility and process. They also address questions about the water rights process. If a facility were planned to be built on state lands the Wyoming Office of State Lands and Investments would need to be contacted for leasing issues. The Wyoming State Historic Preservation office can be consulted during the siting process to avoid locations with historic and cultural resources. Land use planning and zoning, and noise and odor control requirements vary by County and would require contacting the local organizations.

The Wyoming Game and Fish Department manages wildlife and listed Threatened and Endangered $(\mathrm{T}+\mathrm{E})$ species. Of particular interest to state and federal wildlife agencies is the management and protection of sage grouse habitat. The greater sage grouse (Centrocercus urophasianus) is currently listed as a candidate $\mathrm{T}+\mathrm{E}$ species by the U.S. Fish and Wildlife Service. Wyoming has about $54 \%$ of the greater sage grouse population in the United States and is aggressively managing the resource. If the greater sage grouse were formally declared to be threatened, the plant, power transmission, and product pipeline systems would need to be located to avoid habitat important to its survival. The state has high quality GIS coverage of all habitats within the state that should prove valuable during site evaluations to avoid conflicts with sage grouse and other wildlife habitat or migration corridors.

A number of federal agencies would need to be consulted in the siting and permitting of a gas fired (nonnuclear) hybrid energy system. Key agencies include the Environmental Protection Agency (EPA) for greenhouse gas permits; the Army Corp of Engineers for wetland permits; the U.S. Fish and Wildlife

Service for federal T $+E$ species issues; and the Bureau of Land Management (BLM) or other federal land managers if the facility were to be sited on federal lands or if they have transmission or pipelines that cross Federal lands. If the facility were to be located on Federal lands the agency managing those lands would need to develop the documents to ensure compliance with the National Environmental Policy Act.

The relevant State and Federal agencies are experienced in permitting different types of power production systems. Although a hybrid energy system would be different from a typical plant, much of the permitting process should be similar. A recent report produced by the Western Research Institute (McDonough 2012) examined the legal feasibility of siting a small scale modular Wyoming Stranded Gas (WYSG) facility to clean and convert natural gas into liquid fuels such as gasoline or chemical feedstock, similar to a small scale version of a hybrid energy system. This report identifies the appropriate agencies to involve in the permitting process and makes several recommendations that the legislature could consider to enhance the possibility of building and operating a Stranded Gas plant in Wyoming. One of the issues that needs to be better defined is which agency has lead responsibility for $\mathrm{CO}_{2}$ regulation. The state DEQ Air Quality Division could seek to assume primacy over the Point Source Discharge (PSD) program in lieu of EPA doing the regulating and permitting. This point is discussed in more detail in the WYSC reports (McDonough 2012; WRI 2012). The time frame for obtaining permits from the state 
agencies will be on the order of months to a year if public meetings are required for a nonnuclear hybrid energy system using natural gas as its energy source.

If a small modular nuclear reactor were to be part of a more complex hybrid energy system, a license to construct and operate the reactor would need to be obtained from the federal Nuclear Regulatory Commission (NRC). NRC submitted a report to Congress on Advanced Reactor Licensing (U.S. NRC 2012) which outlined the strategy for and approach to preparing to license advanced reactors. NRC includes small modular reactors within their group of advanced reactors. One of the initial steps is to have industry submit their reactor designs to NRC for design certification. The NRC Commissioners have stated their expectations that, at a minimum, the advanced reactors will provide enhanced margins of safety or use simplified, inherent passive, or other innovative means to accomplish their safety and security functions.

NRC's current licensing requirements and processes set forth in 10CFR Part 50 and 10 CFR Part 52 can be used for licensing small modular reactor design and technologies. It would take time to develop the application for a license and NRC would need to develop the documents to address the NEPA process. Because to date no small modular reactors have been licensed by the NRC, obtaining the construction and operating license would likely require the greatest amount of time in the overall regulatory process. NRC has received several pre-application requests for review and expects to receive full applications for staff review as early as in 2013 .

For a typical full scale nuclear reactor the NRC has a well established process. From the time an applicant files an application for a combined construction/operating license (COL) it typically takes about 30-36 months until the final NEPA document is issued. There is a high probability that the timeline for small modular reactors will be about the same or less once NRC has an established process to understand the NEPA and safety issues associated with the new designs.. It is uncertain whether NRC will use a COL for the new small modular reactors. Once application are received by NRC they will use the guidance in the 10 CFR Parts 50 and 52 to make a determination. NRC has undertaken an initiative to streamline its review of new applications by integrating the use of risk insights to create design-specific review plans and standards for light-water small modular reactor design and development (U.S. NRC 2012). If NRC receives high quality design certification applications from vendors they plan to conduct their review in less than 30 months. Once NRC has licensed a few such reactors the time required for the safety and NEPA review will be much better understood.

One important issue in siting and permitting a small modular reactor-hybrid energy system is availability of sufficient cooling and process water. The Wyoming State Engineers Office can address water availability and water right issues. Water needs in the semi-arid conditions of Wyoming need to be carefully planned for as part of the federal NRC licensing process. Under the NRC licensing process, the applicant must identify that adequate supplies of the proper type of water will be available to meet operational and ecological needs under normal and drought conditions.

\subsection{Supply Chain}

Supply chain management for a small modular reactor involves a network of businesses providing product and service packages. For the situation in Wyoming, the supply chain customer will likely be a utility or group of investors willing to invest in a small modular reactor (Rosner and Goldberg 2011) and design it as part of an hybrid energy system.

The challenge of design and construction of a small modular nuclear reactor hybrid energy system is that none have been built to date (Biello 2012). The advantage of a small modular reactor design is that most of the construction can be done off site and the modular parts can be brought to the plant location and installed there. There may be concerns whether enough manufacturers in the U.S. have the required accreditations and certifications to produce the boilers and pressure vessels needed for the reactor. Construction-related procurement of a reactor-powered hybrid plant in Wyoming will have to compete with the global demand for similar products. As the use of small modular reactors increases, the demand 
for these components will also increase. The long lead times for components of small modular reactor will require that the design team be aware of the global sourcing challenges and opportunities.

The supply chain for a small modular reactor hybrid energy system starts with the raw materials of steel, concrete, rubber, aluminum and other materials used to construct the components that will be needed in the modular parts of the main plant. As soon as the licensing process is complete, the preconstruction supply chain needs to be established. Feed pumps and pressurizers are typically the first items to be ordered and can take up to 36 months to deliver, assuming the designs are standard. The reactor vessel and steam and turbine generators can take up to 33 months to be constructed. Valves and piping can take up to 24 months to order depending on the nature of the valves. Pipe fittings for the plant typically take 15-18 months of lead time prior to construction. If heavy forging is needed it typically takes about 18 months. The plant instrumentation, simulation and control systems typically take about 18 months to design and construct but are not needed until later in construction. All these lead times are typical for fairly standard designs. If unique design are needed for new small modular reactor designs, lead times need to be expanded. Supply chain issues might need to be addressed beginning two to three years prior to the start of plant construction.

Pipes and valves could become a supply chain issue since the current boom in natural gas is consuming much of the existing capacity in the U.S. and Europe. Suppliers of valves and pumps such as ClydeUnion Pumps have stated they have no plans to expand manufacturing capacity and are confident that their five factories in the North America and Europe can meet demand and add additional shifts to meet future demand (Hayes 2012). While this level of capacity is good for the construction of a hybrid energy system in Wyoming, it suggests there would be limited opportunity for new manufacturing of pumps or valves in the state.

The most basic raw material for structural members, vessels, pipes and valves is steel. It currently remains plentiful on the global market. U.S. steel production is at about $75 \%$ of capacity, according to the American Iron and Steel Institute (Hayes 2013). About 7.2\% of steel production went to the energy industry in 2011, and that share is expected to grow in 2012 . However, with about $25 \%$ of capacity available there should not be a supply chain issue with steel in meeting construction needs.

Concrete, the other basic construction material, might be a supply chain issue given interest in Wyoming's wind energy resource. Table 13 is a comparison of the amount of steel and concrete projected to be needed for the fabrication of windmills and nuclear reactors. For the same amount of electricity produced, windmills require 50 times more steel and 60 times more concrete that a full scale nuclear reactor such as a European Pressurized Reactor (EPR) (Peterson, et al., 2005). In another comparison, a wind farm of about 250 turbines, the scale of those currently being built, would use roughly the same amount of concrete and steel as an EPR reactor.

Table 13. Comparison of the amount of steel and concrete needed for the fabrication of wind turbines and nuclear reactors per TWh of power [Peterson et al., 2005]

\begin{tabular}{|l|l|l|}
\hline & \multicolumn{1}{|c|}{ EPR nuclear reactor } & \multicolumn{1}{c|}{ Typical modern wind turbnie } \\
\hline Power & $1600 \mathrm{MW}$ & $2 \mathrm{MW}$ \\
\hline Coeff production (h/year) & $7000 \mathrm{~h}(80 \%$ of $8760 \mathrm{~h})$ & $1750 \mathrm{~h}(20 \%$ of $8760 \mathrm{~h})$ \\
\hline Life time & 60 years & 15 years \\
\hline $\begin{array}{l}\text { Total production in TWh } \\
\text { (over entire lifetime) }\end{array}$ & $670 \mathrm{TWh}$ & $0.053 \mathrm{TWh}$ \\
\hline Tons of steel & 40000 & 150 \\
\hline Tons of concrete & 200000 & 1000 \\
\hline Tons of steel per TWh & 60 tons of steel per TWh & 2830 tons of steel per TWh \\
\hline Tons of concrete per TWh & 300 tons of concrete per TWh & 18,900 tons of concrete per TWh \\
\hline
\end{tabular}


Managers in the Wyoming concrete industry indicate that supply for hybrid system construction should not be problematic since most of the raw materials for the concrete come out of the nearby Dakotas. Plants in Wyoming may need to go to a second shift during peak construction periods but with adequate planning the capacity issues are manageable.

A review of the major raw materials needed to support a small modular reactor hybrid energy system does not indicate there would be major supply chain issues as long as the design team allows an adequate planning horizon for ordering of system components. At the same time the manufacturing capability within the global supply chain appears adequate to fabricate the components needed in construction of a small modular reactor hybrid energy system. There may be schedule challenges especially for new designs of the modular components for a new small modular reactor, but these should not be limited by raw materials.

The fact that raw material and manufacturing capabilities exist on the global supply scale minimizes the opportunity for Wyoming to design and construct new manufacturing facilities. However, as hybrid energy systems are built and operated consumables such as lubricants, chemicals, water treatment chemicals, and others may offer an opportunity for Wyoming businesses to capitalize on these new and expanding markets. These markets will not materialize overnight due the long licensing and construction time line needed to bring a small modular reactor hybrid energy system on line. There will be adequate time for businesses to identify needs and expand or develop the markets to meet these needs.

Wyoming has established fabrication plants for piping, structural steel, pressure vessels, and reactors with Puma steel located in Cheyenne and High Country Fabrication located in Casper. As the small modular reactor industry develops there is an opportunity for fabricators and constructors in Wyoming to apply the experience they gain with the Wyoming installation to small modular reactor installations elsewhere. Beyond this, one of the claimed advantages of small modular reactor is that they can be built at lower cost in a factory and then be shipped to the field site. As of now sites for these factories have not been announced. If a small modular reactor factory were to be constructed in Wyoming as part of installing one of the first few small modular reactors in a hybrid system, it could be a long-term contributor to the state economy.

\subsection{Education and Training - Challenges, Needs and Opportunities}

Wyoming will need a workforce with the necessary knowledge and skill sets, as well as access to engineering research capabilities and testing facilities that can provide support to the design of a hybrid energy system. About 500 new positions would be opened to provide engineering support, operate, maintain, conduct business transactions, and manage a nuclear hybrid energy system. If the system has a small modular reactor as part of the design, special skills such as health physics would be needed to manage, track and secure the nuclear system. In the case of development of a hybrid energy system, the degreed work force will need to come from a variety of disciplines and the crafts people will need specialty skills in areas such as welding and pipe fitting.

For design and construction of a hybrid energy system in Wyoming there will be a need for highly trained craft people with skills in welding; mechanical, electrical, and plumbing technologies; computer and instrumentation skills; and process control operators. Institutions like WyoTech schools (in Laramie and other locations) that focus in automotive and diesel technologies and the McMurry Training Center in Casper run by the Wyoming Contractors Association train skilled craft people to support the energy production industries. The McMurry Training Center currently has a welding program mainly focused on structural steel with some pipe welding. If a hybrid energy system were to be constructed in Wyoming, there would need to be training programs developed in TIG (tungsten inert gas) and advanced metal welding up to nuclear grade. Most of the trade schools are seeing an increase in enrolment due to increasing energy production throughout the Rocky Mountain region. The McMurry training center currently places about $95 \%$ of its graduates, leaving few to support a hybrid energy system project. However, the center has the capacity and could expand their programs to meet the demand for a program 
if sufficient students are available. There has been and will continue to be a need to train heavy equipment and truck drivers to support the energy extraction and transportation industry.

At the University of Wyoming, the School of Energy Resources (SER) was created in 2006 to bolster the University's energy-related education, research and outreach. SER objectives, assigned by the Wyoming State Legislature, were to provide competitive energy-related education; to advance science, technology and economic research; and to support outreach to industry, academic institutions, governmental agencies and the public. SER takes a holistic approach in building secure and sustainable energy future. The same holistic approach will be needed for the design and construction of a hybrid energy system, especially those that have a nuclear component. There are a number of institutes within SER that are currently graduating civil, electrical, chemical, mechanical and petroleum engineers that could support a hybrid energy system project. SER is planning to develop an Advanced Conversion Technology Center to promote research to improve the conversion of fossil resources to higher value fuels and products. This type of effort would be valuable if a hybrid energy system project or industry were to be developed in Wyoming,

One of the main challenges in educating and training a work force is that a number of energy producing states to the East and South compete for Wyoming graduates. At the University of Wyoming, graduates in civil engineering can often find construction work within the state. Those that graduate in electrical and mechanical engineering are being enticed to move to larger cities such as Dallas, Fort Worth, or Oklahoma City where the compensation is better. Those graduating in chemical and petroleum engineering are finding jobs with energy related companies and often need to be mobile to head to various oil and gas fields. According to the Bureau of Labor Statistics' seasonally adjusted rates for July 2012, Wyoming has the eighth lowest unemployment rate at 5.6\%. States located around Wyoming, especially to the east, have some of the lowest rates with North Dakota at 3\%; Nebraska at 4\%; South Dakota at $4.4 \%$; Oklahoma at 5\%; Utah at $6 \%$ and Idaho at $7.5 \%$. Wyoming's unemployment rate has been steady with only a $0.4 \%$ downward change since 2011 .

Wyoming is generally well positioned to meet a synfuel industry's educational and training needs with well trained students although some effort to offer specific types of advanced training might be necessary. The exact needs will depend on the kinds and number of projects to be built. The limiting factors may be the availability of students and the ability to attract and retain graduates within the state of Wyoming against competition with oil and gas development throughout the U.S. The educational system and the Legislature are currently taking steps to ensure that the state can attract students into the science, technology, engineering and math fields in the early grades to ensure there are enough students to fill the degree programs. This level of effort will need to continue into the foreseeable future to ensure that well trained students in the $\mathrm{K}$ though 12 grades would be available to enter the secondary schools over the next 5-10 years about the time when a hybrid energy system could be build and operated for the state

\subsection{Business Structure}

The proposed hybrid system combines elements from several disparate industries that must work in coordinated fashion for the overall enterprise to be successful. This is true at the physical level of the streams flowing between plants as well as at the financial level of the revenues and profits of each participant. There will be a complex relationship between all the participants that cannot be specified in this report. Rather, some of the areas of discussion will be identified.

\subsubsection{Number of Parties Involved}

The hybrid system examined and recommended in this report uses a nuclear reactor to make power to partially offset the variability of a wind farm's output before it is delivered to the power grid. When that supplemental power is not needed, the corresponding nuclear heat is sent to a natural gas-to-gasoline process. This system has six major roles that, because of the different expertise required for each, are likely to be filled by different companies or organizations. They are 
- Nuclear power plant operator

- Wind farm operator

- Regional power grid operator

- Natural gas supplier to the synfuel plant

- Natural gas reforming and synfuel plant operator

- Fuel recipient (either a distributor or a transport terminal)

The nuclear and synfuel plants have a close and dynamic operational interaction with each other, while the other four are buyers or sellers who must be willing to accept, within limits, the delivery constraints tied to operations. In addition to the daily operational interactions, this must include coordinated handling of plant shutdowns, both planned and unplanned. Differences in how each participant's home industry normally handles these issues would be expected and must be reconciled. The formation of a single joint venture company to assure facility-wide optimization of plant operations could help avoid the potential problems of the tragedy of the commons in which one member in a group acts for his own short term benefit at the long term expense of the entire group.

\subsubsection{Individual Plant Construction Schedule and Lifetimes}

The facilities in a hybrid energy system have construction times significantly different from each other. The two key plants - because they are the most expensive - are the nuclear and synfuel plants. Large chemical process facilities typically take 3-4 years to design and construct. A nuclear plant is often cited at twice that range, and that might be extended if there are problems in licensing. The problem is then how to schedule their planned startup dates and what to do if they are not met. If both plants begin construction simultaneously, the chemical plant will be done perhaps three years before the nuclear plant. Its owner would like it to run and generate revenue during that time, but this would require a temporary heat source. That heat would likely be more expensive that the planned nuclear heat especially if it is fossil-fired heat subject to $\mathrm{CO}_{2}$ emission penalties. On the other hand, if the two plants are planned for simultaneous completion, the nuclear plant must start several years early with the risk that its completion is delayed after the process plant is started, leaving the synfuel plant without a heat source. Alternatively, market, regulatory, and corporate conditions that change in the years before the synfuel plant's construction starts might cause its owner to renege on the agreement. The emergence of factory-built small modular reactors would be expected to mitigate this risk by reducing their construction times hence the overall scheduling problem, but this has not yet been demonstrated.

A similar problem exists towards the end of each facility's life. Most chemical complexes have planned lifetimes shorter than the 40 to 80 years expected for nuclear plants. The economics of plant operation, maintenance, and repair, or competition from newer less expensive production processes, might argue for shutdown well before the nuclear plant is ready to do the same. One option for addressing this is to then operate the nuclear plant to make electricity full time, with no sales of heat to another user. Such a shift from addressing the variability of wind energy to providing base load power would be a significant change requiring careful analysis of the market consequences.

\subsubsection{Operational Interactions}

Basic interactions such as the sale of energy between systems should be handled by established methods. More complex are operational interactions in which an upset such as an unexpected change of operating rate spreads from one plant to another in the hybrid system. For example, a suddenly downed transmission line at the wind farm could instantly create demand for more electricity from the nuclear plant, in turn dropping the supply of heat to the synfuel plant. Each of these facilities would have its own control system and operators, but in an incident like this their responses should be coordinated. How this is done, especially how closely their computerized control systems are tied together, must be established. Some degree of interaction and data sharing would be necessary for continuous on-line optimization of system performance to maximize profits for all the facilities involved. This sharing would on the other 
hand raise concerns about cyber security for the protection of proprietary operating data and to prevent malicious assaults on equipment operation. 


\section{ADDED-VALUE STEPS IN THE URANIUM SUPPLY CHAIN}

Wyoming has rich reserves of uranium that are recovered by several companies using in situ leaching. The metal is processed into yellowcake, $\mathrm{U}_{3} \mathrm{O}_{8}$, and shipped out of state for several steps of further processing, ultimately into fuel assemblies for installation in nuclear reactors. This chapter explores value-added energy products downstream in this value chain that might be made in Wyoming.

\subsection{Steps in Fuel Fabrication}

Extraction of uranium from its native ore can be done by mining and milling or, as is the case in Wyoming, by in situ leaching using special solutions to extract uranium in the subsurface. According to EIA information (EIA 2012), twelve different entities are permitting, developing, operating, idling, or restoring a total of twenty uranium properties in the United States, seven of them in Wyoming. The six of the twenty in an operational status in the second quarter of 2012 have a total production capacity of 10.8 million pounds of yellowcake per year. Actual production, however, has been steady since 2006 at about 4 million pounds annually. Over that same period the annual weighted average sales price has increased from $\$ 28.98$ to $\$ 52.36$ in 2011 . The large amount of competition and current overcapacity is explained by the recent years' expectations of growth of the nuclear fleet (the nuclear renaissance) and the coming expiration of a program that blends excess weapons-grade military uranium into commercial reactor fuel.

The next step of uranium processing is conversion (Figure 26). Yellowcake, shipped to a conversion plant in 55 gallon drums, is converted by one of two processes to uranium hexafluoride, $\mathrm{UF}_{6}$, a volatile compound suitable for isotopic enrichment. There are only two conversion plants in North America, one in Metropolis, Indiana owned and operated by Honeywell/Converdyn, the other in Port Hope, Ontario run by Cameco Corp. There are only eight in total in the world, with the others in Russia (2), China, the United Kingdom, France, and Brazil (with capacity about $1 \%$ of the others) [WNA 2012a]. The Port Hope plant began uranium processing in 1942. The Metropolis plant, built in 1958 and expanded several times since, was recently prevented by the Nuclear Regulatory Commission from restarting after a planned maintenance shutdown while its safety in extreme seismic and tornado events is re-evaluated [Energy Daily 2012a]. The evaluation and equipment upgrades are expected to take 12-15 months, leading to declaration of force majeure in supplying its contracted customers [Energy Daily 2012b]. This is the one stage of uranium processing where there is not already excess capacity and therefore is where Wyoming might best try to enter this industry.

The converted uranium hexafluoride is shipped as a solid in large cylinders to an enrichment plant that concentrates $U$ -

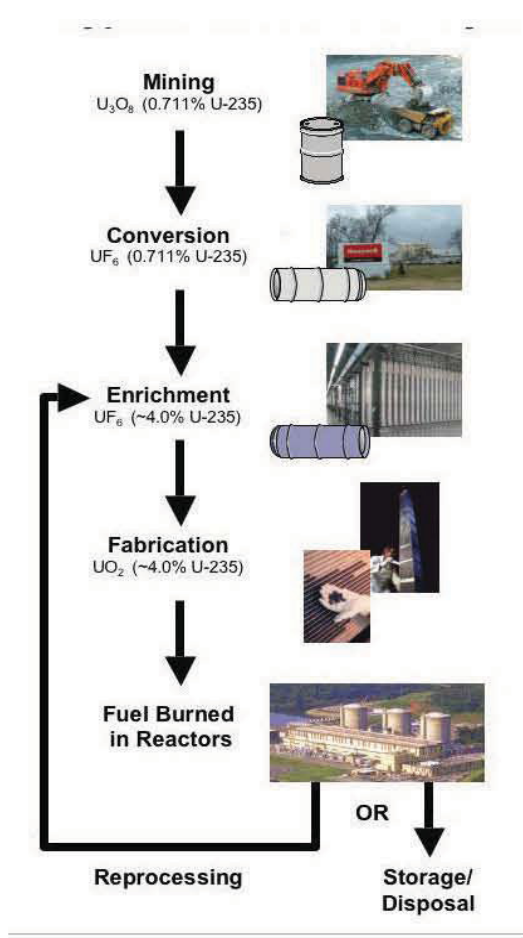

Figure 26. Typical nuclear fuel cycle. Source: Converdyn. 235 , the fissile isotope, from the natural value of $0.7 \%$ to the amount needed for each particular reactor design, usually $3-5 \%$. The resulting byproduct stream of U-238 with low U-235 content is called depleted uranium. Enrichment is done in large facilities with many gas centrifuges, although older plants using a diffusion process are still in operation. There are five enrichment plants operating or announced in the United States, including a gaseous diffusion plant in Paducah, Kentucky scheduled for shutdown in 2013. Offsetting this shutdown are a two billion dollar AREVA facility planned for Idaho Falls, ID [WNA 2012a] but not yet under construction and a GE Hitachi Nuclear Energy laser enrichment facility just approved by the NRC to be built in North Carolina. 
Fuel fabrication uses $\mathrm{UF}_{6}$ enriched in U-235 to make fuel pellets and then fuel assemblies. The steps include chemical conversion to $\mathrm{UO}_{2}$, pressing into pellets, loading them into fuel rods, and installation of the rods into steel and zirconium assemblies that assure proper spacing. These assemblies are highly engineered, custom made for each reactor, and subject to high quality standards. There are 21 fuel fabrication facilities around the world, four in the United States, with most of them owned by reactor vendors. Total demand for light water reactor fuel fabrication is expected to parallel the number of nuclear reactors operating in the world. Total production capacity is substantially in excess of demand and is not expected to present a limitation in the foreseeable future [WNA 2012b].

\subsection{The Chemistry of Conversion}

There are two processes used for conversion of $\mathrm{U}_{3} \mathrm{O}_{8}$ to $\mathrm{UF}_{6}$. The dry process is used in the United States, while the wet process is used at all other plants. The reasons for choosing one over the other and the relative economics of the processes were not available.

The dry process is based on the volatility of $U_{F_{6}}$ to separate it from byproducts. The chemical steps are listed below. In the second step, hydrofluoric acid HF can be either a gas or an aqueous solution. Separation and treatment of unreacted $\mathrm{HF}$ and fluorine gas $\mathrm{F}_{2}$ are not shown.

$$
\begin{gathered}
\mathrm{U}_{3} \mathrm{O}_{8}+2 \mathrm{H}_{2} \rightarrow 3 \mathrm{UO}_{2}+2 \mathrm{H}_{2} \mathrm{O} \\
\mathrm{UO}_{2}+4 \mathrm{HF} \rightarrow \mathrm{UF}_{4}+2 \mathrm{H}_{2} \mathrm{O} \\
\mathrm{UF}_{4}+\mathrm{F}_{2} \rightarrow \mathrm{UF}_{6}
\end{gathered}
$$

The wet process is more involved. It dissolves the incoming yellowcake in nitric acid, extracts the uranium with a selective solvent into a purified uranyl nitrate solution, then evaporates it to form solid uranyl nitrate. Alternatively, ammonium hydroxide is added to the purified uranyl nitrate solution to precipitate solid ammonium diuranate. Either of these solids is then calcined in the presence of hydrogen to form $\mathrm{UO}_{2}$. The final fluorination steps are the same as those of dry processing.

International Isotopes, Inc. has selected a site in New Mexico to build a facility for deconversion, or processing of depleted uranium in the form of $\mathrm{UF}_{6}$ to recover the fluorine [International Isotopes 2012]. The process creates depleted $\mathrm{UO}_{2}$ and high purity $\mathrm{HF}$ which can be used for specialty chemical purposes or recycled for conversion of $\mathrm{U}_{3} \mathrm{O}_{8}$ into $\mathrm{UF}_{6}$. The NRC issued a license for this facility in October 2012.

\subsection{Opportunities for Wyoming}

Because of the few conversion plants, their age, and the planning for increased uranium mining and yellowcake production, conversion appears to be a processing step that could be done in Wyoming to add value to its and others' uranium production. The Cameco conversion plant in Ontario, representative of what might be built in Wyoming, in 2006 had 370 direct employees and generated \$1.4 million (CDN) in local business revenue and $\$ 24.6$ million (CDN) in labor income [Kitchen 2006]. From the standpoint of the plant owner, however, uranium conversion is a business with tight margins [Energy Daily 2012b]. A more thorough market study is necessary to better assess this opportunity and to attract an appropriate owner/operator.

The business model of conversion plants is that a reactor fuel user such as a utility purchases $\mathrm{U}_{3} \mathrm{O}_{8}$ and retains ownership of it from then on. The uranium advances through the various steps of fuel fabrication with the owner paying for processing rather than buying processed material. The intermediate forms of uranium are shipped between successive processing plants. Consequently, a Wyoming plant is not limited to treating only local supplies and could potentially serve clients from all of North America.

Wyoming's experience in minerals processing is applicable to this process. The process operates with high temperatures, flammable hydrogen, toxic and corrosive materials, and mildly radioactive uranium, but these hazards are not outside the range of conditions found in chemical processing located elsewhere and should be acceptable in an industrial zone. The State's good rail and highway access would facilitate shipping the 14 ton cylinders of $\mathrm{UF}_{6}$ to enrichment plants. 
The process uses fluorine in the form of $\mathrm{HF}$ or $\mathrm{F}_{2}$ as an input and $33 \%$ of the product weight is fluorine. If a Wyoming plant is built with 15,000 metric tonnes $\mathrm{UF}_{6}$ annual capacity, a size typical of existing plants, about 4900 tonnes per year of fluorine would be required. This would appear to be an opportunity to mine the raw material from which it is obtained. Fluorite, $\mathrm{CaF}_{2}$, also called fluorspar, exists in Wyoming but fluorspar production elsewhere is quite large. Global production in 2011 was 6,200,000 metric tonnes with 1,080,000 tonnes in Mexico, the second largest producer after Russia [USGS 2012]. Data for United States production of fluorspar is not available, but fluorine equivalent to 130,000 tonnes fluorspar was produced as a byproduct of phosphate mining. The 4900 tonnes per year of additional demand for fluorine that a conversion plant would create, equivalent to 10,060 tonnes fluorspar, is negligible compared to Mexico's and the U.S.'s established industries. New fluorspar or fluorine production capacity in Wyoming to support the uranium conversion industry is not warranted. 


\section{IMPLEMENTATION}

In summary, the use of a hybrid energy system, and in particular one supplied with heat from a nuclear reactor, to facilitate the use of variable wind energy appears to be a technically and economically defensible project. There are many details to be worked out and questions to be resolved before one or more of these are actually operating in Wyoming. This chapter compiles the recommendations and suggestions generated in various parts of this analysis. They constitute a set of next steps.

\subsection{Market Assessment for Power and Fuels}

These items were identified in Chapters 1 and 2. In total, they are intended to develop a detailed understanding of the current and likely future environment for production of vehicle fuels and electricity in Wyoming. A single report addressing those issues primarily from a business and marketing standpoint, rather than one of techno-economic feasibility, could be a useful tool to interest potential synfuel project developers in looking in detail at Wyoming.

1. Review the history of the development of the energy industries in Alberta (oil sands bitumen and petrochemicals in the 1980s), Saudi Arabia (petrochemicals in the 1980-1990s), and China (coal and natural gas today) to understand the problems they faced and the strategies they used to address them.

2. Prepare an overview of Wyoming's current and planned energy industry and its infrastructure as background for further analysis of integrated hybrid energy systems.

a. Characterize the general flow of refined petroleum products in the region, possibly as far as the Pacific and Gulf Coasts, to understand the producers, their locations, seasonal variation in product flows, the transport modes used, and the purchasers.

b. Develop an understanding of the current status and longer-term projections for refined product pipelines into and out of Wyoming to understand whether outbound capacity might be available for an initial hybrid system's synfuel to be shipped to market or what the sources are of products carried by inbound pipelines.

c. Develop an inventory of refineries in Wyoming and surrounding states to characterize their capacity, their age, any recent improvements, and reports or expectations of when they might be retired from service. Retirements would open both market demand and transport capacity to new entrants such as a hybrid system.

d. Maintain awareness of other states' Renewable Portfolio Requirements, including their phase-in schedules, and how they might affect, positively or negatively, demand for Wyoming synfuel and electricity generated using fossil, nuclear, or renewable resources.

e. Develop a schedule of planned electrical transmission lines and their capacities and any uncommitted capacity that might be used by a hybrid system-supported wind farm.

f. Develop projections of the anticipated remaining service life of existing power plants, especially coal and natural gas-fired plants, to identify when their generation capacity might need to be replaced either for obsolescence or high cost of required upgrades.

3. As federal energy policy evolves in the coming years, maintain awareness of trends in vehicle fuel usage and any policy incentives that favor some fuel types over others. Assess these changes by what types of synfuels plants might be needed and if they might require, over the longer term, conversion of some processes that might be built to making another type of fuel or chemical product 
4. Develop a projection based on economic and population trends as well as expected federal energy policies of how a larger synfuel industry might develop in Wyoming, including the possibility of interconnections such as a common syngas supply pipeline. Identify key aspects of this future scenario which might affect design of an initial hybrid energy system.

5. Building on the previous item, generate conceptual maps of how a syngas pipeline system, and possibly hydrogen or $\mathrm{CO}_{2}$ pipelines as well, could be laid out across the state reaching to major users in Billings, Salt Lake City, and Denver. Identify right-of-way issues which might affect location of these pipelines. In laying out these conceptual maps, consider how local conditions such as sage grouse habitat, cooling water availability, or rail access might affect the desirability of building a large energy project along the pipeline route.

6. For any new construction or upgrades to existing pipelines carrying refined products, $\mathrm{CO}_{2}$, and syngas or hydrogen that travel in the general direction of the preferred corridor identified in the previous item, consider the longer term value of providing incentives for the owner to incorporate additional capacity for use if a full network develops. These incentives might apply only to the buried portions of the pipeline which would be more disruptive to change or add to in the future. Surface facilities such as pumps, compressors, or even convenient tie-in points might only require minor modifications now that would facilitate future increases in throughput.

7. The long term regional market for $\mathrm{CO}_{2}$ and nitrogen (considered individually) for enhanced oil recovery should be projected as part of assessing the attractiveness of retrofitting oxycombustion onto existing coal-fired power plants when $\mathrm{CO}_{2}$ emission limits are instituted.

\subsection{Techno-economic Issues}

8. This report proposes that the power output of a hybrid energy system might best be used to ameliorate, but not totally eliminate, the variability of a wind farm's output. A more detailed analysis of this subject is warranted, with a detailed focus on the value to transmission line operators and utility purchasers of reducing the variability in a renewable energy supply. This analysis considered a maximum allowable ramp rate of power decreases; more complex operating strategies that respond to different power demand conditions might offer greater value.

9. As a firm incentive to prospective project developers, the state of Wyoming can consider how the value in the previous item might be collected from exporters of Wyoming wind-generated power so it might be redistributed to at least the initial hybrid energy system builders or operators. This is analogous to the feed-in tariffs and production tax credits that spurred the wind industry itself.

10. The synfuel proposed in this study is gasoline made from natural gas via methanol as an intermediate. It has significantly lower capital costs than a coal-using system even though the feed stock costs are higher. The relative prices under which coal competes well against natural gas should be identified for a range of future economic and market conditions to understand which resource is likely to be in greater demand. When coal becomes much cheaper than natural gas (inclusive of $\mathrm{CO}_{2}$ capture costs), there might be incentive to build a coal gasification system to replace the methane reformer to make syngas for the existing methanol-to-gasoline back end. These plants need not be located adjacent to each other if the syngas pipeline network is built by then.

11. Evaluate the feasibility of operating cryogenic air separation plants in a time-dependent fashion using the variable power from a large wind farm. 


\subsection{Business Issues and Opportunities}

12. As projects are developed, the owner/operators or the technology suppliers can identify consumable items needed by the nuclear or chemical processes whose production in Wyoming might be facilitated by state agencies. The most valuable products would be those also needed by nuclear or hybrid energy systems elsewhere, that is those which compete on the basis of high technical or quality specifications rather than price or quick delivery. Working with technology vendors early in the overall project planning to identify such materials would allow time for Wyoming researchers to develop improved materials for these uses.

13. Similar to the previous point, construction of an initial or early hybrid energy system in Wyoming would give local contractors valuable experience building or installing a new technology which they might be able to offer to hybrid or small nuclear projects elsewhere. To support this possibility, the state can offer incentives for individuals or companies to receive the necessary training to win and capitalize on the initial installation job. This might include providing training on advanced and nuclear-grade welding, nondestructive examination, concrete fabrication, and quality assurance leading to Wyoming shops being able to receive certification of nuclear-grade construction quality. After this, the state could make available marketing expertise to help Wyoming companies offer those skilled services out of state.

14. Developers of small modular nuclear reactors plan to build the reactors in factories where the conditions and costs are better controlled. Where these factories might be located has not been disclosed; planning them in detail might be premature until the reactor design has been licensed by the NRC. If Wyoming is selected as the site of a nuclear hybrid energy system (or if a reactor will be installed after initial operation with a natural gas-fired heat source), it would have an advantage in attracting the factory to a Wyoming location. An initial step in pursuing this possibility is for state economic development personnel to begin contacts with small modular reactor developers to discuss their needs and issues regarding their factory's location and staffing.

15. There is currently a shortage of trained craftsmen, limited in part by the number of students entering such programs. As a long term effort, state efforts to develop interest in science, technology, engineering, and mathematics (STEM) in the early grades would help assure a long term supply of both skilled and degreed workers.

16. Conversion of yellowcake $\left(\mathrm{U}_{3} \mathrm{O}_{8}\right)$ to uranium hexafluoride $\left(\mathrm{UF}_{6}\right)$ is a downstream step in uranium processing that potentially offers an opportunity for Wyoming. It is viewed in the nuclear industry to be a low margin business. Nonetheless, there appears to be room for a new entrant to at least consider offering conversion services. Wyoming economic development representatives might conduct a more detailed analysis of this part of the nuclear fuel industry, including talking to management of all the existing facilities (there are only eight in the world) to assess their possible interest in building and operating a new plant in Wyoming. 


\section{REFERENCES}

Air Products 2012, Increased Production through Enhanced Oil Recovery, www.airproducts.com/ /media/downloads/data-sheets/E/enhanced-oil-recovery-datasheet.pdf, accessed October 25, 2012.

American Association of Cost Estimators (AACE), 2005, Cost Estimate Classification System - As Applied in Engineering.

Biello, D. 2012. Small Reactors Make a Bid to Revive Nuclear Power. Scientific American. Energy \&sustainability, March 27. 2 p.

Boardman, R. D., A. Grandik, R.A. Wood, T. Foulke, D.A. Bell, W. Schaffers, The Feasibility of Siting Coal Gasification and Synfuels Plants in Wyoming, Report for the Wyoming Business Council, INL/MIS-11-22553, 2011.

Bromberg, L. and Cheng, W. K. (2010), Methanol as an alternative transportation fuel in the US: Options for sustainable and/or energy-secure transportation, www.afdc.energy.gov/pdfs/mit_methanol_white_paper.pdf, accessed Sept 3, 2012.

California Public Utility Commission (CPUC), www.cpuc.ca.gov/PUC/energy/Renewables/compliance.htm, accessed August 19, 2012.

Census Bureau. United States Department of Commerce. U.S. Population Projections, 2004-2030. www.census.gov/population/www/projections/projectionsagesex.html Accessed July, 2012.

Chemical and Engineering News (CEN), July 4, 2012.

Chemical Engineering Magazine 2011, "Chemical Engineering Plant Cost Index", Dec. 2011

Cherry, R.S., S.E. Aumeier, R.D. Boardman (2012), Large hybrid energy systems for making low $\mathrm{CO}_{2}$ load-following power and synthetic fuel, Energy Environ. Sci., 5, 5489-5497.

Chou, V.H., John L. Haslbeck, A. Kyle, E. Lewis, L.L. Pinkerton, V. Shah, E. Varghese, M.C. Woods, Cost and Performance Baseline for Fossil Energy Plants, Volume 3c: Natural Gas Combined Cycle at Elevation, DOE/NETL-2010/1396, 2011.

Couture, T. D., Cory, K., Kreycik, C., Williams, E. (2010). A policymaker's guide to feed-in tariff policy design, National Renewable Energy Laboratory, NREL/TP-6A2-44849

Database of State Incentives for Renewables and Efficiency (DSIRE), www.dsireusa.org, accessed August 19, 2012.

DKRW (2012), www.dkrwadvancedfuels.com/projects/medicine-bow/fact-sheet-112.html, accessed September 9, 2012.

Energy Daily (2012a), "NRC orders shutdown of uranium plant over earthquake concerns", July 17, 2012, p.1.

Energy Daily (2012b), "Sole U.S. nuclear fuel processing plant struggling to meet utility contracts", September 12, 2012, p.1.

Energy Information Agency (EIA) 2012, www.eia.gov, various pages accessed July and August 2012.

Energy Information Agency (EIA) 2003, Status and Impact of State MTBE Ban, www.eia.gov/oiaf/servicerpt/mtbeban/, accessed 4 September 2012.

Federal Energy Regulatory Commission (FERC), www.ferc.gov/market-oversight/mkt-electric/ southwest.asp, accessed July 24, 2012. 
Hayes, K. 2012, Oil pipeline crunch shifts U.S. shale race from drillbits to valves. Reuters July 30.

INL 2009, “Advanced Fuel Cycle Cost Database”, INL/EXT-07-12107, Rev. 2

INL 2010, Technical Evaluation Study, Nr. 23843 "Nuclear integrated Methanol to Gasoline Production Analysis".

INL 2012 "Nuclear Energy System Evaluation and Screening - Evaluation and Metric for Financial Risk and Economics", INL/ Ext-12-27055

International Energy Agency (IEA), Energy Technology Systems Analysis Programme (IEA-ETSAP) (2010), Industrial Combustion Boilers, www.iea-etsap.org/web/E-TechDS/PDF/101-ind boilersGS-AD-gct1.pdf, accessed August 21, 2012.

International Energy Agency (IEA), Projected costs of generating electricity, 2010 edition.

International Isotopes (2012), Project overview, www.intisod.com/index.php/fep/moreinformation/project-overview, accessed Aug 30, 2012.

Kitchen, H. (2006). Economic and Financial Impact Analysis of Cameco and Zircatec in Port Hope and Northumberland County, www.cameco.com/fuel services/common/pdfs/news/ economic impact study.pdf, accessed October 31, 2012.

McDonough, C.J. 2012. Siting a WYSG facility. Associated Legal Group, LLC. 40 p.

Midwest Independent System Operator (MISO) 2012, https://www.midwestiso.org/MarketsOperations/ RealTimeMarketData/Pages/RealTimeTotalLoad.aspx

National Energy Technology Laboratory (NETL) 2007, Cost and Performance Baseline for Fossil Energy Plants, DOE/NETL-2007/1281.

National Renewable Energy Laboratory (NREL), wind.nrel.gov/Web_nrel. accessed July 2012

Nitrogen+Syngas, North America's syngas boom, July-Aug 2012, pp. 22-25.

Nuclear Energy Institute 2012, White Paper, "The Cost of Generating Capacity in Perspective". http://www.nei.org/resourcesandstats/documentlibrary/newplants/graphicsandcharts/the-cost-of-newgenerating-capacity-in-perspective

Organization for Economic Development and Cooperation (OECD) 2010, OECD/IEA-NEA, 2010, Projected costs of generating electricity, http:/www.world-nuclear.org/info/inf02.html

Peterson, P.F., H. Zhao, R. Petroski. 2005. Metal and Concrete inputs for several Nuclear Power Plants. University of California, Berkeley, California. Report No. UCBTH-05-001. 20 p.

Rosner, R., S. Goldberg. 2011. Small Modular Reactors - Key to future Nuclear Power Generation in the U.S. The University of Chicago; Energy Policy Institute at Chicago. 72 p.

United States Geologic Survey (USGS), Mineral commodity summaries - fluorspar, January 2012, www.minerals.usgs.gov/minerals/pubs/commodity/fluorspar, accessed September 7, 2012.

U.S. NRC, 2012, Report to Congress: Advanced Reactor Licensing, August, pp 61.

Western Research Institute (WRI) 2012, Energy Production \& Generation Group, Distributed Production of Fuels \& Chemicals from Stranded Natural Gas. 34 p.

Wood, R., 2010, Nuclear-Integrated Methanol-to Gasoline Production Analysis, Idaho National Laboratory report TEV-667 revision 1.

World Nuclear Association (WNA 2012a), Uranium enrichment, www.world-nuclear.org/info/inf28.html, accessed September 5, 2012. 
World Nuclear Association (WNA 2012b), Fuel fabrication, www.worldnuclear.org/info/nuclear fuel fabrication-inf127.html, accessed September 5, 2012. Wyoming Infrastructure Authority (WyIA) 2012, Projects, www.wyia.org/projects 


\section{Appendix A}

\section{Energy Conversion Technologies}




\section{Appendix A}

\section{Energy Conversion Technologies}

Hybrid energy systems utilize the strategy that synthetic fuel manufacturing can be decomposed into two problems: providing a source of carbon and hydrogen atoms to build the desired fuel molecules, and providing energy for the chemical reactions that incorporate energy into the product synthetic fuel. Because hybrid systems accomplish these two goals by integrating processes that historically have been designed and operated separately, changes to conventional process designs are necessary. This chapter provides a brief overview of the supply of carbon and energy to processes and some of the problems that must be faced in using each in new ways. While many possible integration schemes appear to be technically feasible, detailed analysis, design, and ultimately operating experience at several scales will be needed to prove their practicality.

\section{A-1. CARBON SOURCES AND CONVERSION}

\section{A-1.1 Raw Materials and Products}

A wide variety of molecules can be used as fuels. In addition to having a high energy density (both by weight and volume), a fuel ideally has beneficial properties in its combustion performance in engines, ease of handling, stability in storage, not being easily prone to accidental ignition, not overly damaging to the environment if spilled, and not highly toxic or corrosive. Gasoline and diesel fuel have these characteristics, so their common usage is not surprising. Synthetic fuels that could be blended into gasoline or diesel fuel stocks would be similarly desirable and would not require a new fuel distribution infrastructure. This implies that hydrocarbons - molecules containing only carbon and hydrogen atomsare the preferred product.

Primary fossil energy resources such as coal, petroleum, natural gas, and kerogen (in oil shale) are predominately hydrocarbons, although they can also contain oxygen, sulfur, and nitrogen atoms that are removed as part of refining these raw materials into fuel products. There are two main categories of such processing. Direct processes act on the molecules in the native fossil fuel resource to break down overly large molecules, remove the undesired other atoms, and separate the resultant small molecules into similar classes to make gasoline, diesel fuel, naphtha, etc. Examples of a direct process include petroleum refining, biomass pyrolysis, and some types of coal liquefaction. In contrast, indirect processes react a fossil feed stock with steam and/or oxygen to make a mixture of carbon monoxide and hydrogen called synthesis gas, or syngas. After molecules containing sulfur or nitrogen are removed, the syngas is reacted over a catalyst to make larger hydrocarbon molecules that are separated into various liquid fuel types. Coal gasification and steam methane reforming are the first steps of indirect processes, with many products possible as final products. Examples of those include Fischer-Tropsch liquids, methanol, and gasoline made by further conversion of that methanol.

In general, indirect processes make a cleaner product and can be tailored to make a narrower range of product molecules. However, they require more aggressive treatment conditions to break the feed molecules all the way down to syngas. Methane, $\mathrm{CH}_{4}$, the major component of natural gas, requires temperatures of about $800^{\circ} \mathrm{C}\left(1470^{\circ} \mathrm{F}\right)$. Its breakdown to syngas can be facilitated by catalysts, allowing use of this lower temperature than would be required otherwise. Coal gasification to make syngas requires temperatures of at least $1200^{\circ} \mathrm{C}\left(2200^{\circ} \mathrm{F}\right)$. As a solid having many contaminants, coal is not amenable to catalytic conversion and must rely solely on this higher temperature to be converted. Once the synthesis

gas from either of these processes has been reacted to make crude products, separation steps are needed to make final products with the necessary quality specification. In fuel and hydrocarbon processing these 
steps are usually distillations conducted at lower temperatures, $150-500{ }^{\circ} \mathrm{C}\left(300-930{ }^{\circ} \mathrm{F}\right)$, that depend on the materials being separated.

\section{A-1.2 Natural Gas Reforming to Produce Syngas}

When natural gas is used as the feedstock, a process called steam methane reforming is used to produce the syngas, as shown in Figure A-1. Methane is the major (90-95\%) component of natural gas while steam is the oxygen source to make the carbon monoxide in syngas.

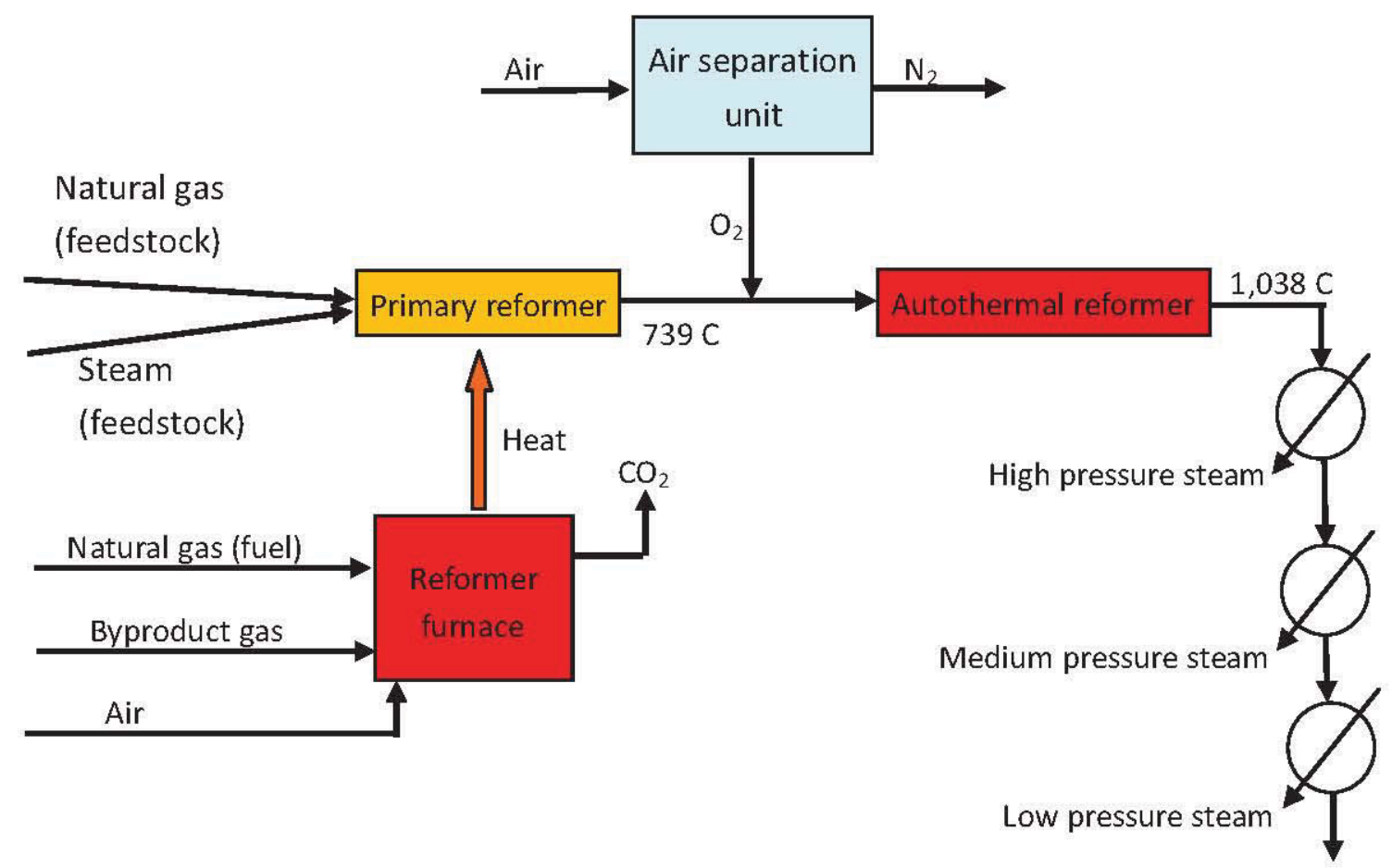

Figure A-1. Dual reformer system that converts natural gas to syngas for liquid fuel synthesis.

Natural gas and steam are fed to the primary reformer, where a high temperature $\left(739^{\circ} \mathrm{C}\right)$, endothermic (heat absorbing) reaction takes place:

$$
\mathrm{CH}_{4}+\mathrm{H}_{2} \mathrm{O} \rightarrow \mathrm{CO}+3 \mathrm{H}_{2}
$$

Heat for the primary reformer is provided by the reformer furnace. The fuel for this furnace is a mixture of natural gas and byproduct gases from downstream liquid transportation fuel synthesis.

Part of the natural gas is converted by this reaction. The effluent from the primary reformer is mixed with oxygen and fed to the autothermal reformer. A partial combustion reaction there releases heat that helps convert the remainder of the natural gas and raises the syngas to a very high temperature, $1038^{\circ} \mathrm{C}$.

$$
2 \mathrm{CH}_{4}+\mathrm{O}_{2} \rightarrow 2 \mathrm{CO}+2 \mathrm{H}_{2}
$$

The heat in the high temperature syngas leaving the autothermal reformer is recovered by making steam at several temperatures (corresponding to several pressures). Some of the high pressure steam is used as feedstock steam to the reformer. The remainder of the high pressure steam, as well as the medium and low pressure steam, are used for process heat and for making electricity.

\section{A-1.3 Coal Gasification to Produce Syngas}

When coal is used as the feedstock, gasification is used to convert the coal to syngas, as shown in Figure A-2. 


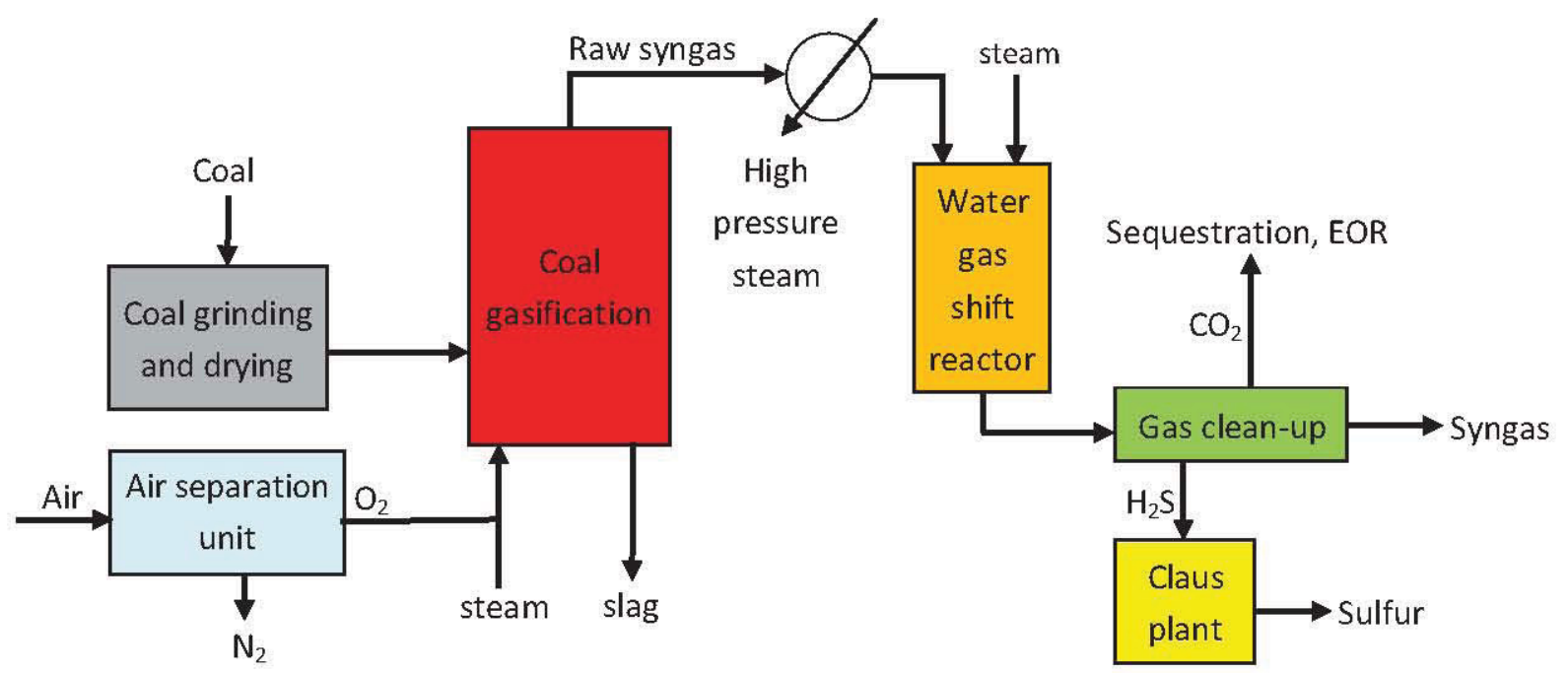

Figure A-2. Coal gasification and syngas preparation.

Coal is ground and dried before it is fed to the gasifier. Oxygen from an air separation plant is also fed to the gasifier to provide heat by its reaction with some of the feed coal. The syngas leaving the gasifier is cooled, producing steam. The syngas contains hydrogen and carbon monoxide and a number of other components including carbon dioxide, steam, sulfur compounds, and trace impurities such as mercury, hydrochloric acid, and ammonia. The hydrogen/carbon monoxide ratio leaving the gasifier is lower than the desired level of 2.0, so part of the carbon monoxide is converted to hydrogen using the water gas shift reaction

$$
\mathrm{CO}+\mathrm{H}_{2} \mathrm{O} \rightarrow \mathrm{CO}_{2}+\mathrm{H}_{2}
$$

Carbon dioxide, sulfur compounds, and other impurities are removed from the shifted gas to produce a syngas with the desired composition.

\section{A-1.4 Methanol to Gasoline Process}

Two processes for converting syngas to liquid transportation fuels are considered in Chapter 4 . The first is the methanol to gasoline (MTG) process, as shown in Figure A-3.

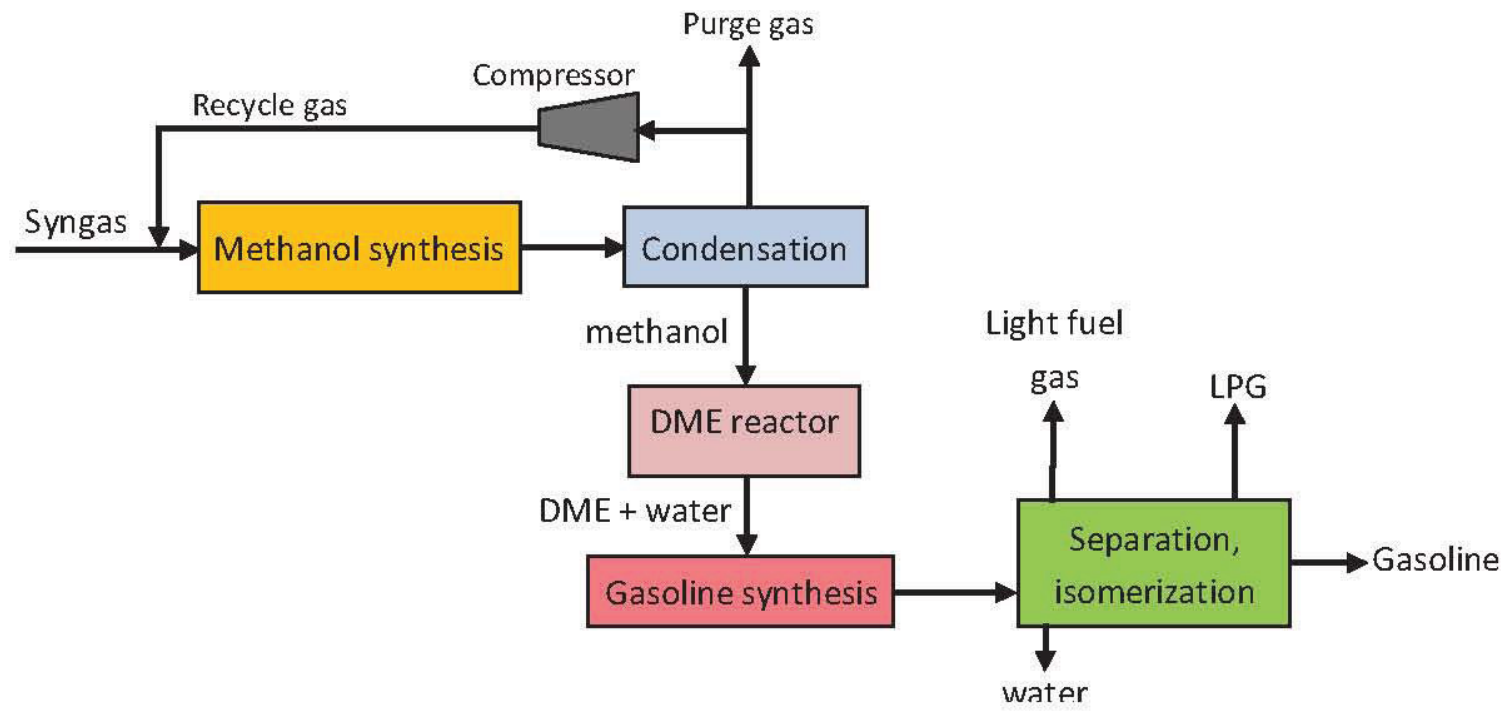

Figure A-3. Methanol to gasoline (MTG) process. 
Syngas is first converted to methanol:

$$
\mathrm{CO}+2 \mathrm{H}_{2} \rightarrow \mathrm{CH}_{3} \mathrm{OH}
$$

Only a portion of the syngas is converted as it passes through the methanol synthesis reactor. After the methanol is separated by condensation, the gas is recompressed and recycled to the synthesis reactor. A portion of this gas is purged to prevent the build-up of inert gases. This purge stream is burned as a disposal mechanism that recovers its heating value to drive a steam turbine and generate electricity.

Methanol is then converted to dimethyl ether (DME) and water:

$$
2 \mathrm{CH}_{3} \mathrm{OH} \rightarrow \mathrm{CH}_{3} \mathrm{OCH}_{3}+\mathrm{H}_{2} \mathrm{O}
$$

DME passes through a proprietary catalyst, forming a mixture of hydrocarbons and water:

$$
\mathrm{CH}_{3} \mathrm{OCH}_{3} \rightarrow-\left(\mathrm{CH}_{2}\right)-+\mathrm{H}_{2} \mathrm{O}
$$

At the proper reaction conditions, about $80 \%$ of the hydrocarbons (which have the generic formula $-\mathrm{CH}_{2}-$ ) fall in the gasoline boiling range. After minimal additional processing in the plant, the gasoline product meets all regular gasoline specifications. A liquefied petroleum gas (LPG) byproduct is also made, primarily a blend of propane and butane. Lighter byproduct gases produced in this part of the process are separated and added to the fuel gas stream to be burned for energy recovery.

\section{A-1.5 Fischer-Tropsch Process}

In the Fischer-Tropsch process to make diesel fuel, syngas reacts to form a mixture of long straightchain hydrocarbons.

$$
\mathrm{n} \mathrm{CO}+2 \mathrm{n} \mathrm{H}_{2} \rightarrow-\left(\mathrm{CH}_{2}\right)_{\mathrm{n}^{-}}+\mathrm{n} \mathrm{H}_{2} \mathrm{O}
$$

The lighter hydrocarbons up to about butane $(n=4)$ and unreacted syngas are used as fuel gas. The rest of the product mixture resembles a light crude oil, and this product can be refined into fuel products using conventional petroleum refinery processes (Figure A-4).

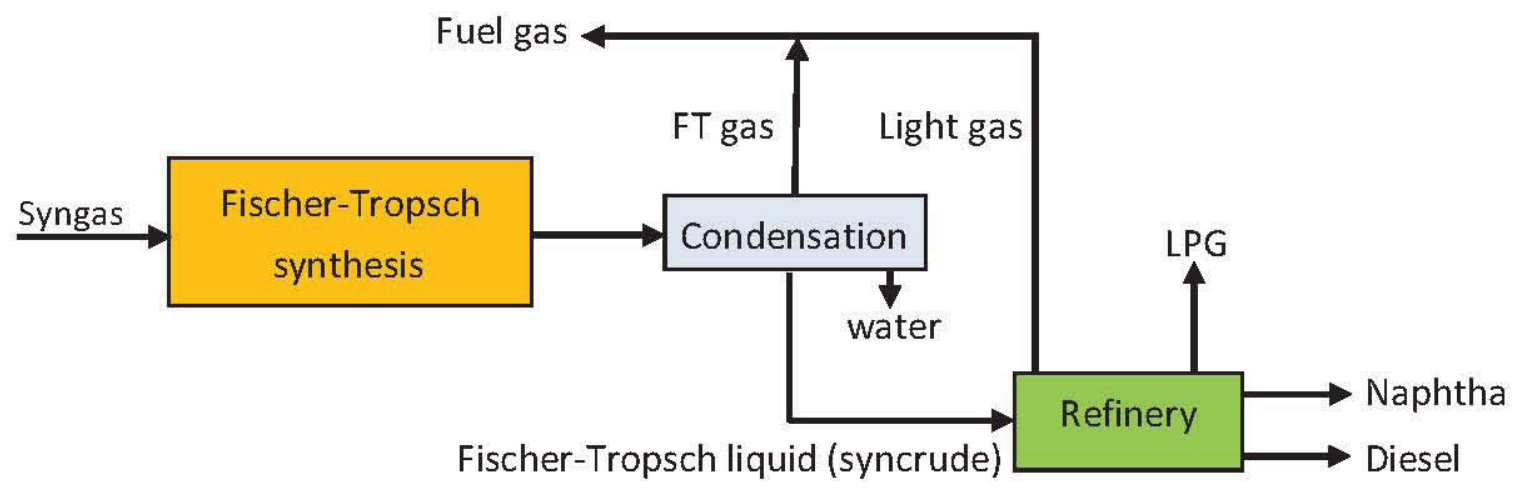

Figure A-4. Fischer-Tropsch (FT) synthesis, with refinery producing diesel as the principal product.

The primary product is a high quality diesel fuel. Blends of Fischer-Tropsch diesel and conventional diesel are sold in Europe by Shell as a premium diesel product.

Byproducts include naphtha (gasoline boiling range hydrocarbons, $n=5$ to 8 ) and LPG ( $n=2$ to 4 ). The lighter products are added to the fuel gas mixture. The naphtha has very low octane numbers, so it is not a good feedstock for gasoline production. This naphtha is however a good feedstock for ethylene and propylene production (the feed stocks for polyethylene and polypropylene plastics), but natural gas liquids are strong competitors for this market. Most ethylene/propylene producers are on the Gulf Coast, so there would be high shipping charges for a Wyoming Fischer-Tropsch plant. 


\section{A-2. ENERGY SOURCES AND CONVERSION}

Chemical processes most frequently use heat as a way of adding energy to the materials being processed. In some cases, pressure, electricity, or added high-energy chemicals can be used. This heat must be added at the proper temperature to be absorbed by the desired chemical reaction and must be delivered at a somewhat higher temperature than that so it will spontaneously flow from the heat supply system into the somewhat cooler reaction vessel. The temperature at which heat can be produced is therefore critical to the use of a heat source in a chemical process. This section discusses the relationship between possible heat sources, possible heat delivery systems, and the final heat use. This is important in adapting a conventional chemical process typically using steam heat to run using heat from a nuclear reactor.

\section{A-2.1 Heat Sources}

For the processing considerations of this report, heat sources can be categorized into four classes by the nominal source temperature. At the level of this analysis, the differences between members of each class are negligible compared to the differences between classes. In design of an actual plant, however those detailed technical and especially economic differences will be important. For general evaluation of the feasibility of a variety of hybrid system configurations, temperature differences of less than about 100 ${ }^{\circ} \mathrm{C}$ can be assumed handled by design changes; heat sources several hundred degrees apart would be used differently in processes. Table A-1 shows the different classes, their sources, and some common uses of heat in that range.

Table A-1. Categories of heat sources used in the process analysis. "Reactor" refers to nuclear systems.

\begin{tabular}{|c|l|l|}
\hline Heat class & \multicolumn{1}{|c|}{ Representative sources } & \multicolumn{1}{c|}{$\begin{array}{c}\text { Example uses that operate } \\
\text { at this temperature }\end{array}$} \\
\hline $1200-1500^{\circ} \mathrm{C}$ & $\begin{array}{l}\text { Combustion of natural gas or } \\
\text { coal; electric arc; } \\
\text { concentrating solar power }\end{array}$ & Coal gasification; steel-making; cement-making \\
\hline $700-850^{\circ} \mathrm{C}$ & $\begin{array}{l}\text { High temperature gas-cooled } \\
\text { reactor }\end{array}$ & $\begin{array}{l}\text { Steam methane reforming; cracking of natural } \\
\text { gas liquids to ethylene and propylene; solid } \\
\text { oxide fuel cell operation }\end{array}$ \\
\hline $500^{\circ} \mathrm{C}$ & $\begin{array}{l}\text { Molten salt reactor; liquid } \\
\text { metal cooled reactor }\end{array}$ & $\begin{array}{l}\text { Distillation, cracking, and reforming of } \\
\text { petroleum heavy end products; biomass } \\
\text { pyrolysis; in-situ oil shale retorting }\end{array}$ \\
\hline $300^{\circ} \mathrm{C}$ & $\begin{array}{l}\text { Light water reactors; some } \\
\text { geothermal (near 200 }\end{array}$ & Many chemical processes; biomass torrefaction \\
\hline
\end{tabular}

Any higher temperature source can be used to heat a lower temperature stream, even one many hundreds of degrees cooler. Consequently, an application matched to one class of heat could be supplied by any of the hotter classes as well. However, doing this is not efficient from the standpoint of exergy, a thermodynamic property describing the ability of a heat flow to do work. Delivering heat across unnecessarily large temperature differences causes a loss of work potential that might have been recovered to, for instance, compress a gas stream or generate electricity. Avoiding such losses is a key part of designing efficient energy conversion processes.

There are specific nuclear reactor designs to be considered in each broad heat class. About thirty different designs for small ( $<300 \mathrm{MWe})$ and medium $(<700 \mathrm{MWe})$ modular nuclear reactors are under development around the world, with some still at the conceptual stage [IAEA 2011]. The seven U.S. designs under development in 2011 are representative and are summarized in Table A-2. These small and medium sized reactors are much smaller than the existing large reactors of 1000-1700 MWe (roughly 3000-5000 MW thermal) designed to capture economies of scale. With the thermal demand of a large 
chemical plant being in the range of a few hundred megawatts, one or a few reactors in this reduced size range can be matched to one or a few world scale process plants to make a single operating complex.

Table A-2. Thermal characteristics of US small modular reactors under development

\begin{tabular}{|c|l|c|c|}
\hline Reactor class/name & \multicolumn{1}{|c|}{ Manufacturer } & $\begin{array}{c}\text { Max heat delivery } \\
\text { temperature }\left({ }^{\circ} \mathbf{C}\right)\end{array}$ & $\begin{array}{c}\text { Thermal } \\
\text { capacity (MW) }\end{array}$ \\
\hline Light water reactors & & 320 & 500 \\
\hline mPower & Babcock and Wilcox & approx 300 & 165 \\
\hline NuScale & NuScale Power Inc. & 310 & 800 \\
\hline Westinghouse SMR & Westinghouse & & 471 \\
\hline Liquid metal-cooled reactors & & 485 & 70 \\
\hline Prism & GE-Hitachi & 500 & \\
\hline HPM & $\begin{array}{l}\text { Hyperion Power } \\
\text { Generation Inc. }\end{array}$ & & 350 \\
\hline Gas-cooled reactors & & 750 & 500 \\
\hline GT-MHR & General Atomics & 850 & \multirow{2}{*}{} \\
\hline EM $^{2}$ & General Atomics & & \\
\hline
\end{tabular}

Another way of adding heat to a process is electric resistance heaters or, equivalent but more complicated, inductive or microwave heating. The conversion efficiency of electrical power to heat is essentially $100 \%$, the heat delivery is not constrained by the temperature of the target process stream, and the heat addition is easily controlled. However, generating the electricity requires a large amount of thermal energy, two to three times as much as the resultant electrical energy, making it expensive. If this heat originates in the hybrid system, it would be better to transfer it directly into the stream to be heated than to suffer the losses of first making power that is converted back into heat, especially if the thermal source is high temperature combustion. However, medium temperature heat such as from a light water reactor at $300^{\circ} \mathrm{C}$ can be used to make electricity which then powers a high temperature resistance heater. There are circumstances where electrical heating might be desirable: only a small amount of high temperature heat is needed, medium temperature heat from which to generate electricity is available at low cost, excess electricity is available on-site without additional combustion, or the electricity is drawn from the power grid as an infrequently used safety, backup, or startup/shutdown supply of heat. In general, though, process heating using electricity is not a preferred approach primarily because of its expense.

\section{A-2.2 Issues with Using Nuclear Heat in Chemical Processes}

Nuclear heat sources cannot, in general, simply be directly substituted for conventional heat sources in a chemical process without additional process modifications. This section covers two of the major difficulties.

Chemical and nuclear reactions generate (or, in some chemical reactions, absorb) heat at one temperature. They are analogous to latent heat systems based on a phase change (such as the condensing of steam into water) with a concomitant release of heat at a constant temperature. All of these are contrasted with sensible heat effects in which the energy release is tied to the temperature of a material, for example the heat released to the surroundings as hot water cools. Pairing latent (or reaction) and sensible het effects in a heat transfer operation can lead to a temperature pinch in which the two streams' temperatures approach each other and heat transfer stops. This difficulty generally can be addressed by altering the streams' flow rates or temperatures. However, for safety reasons nuclear systems (including the secondary loops that might deliver reactor heat to a power or chemical plant) designed for specific operating conditions are not easily changed from what was approved in licensing of the reactor's design.

Nuclear heat cannot match the heat transfer rates achievable in conventional furnaces that rely on radiative heat transfer. With their very high flame temperatures, furnaces give high rates of heat transfer 
and allow rapid heating of process streams. As an example, during steam cracking of naphtha to ethylene the feed stream is heated to $800^{\circ} \mathrm{C}$, reacted, and quenched all within $50-100$ milliseconds. Such rapid

processing is necessary to minimize the undesired formation of byproducts. The use of furnaces to heat or react chemical process streams does not currently have an analogous operation in the nuclear world. Developing a nuclear heat exchange system to directly replace combustion-heated systems operating at high temperatures will require significant design and testing work.

\section{A-3. REFERENCES}

International Atomic Energy Agency (IAEA), 2011, Status of small and medium sized reactor designs, http://aris.iaea.org, accessed September 2012. 


\section{Appendix B}

\section{Basis for Economic Calculations}




\section{Appendix B}

\section{Basis for Economic Calculations}

\section{B-1. COST MEASURES FOR THE SYNFUEL PLANT \\ B-1.1 Yields and Plant Capacity}

This report uses a prior INL technical evaluation of nuclear-heated synfuel processes [INL 2010] as a basis for plant design and cost analysis. The report was prepared for the Next Generation Nuclear Plant (NGNP) project with the goal to broaden the environmental and economic benefits of nuclear energy in the US. Among other issues, it discusses the potential integration of a high-temperature-gas-cooled reactor with a methanol-to-gasoline (MTG) plant. The reactor would provide heat and electricity to the MTG process, and hence support the production of a valuable chemical product. The study provides detailed flow schemes of these cases and conducts an economic analysis of the MTG plant and the nuclear-assisted MTG plant. Assumptions and strategies utilized in that report have largely been adopted in this present study.

This analysis is based a gasoline production of $10,000 \mathrm{bbl} /$ day from the synthetic fuels plant. The corresponding yields of LPG, water, and the intermediate product methanol are based on previous studies [INL 2010 and ExxonMobil 2010] and are shown in Table B-1. A methanol plant size of 3300 tons per day is reasonable as the capacity of a world scale methanol plant has increased from 2500 tons/day about a decade ago to 5000 tons/day today [Haldor Topsoe 2009].

Table B-1. Yields of products and intermediates

\begin{tabular}{|l|c|c|}
\hline \multicolumn{1}{|c|}{ Product/Intermediate } & Barrels/ day & Tons/day \\
\hline Methanol & 26,162 & 3293 \\
\hline Gasoline & 10,000 & \\
\hline LPG & 1,577 & \\
\hline Water & 14,572 & \\
\hline
\end{tabular}

\section{B-1.2 Capital Costs}

The capital costs for the natural gas-to-MTG plant were estimated using the procedure described in a previous report [INL 2010]. Literature estimates and estimates scaled by capacity, year, and material from previous quotes were utilized for major plant processes (natural gas reforming, air separation unit, pressure swing absorption unit, methanol synthesis, MTG synthesis, and steam turbine, heat recovery steam generator and combustion turbine). The plant capacities for these processes were adjusted using the six-tenths exponent rule. The presented cost estimates are Class 5 estimates and have probable errors of $+50 \%$ and $-30 \%$ [AACE 2005]. The Chemical Engineering Plant Cost Index [Chemical Engineering 2012] was used to adjust equipment prices from previous years. The costs for water systems, piping, instrumentation and control, electrical systems, and buildings and structures were based on scaling factors (Table B-2) for the total installed equipment costs [NETL 2000]. 
Table B-2. Cost factors for ancillary components

\begin{tabular}{|l|r|}
\hline \multicolumn{1}{|c|}{ System } & Factor \\
\hline Water systems & $7.1 \%$ \\
\hline Piping & $7.1 \%$ \\
\hline Instrumentation and Control & $2.6 \%$ \\
\hline Electrical systems & $8.0 \%$ \\
\hline Buildings and structures & $9.2 \%$ \\
\hline
\end{tabular}

An engineering fee of $10 \%$ and a project contingency of $18 \%$ were assumed for the estimated total capital investment (TCI) of the natural gas-to-synthetic fuels plant. Table B-3 presents the capital cost estimate breakdown for the natural gas-to-gasoline plant.

Table B-3. Total capital investment for the natural gas-to-fuels plant

\begin{tabular}{|c|c|c|c|c|}
\hline & $\begin{array}{l}\text { Installed Cost } \\
\text { (\$ millions) }\end{array}$ & $\begin{array}{l}\text { Eng'g Fee } \\
\text { (\$ millions) }\end{array}$ & $\begin{array}{l}\text { Contingency (\$ } \\
\text { millions) }\end{array}$ & $\begin{array}{c}\text { Total Cost } \\
\text { (\$ millions) }\end{array}$ \\
\hline Natural gas reforming & 94 & 9 & 19 & 122 \\
\hline Air separation unit & 59 & 6 & 12 & 77 \\
\hline Pressure swing absorption & 4 & 0 & 1 & 5 \\
\hline Methanol synthesis & 102 & 10 & 20 & 133 \\
\hline MTG synthesis & 134 & 13 & 27 & 174 \\
\hline Power systems $^{\mathrm{a}}$ & 17 & 2 & 3 & 22 \\
\hline Water systems & 29 & 3 & 6 & 38 \\
\hline Piping & 29 & 3 & 6 & 38 \\
\hline Instrumentation and controls & 11 & 1 & 2 & 14 \\
\hline Electrical systems & 33 & 3 & 7 & 43 \\
\hline Buildings and structures & 38 & 4 & 8 & 49 \\
\hline Total capital investment & & & & 713 \\
\hline
\end{tabular}

\section{B-1.3 Manufacturing Costs}

The manufacturing cost estimates for the natural gas-to-synthetic fuels plant were again based on a previous study [INL 2010]. Manufacturing costs included natural gas, electricity, labor, maintenance, overhead, taxes, and insurance. Natural gas was determined explicitly while the costs for labor, maintenance, overhead, taxes, and insurance were assumed to be percentages of the total capital investment (TCI) costs [INL 2010]:

Table B-4. Estimation of manufacturing cost for the natural gas-to-fuels plant.

\begin{tabular}{|l|l|}
\hline \multicolumn{1}{|c|}{ Cost Type } & \multicolumn{1}{c|}{ Factor } \\
\hline Labor costs & $1.15 \%$ of TCI \\
\hline Maintenance costs & $3 \%$ of TCI \\
\hline Taxes and insurance & $1.5 \%$ of TCI \\
\hline Overhead & $65 \%$ of labor and maintenance costs \\
\hline Royalties & $1 \%$ of coal and natural gas costs \\
\hline
\end{tabular}


The costs to purchase electricity have been extracted from [EIA 2012]. Costs for water clarification and treatment have been assumed to be the same as in the previous report [INL 2010] adjusted for inflation. These costs represent only a small fraction of the manufacturing costs. Three natural gas prices were assumed: 4,6 , and $8 \$$ MSCF. These are higher than the current price of about $\$ 3$ per MSCF because of an expected rebound from current minimally profitable levels.

Table B- 5 shows the manufacturing costs for the three different natural gas prices. Table B-6 shows the breakdown of the manufacturing cost estimates for the proposed natural gas to methanol to gasoline process at a natural gas price of $\$ 4$ per MSCF. At other natural gas prices only the cost in the first row of the table changes. For natural gas at $\$ 6$ or $\$ 8$ per MSCF, the annual costs rise to $\$ 173,273,000$ and $\$ 231,030,000$. These changes raise the total annual manufacturing cost to $\$ 258,976,000$ and $\$ 317,311,000$. For natural gas prices of 4,6 , and $8 \$ \mathrm{MSCF}$, the percentage of manufacturing cost attributable to this feed is 58,67 , and $73 \%$.

Table B-5. Manufacturing costs for the natural gas-to-fuels plant and the nuclear-integrated natural gasto-fuels plant assuming various natural gas prices

\begin{tabular}{|l|c|c|c|}
\hline Natural gas price, \$/MSCF & 4.00 & 6.00 & 8.00 \\
\hline Manufacturing costs, \$/gal gasoline & 1.31 & 1.69 & 2.07 \\
\hline
\end{tabular}

Table B-6. Manufacturing cost estimate for a low natural gas price ( $\$ 4.00 / \mathrm{MSCF})$

\begin{tabular}{|c|c|c|c|c|c|}
\hline & \multicolumn{2}{|c|}{ Price } & \multicolumn{2}{|c|}{ Amount Consumed } & \multirow[t]{2}{*}{ Annual Cost } \\
\hline Direct Costs & & & & & \\
\hline Materials & Value & Units & Value & Units & \\
\hline Natural Gas & 4.00 & \$/MSCF & 86 & MMSCFD & $\$ 115,515,000$ \\
\hline Water Clarification & 0.026 & $\$ /$ k-gal & 2670149 & gal/day & $\$ 24,000$ \\
\hline Water Treatment & 1.416 & $\$ /$-gal & 1845245 & gal/day & $\$ 877,000$ \\
\hline Hydrolysis Catalyst & 700 & $\$ / \mathrm{ft}^{3}$ & 0.042 & $\mathrm{ft}^{3} /$ day & $\$ 10,000$ \\
\hline Zinc Oxide & 300 & $\$ / \mathrm{ft}^{3}$ & 0.393 & $\mathrm{ft}^{3} /$ day & $\$ 40,000$ \\
\hline Preforming Catalyst & 2350 & $\$ / \mathrm{ft}^{3}$ & 0.000 & $\mathrm{ft}^{3} /$ day & $\$ 0$ \\
\hline $\begin{array}{l}\text { Primary Reforming } \\
\text { Catalyst }\end{array}$ & 750 & $\$ / \mathrm{ft}^{3}$ & 0.118 & $\mathrm{ft}^{3} /$ day & $\$ 30,000$ \\
\hline $\begin{array}{l}\text { Secondary Reforming } \\
\text { Catalyst }\end{array}$ & 650 & $\$ / \mathrm{ft}^{3}$ & 0.027 & $\mathrm{ft}^{3} /$ day & $\$ 6,000$ \\
\hline Methanol Catalyst & 750 & $\$ / \mathrm{ft}^{3}$ & 0.073 & $\mathrm{ft}^{3} /$ day & $\$ 18,000$ \\
\hline DME Catalyst & 840 & $\$ / \mathrm{ft}^{3}$ & 0.042 & $\mathrm{ft}^{3} /$ day & $\$ 12,000$ \\
\hline MTG Catalyst & 50.39 & $\$ / 1 b$ & 381 & $\mathrm{lb} /$ day & $\$ 6,942,000$ \\
\hline HGT Catalyst & 2500 & $\$ / \mathrm{ft}^{3}$ & 0.227 & $\mathrm{ft}^{3} /$ day & $\$ 191,000$ \\
\hline \multicolumn{6}{|l|}{ Utilities } \\
\hline Electricity & 1.654 & $\$ / \mathrm{kW}$-day & 29250 & $\mathrm{~kW}$ & $\$ 16,242,000$ \\
\hline Water & 0.05 & $\$ /$-gal & 2670148.8 & gal/day & $\$ 44,000$ \\
\hline Royalties & & & & & $\$ 1,155,000$ \\
\hline Labor and Maintenance & & & & & $\$ 29,598,000$ \\
\hline \multicolumn{6}{|l|}{ Indirect Costs } \\
\hline Overhead, TCI & & & & & $\$ 19,239,000$ \\
\hline Insurance and Taxes, TCI & & & & & $\$ 10,698,000$ \\
\hline Manufacturing Costs & & & & & $\$ 200,641,000$ \\
\hline
\end{tabular}




\section{B-1.4 Cost Comparison}

To evaluate the attractiveness of the various economic cases the Internal Rate of Return (IRR) was calculated assuming different gasoline selling prices and natural gas prices. First, the yearly revenues were estimated. Three different gasoline selling prices $(1.22,2.40$, and $3.58 \$ /$ gal $)$ were assumed based on the recent price history as documented by the EIA. These wholesale prices do not include distribution costs, taxes, or retailer markup. Prices for electricity and LPG were also extracted from the EIA and adjusted for inflation to 2012. No credit was taken for the sale of nitrogen from the air separation unit. The following assumptions were made for the analysis based on INL 2010:

- The plant startup year is 2015 .

- The construction period lasts three years. To easily perform the analysis in 2012 dollars, the natural gas-to-MTG plant construction is assumed to begin in 2012.

- Percent capital invested for the fossil plant is $33 \%$ per year

- Plant startup time (a period of reduced performance) is one year.

- Operating costs are $85 \%$ of the total value during startup

- Revenues are $60 \%$ of the total value during startup

- The analysis period for the economic evaluation assumes an economic life of 30 years, excluding construction time (the model is built to accommodate up to 40 years).

- An availability of $92 \%$ was assumed for the natural gas-to-MTG plant.

- An inflation rate of $2.5 \%$ is assumed.

- A debt to equity ratio of $80 \% / 20 \%$ is assumed

- The interest rate on debt is assumed to be $8 \%$

- The repayment term on the loan is assumed to be 15 years

- The effective income tax rate is $38.9 \%$.

- $\quad$ State tax is $6 \%$

- Federal tax is $35 \%$

- Modified accelerated cost recovery system (MACRS) depreciation is assumed.

- Unless stated otherwise, there are no $\mathrm{CO}_{2}$ emission penalties and no credits for domestic synfuel production

\section{B-2. COST CALCULATION FOR NUCLEAR ELECTRICITY}

This section outlines the methodology for calculating the levelized costs of electricity. The numerical values used are taken from the source documents and are not reflective of the cases or conditions examined in the body of this report. The levelized cost of electricity (LCOE) is a commonly used metric to compare the costs of different power generation technologies. The LCOE is equal to the present value of the sum of discounted costs divided by total production adjusted for its economic time value. In other words, the LCOE is a constant price for electricity that would equalize the two discounted cash flows. [NEA 2010 and INL 2012].

$\int_{0}^{T_{\text {Plant }}} L C O E * E(t) e^{-r t} d t=\int_{0}^{T_{\text {plant }}} K(t) e^{-r t} d t$

$\mathrm{T} \quad=$ plant lifetime [years]

$\mathrm{LCOE}=$ the constant price of electricity [cents $/ \mathrm{kWh}]$

$\mathrm{E}(\mathrm{t}) \quad=$ the time profile of the electricity generated over the life of the plant

$\mathrm{K}(\mathrm{t})=$ the dollar value of the expenditures sustained at time $\mathrm{t}$

$\mathrm{r}=$ discount rate $\left[\right.$ year $\left.^{-1}\right]$ 
The discounting is expressed as continuously compounded. If it is assumed that $\mathrm{E}(\mathrm{t})$ is constant, a reasonable assumption for a base -load power plant. [INL 2012], LCOE can be calculated as follows:

$L C O E=\frac{1}{E} \frac{r}{1-e^{-r T} \text { plant }} \int_{0}^{T \text { plant }} K(t) e^{-r t} d t$

According to equation ( 2 ) the levelized cost is the integral of the net present value of the expenditures multiplied by a term called "capital recovery factor", which is a function of the discount rate $\mathrm{r}$ and the plant life time (T) [INL 2012]. The discount rate does not vary during the lifetime of the project. A commonly used value for nuclear projects is 5\% [NEA 2010, INL 2012], however, other values up to $10 \%$ are suggested in the literature. Assuming a plant life $\mathrm{T}$ of 60 years enables us to calculate the capital recovery factor:

Capital recovery factor $\left[\right.$ year $\left.^{-1}\right]=\frac{r}{\left(1-\exp ^{-r T}\right)}=0.0526$ year $^{-1}$

Making the following assumptions for the power plant:

- 1000 MWe power (arbitrary)

- $92 \%$ plant availability

The electricity E generated yearly can be calculated as follows:

$E=$ Power $*$ Availability $* \frac{\text { hours }}{\text { year }}=1000 \mathrm{MWe} * 0.92 * 8766 \frac{\text { hours }}{\text { year }}=8.06 \cdot 10^{9} \frac{\mathrm{kWh}}{\text { year }}$

The levelized cost of electricity necessary to recover the capital investment is calculated by assuming a specific capital cost (including both overnight cost and interest during construction) of $\$ 3900 / \mathrm{kWe}$ (Table B-6, [INL 2009]), resulting in a total capital cost of \$3.9 billion for a 1000MWe power plant. Utilizing the capital recovery factor and yearly generated electricity (equations (3) and (4)) the levelized cost of electricity necessary to pay the capital charges can be calculated using equation (5) at 2.6 cents/kWh.

Levelized capital costs $=\$ 3.9 \cdot 10^{9} * \frac{r}{\left(1-\exp ^{-r T}\right)} * \frac{1}{E}$

The total O\&M cost is the sum of the following two components: fixed $(\$ 66 / \mathrm{kWe}-\mathrm{y}$, Table B-7) which is essentially the part of the O\&M proportional to the power of the reactor, and variable $(0.18$ cents $/ \mathrm{kWh}$ ) which reflects the part of $O \& M$ proportional to the electricity produced. The $O \& M$ components presented in Table B-6 are adjusted to include average lifetime capital replacements for the reactor and contributions to a D\&D fund to decommission the reactor at the end of its life.

Fuel cycle costs must also be included in the total expenditures. NEA 2010 assumes 0.7 cents $/ \mathrm{kWh}$ for the front end (uranium mining and milling, conversion, enrichment and fuel fabrication) and 0.23 cents $/ \mathrm{kWh}$ for the back end (spent fuel transport, storage, reprocessing and disposal).

In this example the O\&M costs and fuel cycle costs are not discounted. This assumption is valid as these costs are sustained almost continuously throughout the plant's life and the electricity is also sold continuously. For the $1000 \mathrm{MWe}$ power plant assumed in this example, the fixed operating costs are 0.82 cents $/ \mathrm{kWh}$.

The total expenditures for our example are:

- 2.6 cents/ $\mathrm{kWh}$ levelized capital costs

- 0.82 cents/ $\mathrm{kWh}$ fixed O\&M costs ( $\$ 66$ million per year)

- 0.18 cents $/ \mathrm{kWh}$ variable $\mathrm{O} \& \mathrm{M}$ costs

- 0.7 cents $/ \mathrm{kWh}$ fuel cycle front end

- 0.23 cents/ $\mathrm{kWh}$ fuel cycle back end

The sum of these values yields the levelized cost of electricity, 4.53 cents/ $\mathrm{kWh}$. 
Table B-7. Typical costs for a LWR

\begin{tabular}{|l|c|c|c|c|}
\hline Cost component & $\begin{array}{c}\text { Reference value } \\
\text { (at ref. capacity) }\end{array}$ & Low estimate & High estimate & Nominal cost \\
\hline $\begin{array}{l}\text { Generic U.S. LWR } \\
\text { (NOAK) }\end{array}$ & $\$ 3200 / \mathrm{kWe}$ & $\$ 2300 / \mathrm{kWe}$ & $\$ 5000 / \mathrm{kWe}$ & $\$ 3500 / \mathrm{kWe}$ \\
\hline $\begin{array}{l}\text { Specific total capital cost } \\
\text { with financing, 5\% } \\
\text { discount rate (NOAK) }\end{array}$ & $\$ 3500 / \mathrm{kWe}$ & $\$ 2600 / \mathrm{kWe}$ & $\$ 6500 / \mathrm{kWe}$ & $\$ 3900 / \mathrm{kWe}$ \\
\hline $\begin{array}{l}\text { Non-fuel O\&M, with } \\
\text { D\&D fund contribution }\end{array}$ & $\$ 62 / \mathrm{kWe-yr}$ & $\$ 55 / \mathrm{kWe-yr}$ & $\$ 80 / \mathrm{kWe-yr}$ & $\$ 66 / \mathrm{kWe-yr}$ \\
\hline $\begin{array}{l}\text { Non-fuel O\&M, with } \\
\text { capital replacements, } \\
\text { variable component }\end{array}$ & $\begin{array}{c}\$ 0.00045 / \mathrm{kWh} \\
\text { (w/o cap. replace. } \\
\text { adjustment) }\end{array}$ & $\begin{array}{c}\$ 0.00080 / \mathrm{kWh} \\
\text { (with adjustment) }\end{array}$ & $\begin{array}{c}\$ 0.00250 / \mathrm{kWh} \\
\text { (with adjustment) }\end{array}$ & $\begin{array}{c}\$ 0.00180 / \mathrm{kWh} \\
\text { (with adjustment) }\end{array}$ \\
\hline
\end{tabular}

[INL 2009, Table R1-6] $\left(\right.$ NOAK $=\mathrm{n}^{\text {th }}$ of a kind $)$

\section{B-3. REFERENCES}

ExxonMobil 2010, Mitch Hindman, ExxonMobil Research and Engineering: Methanol to Gasoline (MTG) Technology (www.exxonmobil.com/apps/refiningtechnologies/files/ conference_2011.1204.MTG_World_CTL.pdf).

Haldor Topsoe 2009, "Large Scale Methanol Production from Natural Gas", Product Brochure.

INL 2009, “Advanced Fuel Cycle Cost Database”, INL/EXT-07-12107, Rev. 2

INL 2010, Technical Evaluation Study, number 23843 "Nuclear-integrated Methanol to Gasoline Production Analysis".

INL 2012, "Nuclear Energy System Evaluation and Screening - Evaluation and Metric for Financial Risk and Economics", INL/EXT-12-27055

NEA 2010, "Projected Costs of Generating Electricity" International Energy Agency (IEA), Nuclear Energy Agency (NEA) and Organization for Economic Co-Operation and Development (OECD)

National Energy Technology Laboratory (NETL) 2000, Shell Gasifier IGCC Base Cases. PED-IGCC-98-002. 